\title{
On the origin of bodily sensations in panic disorder
}

Citation for published version (APA):

Kroeze, S. (1999). On the origin of bodily sensations in panic disorder. [Doctoral Thesis, Maastricht University]. Universiteit Maastricht. https://doi.org/10.26481/dis.19990204sk

Document status and date:

Published: 01/01/1999

DOI:

10.26481/dis.19990204sk

Document Version:

Publisher's PDF, also known as Version of record

\section{Please check the document version of this publication:}

- A submitted manuscript is the version of the article upon submission and before peer-review. There can be important differences between the submitted version and the official published version of record.

People interested in the research are advised to contact the author for the final version of the publication, or visit the DOI to the publisher's website.

- The final author version and the galley proof are versions of the publication after peer review.

- The final published version features the final layout of the paper including the volume, issue and page numbers.

Link to publication

\footnotetext{
General rights rights.

- You may freely distribute the URL identifying the publication in the public portal. please follow below link for the End User Agreement:

www.umlib.nl/taverne-license

Take down policy

If you believe that this document breaches copyright please contact us at:

repository@maastrichtuniversity.nl

providing details and we will investigate your claim.
}

Copyright and moral rights for the publications made accessible in the public portal are retained by the authors and/or other copyright owners and it is a condition of accessing publications that users recognise and abide by the legal requirements associated with these

- Users may download and print one copy of any publication from the public portal for the purpose of private study or research.

- You may not further distribute the material or use it for any profit-making activity or commercial gain

If the publication is distributed under the terms of Article $25 \mathrm{fa}$ of the Dutch Copyright Act, indicated by the "Taverne" license above, 
On the origin of bodily sensations

in

\section{Panic Disorder}


Printed by: ThelaThesis, Amsterdam

ISBN 90-9012393-8 


\title{
On the origin of bodily sensations
}

\author{
in \\ Panic Disorder
}

\section{PROEFSCHRIFT}

ter verkrijging van de graad van doctor aan de Universiteit Maastricht,

op gezag van de Rector Magnificus, Prof. A.C. Nieuwenhuijzen Kruseman, volgens het besluit van het College van Dekanen, in het openbaar te verdedigen op donderdag 4 februari 1999 om 14.00 uur

door

Sabine Kroeze 


\section{Promotor:}

Prof. dr. M.A. van den Hout

\section{Beoordelingscommissie:}

Prof. dr. E.J.L. Griez (woorzitter)

Prof. ar. O van den Bergh (Universiteit Leuver)

Prof. dr. P. Emmelkamp (Universiteit van Amsterdam)

Prof. dr. H.L.G.J. Merckelbach

Dr. M. Kindt

Het onderzoek in dit proefschrift werd financieel gesteund door de Stichting Gedragswetenschappen (SGW), die wordt gesubsidieerd door cle Nederlandse Organisatie voor Wetenschappelijk Onderzoek (NWO; projectnummer 575-68-061) 


\section{Contents}

Why Panic?

Panic and panic disorder 7

Pathophysiological models 8

Cognitive models 9

Aim of this dissertation $\quad 16$

Study 1. Symptom reporting and interoceptive attention in panic patients 19

Study 2. Selective attention for hyperventilatory sensations in panic disorder 27

Study 3. Selective attention for cardiac information in panic patients 43

Study 4. Can selective attention for heartbeat information be induced by fear of heartbeat acceleration?

Study 5. No superior perception of hyperwentilatory sensations in panic disorder

Study 6. No superior perception of respiratory resistance in panic disorder

Conclusions and General Discussion

Results of experimental studies 87

Discussion $\quad 88$

$\begin{array}{ll}\text { References } & 95\end{array}$

$\begin{array}{ll}\text { Summary } & 103\end{array}$

$\begin{array}{lr}\text { Samenvatting } & 107\end{array}$

Dankwoord 111

$\begin{array}{lr}\text { Curriculum Vitae } & 112\end{array}$ 



\section{Why Panic?}

\section{Panic and panic disorder}

Although panic will be regarded by virtually everybody as a well-known emotion, its status within emotion theories is less clear. Since Darwin, emotions thave commonly been seen as serving some surwival function (Plutchik, 1994). According to Barlow (1988), panic might serve a fight-or-flight function. However, many writers, whilst outhining in detail all the functions of fear and anxiety, never even mention panic. It may be that they regard panic as just an extreme form of fear. Alternatively, they may see panic as a special phenomenon that does not seem to fit in the same category as other emotions. Frijda (1986), for instance, makes an exception for panic when describing anxiety as a response to inhibit action. Instead, he describes panic as a "catastrophic reaction" lacking direction or organization. Early writings, dated as far back as 1150 BC, relate catastrophic consequences in cases where armies panicked and were slain easily (Baker, 1989). Whatever the case, panic seems connected to dramatic outcomes.

Whereas panic may have severe consequences in life-threatening circumstances as in the case of a fleeing army, panic and more specifically panic attacks may become debilitating when experienced recurrently as a form of psychopathology that is called panic disorder. In the fourth edition of the Diagnostic and Statistical Manual of Mental Disorders (DSMIV), a panic attack is defined as "a discrete period of intense fear or discomfort, in which four or more of the following symptoms dewelop abruptly and reach a peak within 10 minutes" (American Psychiatric Association, 1987). The symptoms listed are palpitations, sweating, trembling or shaking, sensations of shortmess of breath or smothering. feeling of choking, chest pain or discomfort, nausea or abdominal distress, feeling dizzy or faint, derealization or depersonalization, feeling of losing control or going crazy, fear of dying, paresthesias and chills or hot lushes. However, having panic attacks is not sufficient for being diagnosed as having panic disorder. According to the DSM-IV, this is only the case when the attacks experienced are unexpected and when at least one of the attacks has been followed by 1 month (or more) of persistent concern about having additional attacks, worry about the implications of the attacks or its consequences, or a significant change in behaviour related to the attacks (American Psychiatric Association, 1987). When a person, in addition to his panic disorder, is extremely affraid of going into public places like shopping malls, trains and cinemas, typically places from which escape would be difficult or in which help would not be available in case of an panic attack, this person is said to have panic disorder with agoraphobia (American Psychiatric Association, 1987). 


\section{Introduction}

Paric disorder is particularly debilitating and its lifetine prevalence is considerably high, with as much as $1.4 \%$ (Eaton, Dryman \& Weissman, 1991) and 3.8\% (Katerndahl \& Realini, 1993) of the population having been estimated to suffer from the disorder. The question which mechanisms are responsible for this disorder has been addressed by many researchers. This research has yielded numerous models of the development of panic attacks and paric disorder that again inspired more research. Two classes of models will now be outlined: pathophysiological models and cognitive models. The latter will be dealt with more extensively since these are the models on which this dissertation is built.

\section{Pathophysiological models}

These models assume some pathophysiology to lie at the source of panic disorder (Margraf \& Ehlers, 1988). They typically regard panic as being qualitatively different from extreme anxiety or fear. A main reason to differentiate between fear and panic is the fact that painic attacks as experienced in panic disorder come unexpectedly and seem to have no demonstrable cue. When assuming a medical reason for the panic attacks, it is not necessary to assume some trigger from outside to give rise to fear. Panic attacks may stem directly from the pathophysiology. A wide variety of medical abnormalities have been proposed to underlie panic attacks. Panic patients have been proposed to have a dysregulation of the noradrenergic system (Charney et al., 1990; Nutt \& Lawson, 1992), a dysregulation in the serotonin system (Maser \& Woods, 1990), a higher sensitivity to $\mathrm{CO}_{2}$ (Gorman \& Papp, 1990; Papp, Klein \& Gorman, 1993), and more.

Evidence for medical abnomalities is mainly derived from so-called challenge studies (McNally, 1994). Panic patients and normal control subjects are for instance infused with agents that target the noradrenergic system or are made to inhale large quantities of $\mathrm{CO}_{3}$ in air. Most of these challenges produce intense physical sensations and as a rule prowoke panic in a considerable number of panic subjects and significantly less so in nomal subjects. Advocates of the pathophysiological model hold that challenges directly provoke panic by exacerbating a neurobiological dysfunction. However, there are some problems with this interpretation. The agents used to provoke panic have very different, sometimes even opposite pharmacological properties. For instance, both sodium lactate and $\mathrm{CO}_{2}$ have been used as a panic-inducing agent. However, sodium lactate leads to alkalosis (increase of $\mathrm{pH}$ ) while breathing $\mathrm{CO}_{2}$ continuously leads to acidosis (decrease of pH). Also, challenges that do not readily pass the blood-brain barrier, such as adrenaline, have been found to induce panic in panic patients (Van Zijderveld, 1995). It seems difficult to 
explain these findings with a medical model. An alternative is proposed by cognitive models of panic.

\section{Cognitive models}

In contrast to pathophysiological models, cognitive models of panic do not assume that panic attacks are caused by some medical abnormality. Instead, they assume the extreme fear during the attacks to be psychologically explicable. Cognitive models take the view that panic attacks are preceded by bodily sensations. Panic patients fear these bodily sensations and experiencing them will lead to anxiety. Since anxiety leads to even more sensations a vicious circle arises that eventually culminates in a panic attack (Beck, Emery \& Greenberg, 1985; Clark, 1986; Griez \& Van den Hout, 1984). Thus, instead of regarding panic as qualitatively different from fear, panic is now just an extreme form of fear, triggered by bodily sensations. Because the triggers are internal, they are often seen as part of the attacks and the attacks appear to come out of the blue.

In the same way the panicogenic effect of challenges in studies with panic patients might be explained. All the agents used in challenge studies give rise to sensations panic patients fear. The sensations caused by the agents will be catastrophically misinterpreted by panic patients but not by normal controls. As a consequence, panic patients will experience a panic attack whereas nomal controls will not (Clark, 1993; Margraf, Ehlers \& Roth, 1986; Rapee, 1995). Support for this interpretation comes from experiments that show that manipulation of cognitive variables can influence the occurrence of panic during challenges (Clark, 1992; Margraf. Ehlers \& Roth, 1992; Rapee, Mattick \& Murrell, 1986; Sanderson, Rapee \& Barlow, 1989). Ot course these findings do not prove that all panic attacks are cognitivelly mediated but they do show that cognitive theories have a lot of explanatory power.

Stating that bodily sensations trigger the pantic response in panic patients raises two central questions. The first is, why panic patients fear bodily sensations in such way that they cause such extreme anxiety. The second question has to do with the origin of the fearful bodily sensations: where do they stem from?

\section{Why do panic patients fear bodily sensations?}

One answer to this question has been given by Clark (1988), who states that "individuals who experience panic attacks do so because they have a relatively enduring characteristic tendency to interpret certain bodily sensations in a catastrophic fashion" (p149). An 


\section{Introduction}

example of a misinterpretation is that a person feels palpitations and interprets this as a sign of an impending heart attack. Thus, according to Clark, the fear for bodily sensations originates from the fear of dying of some illness.

Another answer is given by a conditioning approach of panic disorder. This approach assumes that interoceptive cues that have become associated with the attacks lead to anxiety because they are seen as predictors of an artack (Goldstein \& Chambless, 1978). Although this approach has been proved popular, McNally (1990) has pointed out that the parallel with Pavlowian conditioning is faulty because the internal cues that are seen as predicting the attack (like palpitations or a feeling of arousal) are part of the attack itself. Also it is unclear what led to panic in the first place, before any conditioning had taken place. McNally concludes that although the conditioning hypothesis has inspired fruitful research and successful treatment methods, it does not constitute a satisfactory explanation for the mechanisms underlying panic.

Recently, the boundaries between cognitive and conditioning approaches have become increasingly blurred. It is asserted that after conditioning the conditioned stimulus that predicts the unconditioned stimulus activates a cognitive representation of the unconditioned stimulus (Davey, 1989; Davey, 1992). In the case of panic attacks, this would mean that for instance the feeling of palpitations activates the cognitive representation of a heart-attack and consequently fear is elicited. However, the supposition that a palpitation activates the "cognitive representation" of a heart-attack closely resembles the idea that a palpitation is misinterpreted as being the forenunner of a heartattack. In both cases bodily sensations are held to predict danger and this is the reason that they are feared.

\section{What is the origin of bodily sensations in panic disorder?}

James (1890) already hypothesized that our emotions are largely based upon the experiences we have of autonomic changes in our bodies. His theory in fact tried to give an answer to the long standing issue of what comes first: a bodily sensation or a sentiment (Plutchilk, 1994). The cognitive theory of panic is faced with a similar question: does panic start with bodily sensations or with anxiety itsele? Clark's model in a way circumvents this issue. The model assumes a vicious circle; so either the anxiety or the sensations associated with anxiety may come first. Since one of them leads more or less directly to the other they may be difficult to separate. However, what still seems to be an important question is how either the anxiety or the sensations come into being. According to Clark (1986), in some cases anxiety will arise when a threatening externa] stimulus is encountered (such as a supermarket for an agoraphobic who has previously had an attack in a supermarket). In other cases sensations arise from causes not directly related to the attacks, like drinking coffee, changing one's body posture, exercise or hyperventilation. 
Since a patient does not perceive the cause of his sensations, these appear to come out of the blue.

Thus, according to Clark, sensations may come from various sources. However, to be able to predict when a panic attack is most likely to occur, it is necessary to specify the mechanisms that lead to bodily sensations associated with panic attacks (Fhlers, 1993). Furthermore, it may be that sone persons are more prone to experiencing bodily sensations than others. These people seem to have a greater chance to misinterpret sensations and thus have a greater chance to develop panic disonder. In line with this, it is often found that panic patients report more sensations than other people (Barsky, 1992a; Ehlers, 1993; Holt \& Andrews, 1989; Rapee, Ancis \& Barlow, 1988). If panic patients indeed could be found to have characteristics that lead to the experience of bodily sensations, the start of the attacks would be better accounted for. Furthermore, if it is clear where panic sensations stem from, they may be less often misinterpreted.

Identifying sources of bodily sensations and possible risk factors for the development of panic disorder has been the subject of many investigations. Some of the most important hypotheses that have been proposed will now be discussed. One group of hypotheses may be called "bottom-up" since they assume that somatosensory input in panic patients by some reason is increased. Another group of hypotheses may be called "top-down" since they assume the central processing of the input to be responsible for the increased sensation reporting. Interestingly, bottom-up hypotheses closely resemble the pathophysiological models mentioned above. In both views panic patients are assumed to have some characteristic that has some biological correlate. However, an important difference is that pathophysiological models assume that this biological correlate is a direct cause of the panic attacks whereas the cognitive theory assumes that this biological correlate is panicogenic only in combination with cognitive factors.

\section{Bottom-up processes}

These processes assume that for some reason the somato-sensory input in panic patients is increased. The processes of hyperventilation and mitral valve prolapse will be discussed in turn.

\section{Hyperventilation}

The hyperventilation theory of panic supposed that panic patients have an enduring tendency to hyperventilate (Bass, Lelliot \& Marks, 1989; Cowley \& Roy-Byrne, 1987; de Ruiter, Garssen, Rijkers \& Kraaimaat, 1989; Garssen, van Veenendaal \& Bloemink, 1983; Holt \& Andrews, 1989; Ley, 1985; Lum, 1981; Rapee, 1987). Hyperventilation is a breathing pattern in which the respiration is stronger than needed according to bodily 


\section{Introduction}

needs. If the lungs release more $\mathrm{CO}_{2}$ than the body produces, a lowering of $\mathrm{pCO}_{2}$ in the lurigs and the blood follows (Garsen, 1986). This again leads to symptoms like dizziness, paresthestas and palpitations (Gelder, 1986). For some time the hyperventilation theory had a lot of success. Hyperventilation could account for most of the symptoms panic patients complained about and indeed panic patients were found to have a lowered $\mathrm{pCO}_{2}$ in resis (Bass \& Gardner, 1985; Bass et al, 1989; Gorman, Liebowitz, Fyer, Fyer \& Klein, 1986; Liebowitz et 1., 1985; Van den Hout, Hoekstra, Arntz \& Christiaanse, 1992). Furthermore, when anxiety increases, in many cases hyperventilation increases too and might cause even more sensations. This seems to fit remarkably well with the idea of the vicious circle of panic. However, it was also found that panic patients did not hyperventilate more than other anxiety patients who did not have panic attacks (Van den Hout et al. 1992). Also, people have to hyperventilate quite vigorously (blood $\mathrm{pCO}_{2}$ dropping under $20 \mathrm{mmHg}$ ) to experience any sensations from it. It is unlikely that people hyperventilate to this degree in daily life. Studies that measured arterial $\mathrm{pCO}_{2}$ during stress report that arterial $\mathrm{pCO}$, generally remains above $30 \mathrm{mmHg}$ (Garssen, 1980; Grossman, 1983; Suess, Alexander, Smith, Sweeney \& Marion, 1980). Furthermore, ambulatory monitoring revealled that most panic patients do not have an especially lowered $\mathrm{pCO}_{2}$ before or during panic attacks (Hibbert \& Pilsbury, 1989). Hornsveld, Garssen and van Spiegel (1995) concluded the same for a group of subjects with paniclike attacks who scored positive on the hyperventilation test, i.e. who recognized symptoms during 3 minutes of hyperwentilation as being the same symptoms they experienced during attacks. These patients hawe much overlap with panic patients (around $50 \%$ are in general found to meet the DSM-III-R criteria of panic disorder: Hornsveld, 1998) and were even diagnosed as having "the hyperventilation syndrome". The fact that they did not hyperventllate during attacks is a direct refutation of the hyperventilation theory. Therefote, it has to be concluded that although hyperventilation might in some cases give rise to symptoms, which in turn might lead to a panic attack, it is unlikely that hyperventilation is a main generator of sensations in panic disorder (see also Margraf, 1993).

\section{Mirnal walve prolapse}

Another abnormality panic patients may suffer from is mitral valve prolapse. Mitral valve prolapse is a syndrome, generally harmless (Savage, Devereux, Garrison, Castelli, Anderson, Levy, Thomas, Kannel \& Feinleib, 1983), caused by the valve in the heart that separates the left atrium from the left ventricle. Normally, the mitral valve closes completely when the heart contracts but in mitral valve prolapse the valve bends back into the left atrium during systole (Devereux, Perloff, Reichek \& Josephon, 1976). Sometimes 
this has the consequence that blood streams back into the left atrium and then symptoms may occur like palpitations, dizziness and breathessness (Weissman, Shear, Kramer-Fox \& Devereux, 1987). Again, the overlap with panic symptoms is suggestive. However, studies investigating the connection report very inconsistent proportions of panic patients having mitral valve prolapse, probably undicating large differences in the diagnosing of the syndrome (Margraf, Ehlers \& Roth, 1988). On the whole, the prevalence of mitral valve prolapse in panic patients indeed appears to be somewhat higher than in the rest of the population. In contrast, the prevalence of panic disorder in mitral valwe prolapse patients was not found to be elevated compared to the prevalence in other cardiac patients or normal controls (Margraf et al., 1988). This might be due to the relative small number of patients with cardiac problems who also have panic disorder. However, because of the differences in diagnostic criteria the results are difficult to interpret. Most likely, mitral valve prolapse may occasion sensations in some patients with panic disorder but certainly not in all. Another possibility is that signs of mitral valve prolapse might arise as a. consequence of panic disorder (Coplan, Papp, King \& Gorman, 1992; Gorman, 1986).

In summary, both hyperventilation and mitral valve prolapse seemed likely candidates for causing the sensations panic patients complain about. However, although it may be that in some cases the ailments mentioned do cause sensations in panic patients, it is unlikely that they do in many panic patients. Most panic patients do not seem to suffer from either hyperventilation or mitral valve prolapse. Thus, neither of the two hypotheses comes close to giving an acceptable account of sensations in panic disorder. Meanwhile, in some individual cases the sensations misinterpreted and feared may be caused by hyperventilation or mitral valve prolapse.

\section{Top-down Processes}

Apart from abnormalities physically demonstrable, it is possible that normal somatosensory input seems increased because it is processed in deviant way. Two processes, selective attention and superior perception will be discussed in turn.

\section{Selective attention}

One way by which an amplified experience of input may be produced in panic patients is a tendency to selectively attend to bodily sensations. If patients have a habit of continually scanning their body in search for sensations they notice more sensations and these sensations seem to them more salient (Pennebaker, 1982; see also Study 1, this dissertation). To investigate whether panic patients indeed selectively attend to bodily sensations a number of paradigns have been devised. Typically these paradigms present subjects with 


\section{Introduction}

two types of information, one representing threatening bodily sensations or harm related to these sensations, the other one representing some neutral stimulus. A reaction time task has to be carried out by the subject that is made such that the performance on it will be influenced by the information the subject attends to (see Logan \& Goetsch, 1993, and Lavy, 1993, for an overview of paradigms). Performance on the reaction time task will deteriorate or improve in line with the degree to which attention is captured by the (neutral or threatening) distracting stimulus. By comparing panic patients and controls in their degree of deterioration/facilitation due to the threatening information relative to neutral information, selective attertion in panic patients can be assessed. The paradigms most extensively used are the Stroop task and the dot probe detection task. These paradigms will be described in studies 2,3 and 4 of this dissertation.

The results of studies with these paradigms support the hypothesis that panic patients selectively attend to bodily sensations (Asmundson, Sandler, Wilson \& Walker; 1992; Ehlers \& Breuer, 1995; Hope, Rapee, Heimberg \& Dombeck, 1990; McNally, Amir, Louro, Lukach, Rieman \& Calamari, 1994; McNally, Riemann \& Kim, 1990; Mogg. Mathews \& Weinman, 1989). However, several issues have yet to be clarified. One is the relationship between selective attention and fear. Selective attention may be a cause of fear and a risk factor for the development of panic disorder. Alternatively, selective attention may be a consequence of fear. In this case it may still play a maintaining role in panic disorder by causing panic patients to have an increased experience of bodily sensations. For both kinds of relationships support has been found. Selective attention was. found to have been decreased after successful exposure therapy (Lavy \& Van den Hout, 1993; Watts, McKenna, Sharrock \& Trezise, 1986), showing that when fear diminishes, selective attention does too. This suggests that selective attention may just be a result of fear. However, in a study by Van den Hout., Arntz, Janssen, de Jong and Pool (1998), an attempt to create selective attention by substantially increasing fear did not succeed, showing that increased fear is in itself not sufficient to create selective attention. On the other hand, preliminary reports suggest that by training selective attention an increase in state anxiety can be effected (MacLood, 1998), suggesting a probable causal role of selective attention. It is not clear how these results can be reconciled. A reciprocal relationship between selective attention and fear seems to account best for the findings but more specific studies on this issue are desirable.

Another important issue is the fact that almost all studies addressing the subject of selective attention have used verbal stimuli. However, it is not clear whether the results can be generalized to reall life sensations. Of course, verbal descriptions of bodily sensations may be associated with the direct experience of them, but this seems an extra assumption that requires independent tests. Furthermore, in the sudies mentioned, apart 
from bodily sensation words many other words are used, like catastrophe words (c. g. death, collapse: McNally et al., 1990), physical threat words (e.g. disease, mutilated: Mogg et al., 1989; fatal, illness: Hope et al., 1990) or panic threat words (e.g. dizzy. fear: McNally et all, 1994). In panic patients these words may be semantically linked to bodily sensations but again this is a step further. Thus, so far there is only indirect evidence for selective attention to sensations in panic patients. Furthermore, its effect on report of sensations has yet to be demonstrated.

\section{Superior Perception}

Another reason why panic patients may experience sensations may be that they are relatively good in perceiving changes in physiology. Tyrer, Lee and Alexander (1980) were among the first to propose that somatic symptoms in anxious patients might be due: to increased awareness of bodily function. They compared the awareness of cardiac function of anxious, phobic and hypochondriac patients. The anxious and hypochondriac patients showed a higher correlation between subjective and objective heart frequency. However, subjects assessed their heartrate after they had been looking to an exciting and a peaceful film. Therefore the results might be attributed rather to differences in attention paid to heartbeats during the film than to differences in the ability to perceive heartrate. Studies that use paradigms in which attention is directed exclusively and on-line to heartbeats seem better able to measure differences between groups of subjects. However, these studies have yielded inconsistent results (see also studies 5 and 6 , this dissertation). Some studies (Ehlers, 1995; Ehlers \& Breuer, 1992), did find superior perception of heartbeats in panic patients, others did not (Ehlers, Margraf, Roth, Taylor \& Birbaumer, 1988; Hartl, 1992; Asmundson, Sandler, Wilson \& Norton, 1993; Barsky, Cleary, Sarnie \& Ruskin, 1994). One factor responsible for the disparate results relates to differences in the paradigms used to measure perception. Ehlers and co-workers advocate the paradigm in which heartbeats are silently counted by panic patients -in fact the only paradigm with which superior perception has been found. However, as Rapee (1994) has noted, this procedure has the drawback that the number of hearbeats are generally underestimated since some beats will be missed. Persons with a tendency to over-interpret feelings as heartbeats will obtain higher scores since they count more "heartbeats" (which were in fact not heartbeats). Since panic patients may be just the persons who have this tendency, they might score better on the task without actually being better perceivers of heartbeats. Anyway, studies in which subjects had to compare their heartbeats with an external signal did not find that panic patients were better perceivers (Asmundson, Sandler, Wilson \& Norton, 1993; Ehlers, Margraf, Davies \& Roth, 1988). However, since the performance on this task is influenced by the ability of subjects to compare two different signals, this 


\section{Introduction}

paradigm too has its weaknesses. This renders the evidence for superior perception for heartbeats in panic patients inconclusive.

As is the case with selective attention, superior perception might be a cause as well as a consequence of panic disorder. Interestingly, Ehlers (1995) found that if superior perception for hearbeats persisted after subjects had undergone cognitive therapy, this was predictive of relapse of the disorder. Furthermore, the variable predicted relapse independent from "fear of fear" or other variables. Also Ehlers (1993) found that cardiac awareness was not changed by successful exposure treatment. These findings indicate that superior perception might be a vulnerability characteristic rather than a result of the disorder. However, since as noted earlier, it is by no means clear whether panic patients are superior perceivers, the discussion of causaliry may be premature. Unfortunately, research on superior perception on other domains than heartbeat perception is scarce. One study has addressed the issue of superion perception of respitatory resistance (Tiller, Pain \& Biddle, 1987). In this study panic patients seemed to perform worse in perceiving the magnitude of loads added to the inspiration than normals. However, since in this study patients with panic disonder and patients with other anxiety disorders were lumped, it is impossible to draw strong conclusions. Rapee (1994) investigated whether panic patients were better in detecting low concentrations of $\mathrm{CO}_{2}$ in air. When this gas-mixture is inhaled, it induces sensations similar to those reported and feared by panic patients. Patients were not found to be better than normals in detecting the inhalations with $\mathrm{CO}_{2}$.

In summary, two top-down hypotheses concerning panic were discussed: the hypothesis that panic patients selectively attend to bodily sensations and the hypothesis that panic patients may be superior in perceiving bodily changes. For the selective attention hypothesis most evidence exists, but this evidence is, however, indirect. The superior perception hypothesis got some support from shdies about perception of beartbeats. However, this might have been an artifact of the paradigm used. The few studies investigating the perception of other sensations did not show differences between panic patients and controls.

\section{Aim of this dissertation}

In the preceding section it was asserted that cognitive theories explain panic attacks as the manifestation of a vicious circle in which bodily sensations evoke anxiety and vice versa. Since in this view bodily sensations play a crucial role in the development of panic attacks 
and since panic patients complain a lot of these sensations, a central question is how these sensations come into being. Several processes that could account for these sensations were discussed. Of the bottom-up processes brought forward, neither hyperventilation nor mitral valve prolapse seemed strongly associated with panic disorder. These hypotheses therefore seem to have little explanatory power. From the top-down processes especially selective attention seems promising, although direct investigations are still lacking. Investigations of superior perception had mixed results. Furthermore, they have concentrated almost exclusively on heartbeat perception, so that superior perception of other physical changes is a possible origin of sensations in panic disorder which should still be tested.

The experimental studies in this dissertation try to shed light on several issues of topdown processing that are still unclear. Study 1 investigates whether selective attention for internal sensations indeed contributes to a heightened reporting of sensations in panic disorder patients. Studies 2 and 3 explore selective attention in a more direct way than was done hitherto. More specifically, in Study 2 the possibility is explored that panic patients have selective attention for hyperventilatory sensations. Although panic patients have been found not to have a special tendency to hyperventilate, hyperventilation is very well able to induce sensations feared by panic patients. Light hyperventilation is in itself a normal phenomenon, occurring on many occasions, especially when people are stressed or anxious (Bass et al., 1989; Garssen, 1980; Grossman, 1983). It may very well be that sensations produced by hyperventilation go normally unobserved, unless a person pays special attention to these sensations. This could very well be the case in panic disorder patients, who selectively attend to fearful bodily sensations. Thus, study 2 investigates in a direct way whether panic patients pay selective attention to fearful bodily sensations and to hyperventilatory sensations in particular.

A similar direct approach to selective attention is adapted in Study 3. In this study the information presented is visual heartrate feedback. It is hypothesized that panic patients will more than normal controls attend to information about their heartbeats.

Study 4 investigates whether selective attention might be a consequence of fear. A comparable paradigm will be used as in the previous experiment. This time, however, students will be tested who are made to fear different physical changes. It is hypothesized that students who are made to fear heartrate accelerations will selectively attend to the heartrate feedback whereas students who are made to fear an increase in muscle tension will selectively attend to feedback of muscle tension.

Studies 5 and 6 further address the hypothesis that panic patients might be interoceptive experts. In Study 5 again hyperventilation is used as a generator of sensations. Similar to the reasoning in Study 2 it is hypothesized that although panic patients may not be 


\section{Introduction}

excessive hyperventilators it may be that they experience more sensations while they hyperventilate. In this study the possibility is tested that panic patients have an increased ability to perceive sensations of hyperventilation. If this were the case, it is conceivable that also in daly life they will regularly be plagued by these sensations. Study 6 investigates whether panic patients are superior in detecting respiratory resistances. Since panic patients often complain of breathlessness, this seems a promising possibility to examine. 


\section{Study 1}

\section{Symptom reporting and interoceptive attention in panic patients}

\section{Summary}

The present study investigated whether bodily sensations reported by panic disorder patients can be due to interoceptive attention. The attention of both 16 panic patients and 17 normal control subjects was manipulated towards and away from bodily sensations. After each manipulation they had to report the sensations experienced. As expected, panic patients did report more sensations than controls in a baseline condition but against the hypothesis that a ceiling effect would oecur in the panic group, both panic patients and controls reported more sensations after instructions to attend to them. However, when their attention was diverted, panic patients showed a decrease in sensations greater than controls. The findings suggest that interoceptive attention may partly account for the sensations reported by panic patients.

\section{Introduction}

During panic attacks, panic disorder patients report numerous bodily sensations and in between attacks, they report sensations more frequently than others (Barsky, 1992). In attempting to explain the origin of these symptoms, one must recall that panic patients are frightened by these sensations and tend to interpret them as much more dangerous than they actually are (Clark, 1988). As anxiety towards particular cues is associated with an attention bias for these cues (Williams, Watts, McLeod, \& Mathews, 1988), it can reasonably be assumed that panic patients have an attentional bias for bodily sensations. Indeed, there is indirect evidence for such a phenomenon. Several studies using the modified Stroop task report that panic patients show an attentional bias for words denoting physical sensations (Clark, 1988). Other studies using questionnaires to measure body-consciousness report higher scores for panic patients tham for normal subjects (Belfer, \& Glass, 1992). It therefore seems likely that panic patients are more focused on, and selectively attend to bodily sensations.

Kroeze, S., van den Hout, M.A., Haenen, M-A. \& Schmidt, A.J.M. (1996). Symptom reporting and interoceptive attention in panic patients. Perceptual and Motor Skills, 82, 1019-1026. 


\section{Sundy 1}

When panic patients selectively attend to bodily sensations, the saliency of these sensations maly increase. Pennebaker has noted that altentiveness to bodily cues is related to number of reported symptoms (Pennebaker, 1982). In a study by Schmidt, Wolfs-Takens, Oosterlaan and van den Hout (1994) it was found that simply directing one's attention to somatic sensations dramatically increased the number of sensations reported. This inciease was still greater when sensations were expected. If panic patients habitually focus attention on bodily sensations, it is only logical that they should feel many sensations.

Thus, the explanation proposed for symptom reporting in panic patients is that the fear of sensations brings about an attention bias for these sensations, producing a "somatic amplification" of the sensations, which, in turn, leads to heightened reporting of symptons.

The clear implication is that by manipulating the attention of panic patients one can manipulate the reporting of symptoms. With this in mind, we decided to examine the following hypotheses. (1) In a baseline condition panic patients have a higher number of perceived symptoms than normals; (2) since this higher number of perceived symptoms is presumed to be due to attentional factors, normals should display a relatively large increase in reported symptorns when asked to attend to sensations compared with panic patients, since as patients are assumed to habitually attend to sensations, one would expect that additional instructions to do so have little effect; (3) if and when panic patients direct their attention to things other than bodily sensations there should be a steep decline in symptoms reported and their scores will be comparable to those of normal controls.

To investigate this, panic patients and normal controls were compared with regard to symptom reporting in three conditions: one in which attention was directed at internal sensations (Internal condition), one in which attention was directed at outer things (External condition), and a baseline condition. A comparable study with hypochondriacs is reported by Haenen, Schmidt, Kroeze and van den Hout (1995).

\section{Method}

\section{Subjects}

Panic patients as well as normal controls were recruited as subjects by advertisements in local newspapers, one asking for subjects with repeated panic attacks and one asking for healthy subjects. The subjects who reported baving panic attacks were diagnosed by a trained psychologist and were included if meeting the DSM-III-R criteria for panic disorder (American Psychiatric Association, 1987). Sixteen subjects (4 male, 12 female, 
met the DSM-III-R criteria and were selected. Sewenteen subjects whth no past or present panic complaints and of the same age and sex distribution (4 male, 17 femalle) were selected for the control group.

Table 1.1. Descriptive characteristics of the panic disorder and control groups

\begin{tabular}{lccccc}
\hline & $N$ & Age & Stai-State & Stai-Trait & Beck Depression \\
& & & & & \\
Panic pts & 16 & 41.1 & 48.0 & 54.4 & 16.0 \\
Controls & 17 & 41.9 & 32.1 & 40.0 & 6.2 \\
\hline
\end{tabular}

Table 1.1 gives a description of the samples in terms of age, education, as measured by a 7-point measure, state and trait anxiety, as measured by the State-Trait Inventory (Spielberger, Gorsuch, \& Lushene, 1983) and depression, as measured by the Beck Depression Inventory (Beck, Ward, Mendelson, Mock, \& Erbaugh, 1961). The subjects did not differ significantly on age or education. Significant differences existed in state anxiety, $t(32)=4.95, p<0.001$; trait anxiety, $t(32)=4.18, p<0.001$; and depression, $t(32)=3.56, p<0.01$.

\section{Assessment}

Symptom perception was measured with a checklist asking for the intensity of 49 symptoms. 47 of these symptoms were adopted from the checklist used by Schmidt $e t$ al. (1994). As we wanted to monitor all symptoms in the list that are included in the DSMIII-R definition of panic disorder, two extra items were added. Each items reflected a certain symptom or sensation and was scored on a 5 point scalle, anchoted by "0" (absent) to "4" (very strong).

A crucial assumption of our model of symptom reporting was that patients would feel particularly those symptoms they were afraid of. Thus all symptoms were ratted by each subject in terms of how anxious they would be if they fellt the sensation, also on 5-point scale, with " 0 " representing not at all anxious and " 4 " extremely anxious. On the basis of this rating those symptoms were selected that were significantly $(p<0.05)$ more frightening to the panic group than to the control group, according to a Mann-Whitney test. Having done this, a shortened list of 14 symptoms remained which was used in the analysis. The symptoms are isted in table 1.2. Note that most of these symptoms are associated with DSM-III-R-defined panic attacks. 


\section{Sudy 1}

Table 1.2. Symptoms of the Sympton Perception Checklist for which panic patients are more ancious according to Mann-Whiney lests $(p<0.05)$.

1. problenus with breathing deeply enough

2. dizziness

3. a pounding heart

4. un quicker or deeper respiration

5. pain in the lower back

6. a pounding feeling in the neck

7. chest pain

8. feeling faint

9. shaking

10. quick heart rate

11. sweating

12. paresthesisas

13. feelings of unrest, tension

14. lightheadedness

\section{Procedure}

Subjects were told that they would be participating in a study about bodily sensations and that some questionnaires would be administered. To make the manipulation of attention less obvious for subjects they were told that their muscle tension would be measured under different circumstances but that this would not be unpleasant. (The results of these measurements were not intended to be used.) Subjects first completed the Beck Depression Inventory and the State Anxiety measure. Then three electrodes, connected with an electromyotion, were placed on their foreheads. They were told that in this way the overall tension of their muscles could be measured. Then every subject participated in each of the three conditions in alternating order with an equal number of subjects in each of the possible orders. In the internal condition, the subject was asked to shut his eyes and to pay close attention to everything that he felt in his body and to concentrate on these feelings. In the external condition the subject was given a number of photographs and was asked to describe them. In the baseline condition the subject was told he could take a break because some notes had to be made. During this condition the experimenter could be seen writing while the subject sat on a chair.

Every condition lasted 2 minutes and after each one subjects were administered the symptom perception checklist. They were asked to describe the intensity to which they What felt the sensations on the list during the last 2 mimutes. After they had completed the 
last symptom checklist, the electrodes were removed. Finally they completed the measure of trait anxiety and the list which screaned their anxiety for the symptoms, after which they were thanked and given a small remuneration.

\section{Results}

Two scores were calculated in all three conditions: the total score on the 14-item Symptom checklist, reflecting the intensity of the reported sensations and the number of symptoms that received a score of 1 or more, reflecting the number of different sensations felt in that condition. Results are presented in table 1.3. As can be seen, in every condition the panic group reported more different and more intense sensations than the control group. To investigate whether these elevated scores were significantly higher than the scores of the control group, a repeated-measures ANOVA was performed. The analysis of intensity scores yielded a main effect of group, $F(1,31)=6.58, p<0.05$; as did the analysis of number of sensations, $F(1,31)=6.43, p<0.05$.

Post-hoc t tests indicated that intensity was significantly different between the two groups in the baseline condition, $r(32)=2.71, p<0.05$; and in the internal condition, $r(32)=$ $2.65, p<0.05 ;$ but not in the external condition, $t(32)=1.67, p=0.1$.

As our second and third hypotheses regarded shifts in sensations from the baseline condition, two difference scores were computed by subtracting the scores of the baseline condition from either the scores in the internal condition or the scores in the external condition. The difference scores are presented in table 1.4. Skewness was checked and proved to be in the normall range.

A. 2 (panic patients vs controls) $\times 2$ (intemal vs extemal) repeated measures ANOVA on difference scores for intensity gave a main effect of condition, $F(1,31)=11.76, p<$ 0.01 ; indicating that the manipulations did influence overall reporting of sensations. "There was no significant interaction effect, $F(1,31)=3.87, p=0.06$, and no group effect. Paired tests showed that for panic patients the increase in intensity of sensations from the baseline to the internal condition was not significantly greater than for controls. $(32)$ $=0.28$, ns. The difference from the baseline and the external condition however, differed significantly between panic patients and controls, $l(32)=1.90, p<0.05,1$-tailed. When a repeated measures ANOVA was calculated for the difference scores for number of sensations, no effect of group or condition, nor an interaction effect was found. 
Study 1

Table 1.3. Means and standard dewations from scores on the 14-item Symptom Perception Checklist

\begin{tabular}{|c|c|c|c|c|c|c|c|}
\hline & & & Interusicy & & \multicolumn{3}{|c|}{ Number } \\
\hline Group & & neutral & interna! & external & neutrail & internal & external \\
\hline \multirow[t]{2}{*}{ Panic pus } & $M$ & 8.7 & 10.8 & 7.1 & 5.1 & 6.1 & 5.1 \\
\hline & $\mathrm{SD}$ & 8.9 & 8.0 & 6.6 & 4.0 & 3.2 & 3.8 \\
\hline \multirow[t]{2}{*}{ Controls } & $\mathrm{M}$ & 2.5 & 4.9 & 3.9 & 1.8 & 3.4 & 3.1 \\
\hline & $\mathrm{SD}$ & 3.1 & 4.3 & 4.0 & 2.5 & 3.1 & 3.2 \\
\hline
\end{tabular}

Table 1.4. Changes from baseline in symptom scores when attention is manipulated

\begin{tabular}{lccccc}
\multicolumn{2}{l}{} & \multicolumn{2}{c}{ Intensity } & \multicolumn{2}{c}{ Number } \\
Group & & internal & extermal & & external \\
\multirow{2}{*}{ Panic pts } & $\mathrm{M}$ & 2.1 & -1.6 & 1.1 & 0.1 \\
& $\mathrm{SD}$ & 3.9 & 5.3 & 2.7 & 2.5 \\
& & & & & 1.2 \\
Controls & $\mathrm{M}$ & 2.4 & 1.4 & 1.5 & 2.9 \\
& $\mathrm{SD}$ & 3.4 & 3.9 & 2.6 & \\
\hline
\end{tabular}

\section{Discussion}

The prediction that panic patients would report more sensations in the baseline condition was confimed. They reported more different sensations as well as more intense ones. This finding is a replication of that by Barsky (1992), who found that the reporting of more sensations is a concomitant of various anxiety and mood disorders,

"The prediction that panic patients would have a greater decraase in symptoms from the baseline to the external condition than controls was supported for the intensity but not for the number of symptoms. There is no ready explanation for this discrepancy, although it might be argued that probing for intensity is a more sensitive measure than a dichotomous 
measure of absence or presence.

Both panic patients and controls reported more intense sensations in the internal than in the baseline condition. This result, i.e. that the perception of sensations was strongly influenced by attention to bodily cues, is in line with Pennebaker (1982) and Schnidt, er al. (1994). However, although we expected a smaller increase in scores for panic patients when they were instructed to focus on bodily sensations (because of a ceiling effect) no such effect was found. Panic patients still seemed capable of increasing attention to bodily sensations.

Overall, the data lent some support to the proposed explanation that repotting of symptoms in panic patients is due to selective attention to sensations they are afraid of. However, attention to bodily sensations in our panic patients did not reach its maximum in the baseline condition. Also, control subjects were far from reporting as much sensations as panic patients when focussing on them. Assuming that in the intemal condition controls and panic patients allocate as many attentional resources to bodily cues, it seems that other mechanisms also contribute to greater reporting of symploms in panic patients. A possible solution might be that panic patients are superior interoceptors, i.e. are better in perceiving physical sensations (see Ehlers \& Breuer, 1996, for an overview). Focussing on bodily sensations will then rather occasion a greater than a smaller increase in sensations in panic patients than in controls. Nevertheless, it is possible that panic patients are superior perceivers just because they habitually attend to sensations. Frequent attention might train somebody to easily recognise and label sensations otherwise going unnoticed.

In search of alternative explanations for the heightened symptom reporting of panic patients one can look for processes other than selective attention. Of course one cannot rule out the possibility that symptom reporting by panic patients is partly duc to processes gemerating more somatosensory input in panic patients than in controls. Indeed there are some indications that panic patients are hypersensitive to phatmacologically induced increases and decreases in noradrenergic activity, suggesting that reported sensations may be partly explained by a relatively labile noradrenergic system (Nut \& Lawson, 1992).

An obvious explanation for the sensations paric patients feel seems to be anxiety since anxiety is accompanied by physiological changes. An alternative explanation for the results found could then be that panic patients were already more anxious in the baseline condition resulting in higher symptom scores and that they became even more anxious in the internal condition in which they had to concentrate on potentially frightening sensations. In the external condition concentrating on other things could have subdued their anxiety leading to fewer sensations. Unfortunately. anxiety was not measured in every condition. The only indication to support this explanation could come from the EMG 
measurements. When EMG scores were correlated with the report of sensations in the same condition, these comelations were very low and nonsignificant. However, as EMG is not a very sensitive measure of anxiety, this cannot rule out the alternative explanation. Although the report of sensations increased in the internal condition, the increase, especially in the controls, did not seem as large as would be expected from the study by Schmidt, et al. (1994). A reason for this disparity could be the difference in instruccions given. In the study by Schmidt, subjects were asked to concentrate on a specific area of the body, after which they reported the sensations they felt in that area. In this way, 14 areas were focused upon, after which all semsations felt were counted. It is easy to imagine that such instructions might stimulate subjects to report sensations more than the general instructions given in the present study. The instruction to concentrate each time on a specific area, although more time-consuming, seems a better way to demonstrate the influence of attention on sensations.

Not only may an attention bias for sensations partly account for many symptoms panic patients report, selective attention may also play an important maintaining role in the disorder (Ehlers, 1995). The focus of selective attention in panic patients is on bodily sensations, and the selective attention produces an increase in the saliency of the sensaw tions. One must bear in mind that panic patients tend to misinterpret bodily sensations catastrophically, while the occurrence of the latter can easily increase the credibility of catastrophic wiews: the fear that something is wrong with one's heart, for instance, may direct attention to cardiac sensations, increasing their intensity and incidence. These perceptual experiences may strengthen the frightening conviction that one is at risk for cardiac failure.

In sum, the present data show that by distraction, the intensity, but not the number, of sensations felt in panic patients can be decreased. This suggests an important role for attention in the maintenance of panic disorder as selective attention can apparenty induce an intensification of several sensations. Thus the present results lend support to behavioural experiments sometimes used in therapy when patients are shown that their sensations are lessened by directing their attention to external matters (Clark, 1989). These resulis also denonstrate how distraction may work as a therapeutic tool (Craske, Strect \& Barlow, 1989). 


\section{Study 2}

\section{Selective attention for hyperventilatory sensations in panic disorder}

\section{Summary}

According to cognitive theories, panic patients are assumed to display selective attention for feared bodily sensations. So far there has only been indirect evidence for this based on their performance on reaction time tasks like the modified Stroop lask and the dot probe detection task. In the present study a more direct attempt was made to investigate whether panic patients show sellective attention for feared sensations, in particular hyperventilatory sensations. A group of patients with panic disorder and a group of normal controls were compared on their performance on a reaction time task under different distracting conditions. The distractors used were: hyperventilation. isocapnic overbreathing and making a neutral movement. No evidence for selective attention for hyperwentilatory sensations was found. However, panic patients were somewhat slower in the beginning of the hyperventilation conditions. It is discussed whether the lack of clearly finding selective attention for the sensation inducing distractors might be due to methodological issues.

\section{Introduction}

In cognitive theoties of panic disorder the phenomenon of selective attention plays a central role. Panic patients are assumed to scan their bodies for signs of danger. thus increasing the possibility that feared sensations are noticed and misinterpreted (Clark. 1988). Support for selective attention for threatening sensations comes from reaction time paradigms like the Stroop task and the dot probe detection task. In the Stroop task subjects have to name the colour of words whilst ignoring their meaning. In different studies panic patients have been shown to slow down when they have to name the colour of catastrophe words (e.g., death, collapse: McNally. Riemann \& Kim, 1990), bodily sensation words (e.g. dizzy, heartbeat: McNally et al., 1990), physical threat words (e.g. fatal, illness: Hope, Rapee, Heimberg \& Dombeck, 1.990) and panic threat words (e.g. 


\section{Study 2}

dizzy, fear: McNally, Amir, Louro, Lukach \& Calamari, 1994). This could be interpreted as showing that panic patients cannot avoid attending to the meaning of the threatening word. A comparable phenomenon can be seen in the so-called dot probe detection task: Panic patients react more quickly when they have to press a button on the appearance of a dot on a PC screen when it replaced a word related to physical threat than when it replaced a neutral word (Asmundson "Sandler, Wilson \& Walker, 1992). It seems that panic patients selectively attend to words related to their concerns.

However, in the maintenance of panic disorder it is assumed that selective attention or hypervigilance is directed to bodily sensations that are proprioceptively felt. The fact that panic patients selectively attend to words related to these sensations does not directly support this assumption. Evidence from Stroop, or dot probe detection studies merely demonstrate that panic patients scan the external environment for sources of perceived threat. The question whether they are over-attentive to bodily sensations requires independent and direct tests. Ehlers and Breuer (1995) report a study that is especially relevant in the present context. They found that panic patients showed selective attention for genuine bodily sensations. In the study by Ehlers and Breuer the threatening sensation consisted of an electric shock applied to one of the ring fingers. Subjects were then instructed to attend a neutral stimulus that would be applied to one of the index fingers. Panic patients were quicker in reacting to the stimulus when it was applied to the same hand as the shock had been just before, showing that attention had been directed to the threatening sensation. Normal controls did not show this selective attention.

This study seems directly to support the selective attention hypothesis since it shows that panic patients attended to real threatening sensations. However, electric shocks are not the sensations panic patients feel when they have panic attacks. The fact that they showed selective attention for shocks is intriguing but might indicate, for example, that they took the chance to be distracted from much more frightening sensations that might occur from interoceptive sources. It would therefore be important to know whether panic patients also show selective attention for sensations especially frightening for these patients and that can be expected to occur under natural conditions.

One possible candidate as a generator of sensations is hyperventilation. Although studies have failed to demonstrate that falls in $\mathrm{pCO}_{2}$ precede panic attacks (Garssen, Buikhuisen \& van Dyck, 1996; Hibbert \& Pilsbury, 1988; Hornsveld, Garssen, Fiedeldij Dop, van Spiegel \& de Haes, 1996), the method used to measure $\mathrm{pCO}_{2}$ in these studies (trancutaneous) seems not very sensitive to small changes in $\mathrm{pCO}_{2}$ nor to the exact timing of these changes. Still, hyperventilation seens a relatively obvious way by which sensations can be accounted for. Anxious people do tend to hyperventilate a little (Van den Hout, Hoekstra, Arntz, Christiaanse, Randschaert \& Schouten, 1992) and perhaps 
hyperventilation need not be especially strong to make a good attender aware of its effects. Also, Margraf (1993) concluded in his review about the connection between hyperventilation and panic attacks that hyperventilation might act as a trigger of some panic attacks in some patients with panic disorder.

The present study was undertaken to investigate whether panic patients show selective attention for hyperventilatory sensations. If they do, this would directly support the more general theory that panic patients are hypervigilant to bodily sensations, a hypothesis only indirectly investigated by paradigms using words referring to sensations. Furthermore, it would shed light on whether hyperventilation in combination with selective attention could be a trigger of panic attacks.

A combination was used of a reaction time task as described by Crombez, Baeyens and Eelen (1994) to measure distraction and an experimental design used by Hornsveld, Garssen and van Spiegel (1995) to manipulate $\mathrm{pCO}_{2}$. In the task by Crombez et al., healthy volunteers were asked to discriminate between noise of long $(200 \mathrm{~ms})$ and short (100 ms) duration. When during the task a distractor (a painful heat stimulus) was introduced, the subjects suffered a deterioration in performance on the task as shown by an increase in mean reaction times. Deterioration was interpreted as measure of the immediate attentional demand of pain. In the present experiment too, series of tones of 100 and 200 ms were presented to subjects under different attention demanding conditions. Since we wanted to investigate whether panic patients would show selective attention for sensations generated by hyperventilation, a group of panic patients was compared with a group of normal controls on their performance on this discrimination task during hyperventilaton and during control conditions. As it was not known what degree of hyperventilation would be necessary to attract the attention of patients, two levels of hyperventilation were used. To control for attention attracting aspects of the breathing movement during hyperventilation and other unspecific effects, also two levels of so-called placebo-hyperventilation were used. In these conditions subjects breathed in the same way as in the hyperventilation conditions but the drop of $\mathrm{pCO}_{2}$ was prevented by adding $\mathrm{CO}_{2}$ to the inhaled air (Hornsveld et al., 1995). Furthermore, to test if any selective attention in participants was specific to hyperventilation-induced bodily sensations and not to be found for any distractor, a second control condition was added in which the subject executed a neutral movement, requiring some effort. 
Study 2

\section{Method}

\section{Subjects}

Subjects were recruited by an advertisement in a local newspaper asking for persons having recurrent unexpected panic attacks. The persons who reacted were contacted by telephone and were diagnosed by a trained psychologist, using the Structured Clinical Interview for DSMIII-R (SCID, Spitzer \& Williams, 1986)), on fulfilling the DSMIII-R criteria of panic disorder. Exclusion criteria were: current major depression or hallucinations, known asthma or heart problems. In total, 44 persons were interviewed. Of these, 23 fulfilled the stated criteria and were asked to participate. Five of them did not show up at the appointed time; hence ultimately 18 subjects ( 9 women, 9 men) with panic disorder participated in the experiment. As a control group, 19 subjects (10 women, 9 men) matched on age, sex and education were obtained via an advertisement asking for healthy subjects. Descriptive statistics of patient and control groups are presented in table 2.1.

\section{Attentional Measurement}

To measure selective attention a task was used in which subjects had to discriminate between long $(200 \mathrm{~ms})$ and short $(100 \mathrm{~ms})$ tones $(440 \mathrm{~Hz})$. Tones were administered by way of a loudspeaker. After hearing a tone the subject had to press one of two buttons as quickly as possible, one button if the tone had been relativelly short, the other one if the tone had been relatively long. Reaction times and accuracy were recorded. Each task consisted of ten tones ( 5 long, 5 short), separated by a silence of on average $6.5 \mathrm{sec}$. (min. $5 \mathrm{sec}$., max. $8 \mathrm{sec}$.). Long and short tones were randomly chosen. The task was administered 7 times to each subject under different attentional conditions (see below). It was expected that the more subjects were distracted from the discrimination task, the more reaction times and number of mistakes would increase. Differences of these means from baseline could then be considered to be measures of attention directed to the distractor.

\section{Psychological Measures}

At the beginning of the experiment subjects completed the Bodily Sensations Questionnaire (BSQ, Chambless, Caputo, Bright \& Gallagher, 1984) to measure fear for bodily sensations, the State-Trait Anxiety Inventory (STAI, Spielberger, Gorsuch \& Lushene, 1970) to measure anxiety and the Beck Depression Inventory (BDI, Beck, Ward, Mendelson, Mock \& Erbaugh, 1961) to measure current depression.

To measure hyperventilation sensations, at different times 5 sensations were rated by the 
subject on a visual analogue scale (VAS) assessing how strong each sensation was experienced during an appointed time, the scale rating the experience of the sensation from "not at all" to "extremely". Hyperventilation sensacions were chosen on basis of a pilot experinent in which a period of real hyperventilation was compared to a period of "placebo" hyperventilation, "placebo" hyperventilation meaning that the subjects breathed as quick and as deep as in the real hyperventiation condition but that the drop in $\mathrm{pCO}_{2}$ was prevented by adding $\mathrm{CO}_{2}$ to the inspired air. The sensations that differentuated best between these conditions were considered to be most specific for hyperventilation and were therefore used in the present experiment. These sensations were dizziness, trembling, parasthesias, a feeling of unreality and palpitations.

At the same time anxiety was rated on a similar VAS. Also measured regularly with a similar VAS was subjective feeling of exertion and subjective feeling of distraction from the tone task.

\section{Apparatus used to manipulate $\mathrm{pCO}_{2}$}

To be able to manipulate $\mathrm{pCO}_{2}$ the same construction was used as by Kroeze and Van den Hout (1998; see also Hornsweld et al., 1995). Subjects breathed in a race-mask with two separate airways, one for the inhaled air and one for the exhaled air. From the exhaled air $\mathrm{pCO}_{2}$ was assessed by means of a capnograph (DATEX, multicap CNO-103). To the inspiratory airway a plastic tube $(20 \mathrm{~cm}$ long and $8 \mathrm{~cm}$ ID) was attached. Normally, room air was breathed through this tube, but since the tube was connected at its midpoint to a $100 \% \mathrm{CO}_{2}$ cyllinder, $\mathrm{CO}_{2}$ could be added to the inhaled air, the concentration of which could be manually varied. The purpose of adding $\mathrm{CO}_{2}$ to the inhaled air was to be able to let people breathe as though they were hyperventilating while in fact their $\mathrm{pCO}_{2}$ stayed at baseline. Subjects sat with their back to the gas cylinder so that they could not see if $\mathrm{CO}_{2}$ was added or not.

As control distraction mechanism, a footpump was used, which was connected to the lower part of an airbed (Nomad 2000), which was empty at the beginning of the experiment.

\section{Procedure}

After having completed questionnaires, subjects were told that they would get a task in which they had to discriminate longer tones from shorter ones as quickly ats possible. This tone task would be repeated seven times under different conditions. Under some conditions it might be more difficult to execute the task, but they had to try each time to react to the tones as quickly as possible. Then subjects were demonstrated the duration of a long and a short tone; then they practised the task till they had given ten good answets in 
a row. After this they indicated on a VAS how strongly they experienced the five hyperventilation sensations at that moment and how strong their anxiety was. The scores on these scales were taken as baseline measures of sensations and anxiefy.

After this, all subjects had a different sequence of events, scheriatically shown in figure 2.1. The baseline tone task consisted of executing the tone task without any distractors. The baseline $\mathrm{pCO}_{2}$ measurement was obtained by letting the subject breathe for 2 minutes into the same face-mask as used in the hyperwentilation conditions. The hyperventilation conditions were two real hyperventilation conditions and two placebo-hyperventilation conditions. The real hyperventilation conditions consisted of hyperventilating once to about $3.3 \mathrm{Vol} \% \mathrm{pCO}_{3}$ and once to about $2.9 \mathrm{Vol} \% \mathrm{pCO}_{2}$. The subject started breathing according to the instructions of the experimenter and when the desired breathing pace was reached, the subject was encouraged to continue breathing in the same way till the end of the tone task (approximately 1.5 min.). Then the subject was warned that the tone task would start. In the placebo-hyperventilation conditions the subject got the same breathing instructions as in the hyperventilation conditions but the lowering of $\mathrm{pCO}_{2}$ was prevented by adding $\mathrm{CO}_{2}$ to the inspired air.

The air-bed conditions consisted of pumping one time slow and one time quick with one foot on the pump. The subject always started with pumping according to the instructions of the experimenter and when the desired speed was obtained, the tone task was started and the subject continued pumping till the end of the tone task.

The sequence of these conditions was systematically varied (see figure 2.1): Half of the subjects first had to execute the tone task without any distractors (baseline tone task). The other half of the subjects first had their baseline $\mathrm{pCO}_{2}$ measured. Then, the first half of the subjects had their baseline $\mathrm{CO}_{2}$ obtained and the second half of the subjects got the tone task. Then again different sequences followed: From the first and the second half of the subjects, half first got the 4 hyperventilation conditions, in which the order of levels of (placebo and real) hyperventilation varied. The other half first got the 2 air-bed conditions, with sllow and quick alternating. Thereafter, the conditions were reversed for both groups of subjects. Again the order of quick/slow (air-bed) and of levels of (placebo and real) hyperventilation were systematically varied.

After each tone task and after the measurement of baseline $\mathrm{pCO}_{2}$ subjects indicated on a VAS the hyperventilation sensations and the anxiety experienced during the last tone task or the $\mathrm{pCO}_{2}$ measurement. After each experimental condition the subject had a pause of 2 minutes to recover. 
Figure 2.1 Possible sequences of conditions

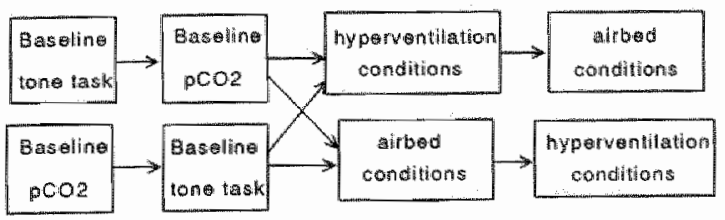

\section{Results}

\section{Questionnaires}

Mean scores of the groups on the different questionnaires are presented in table 2.1. The groups differed significantly on the BSQ, the BDI, the STAI state, and the STAI trait.

Table 2.1. Descriptive characteristics of the panic disorder and normal control groups

\begin{tabular}{lccc}
\hline Questionnaires & Panic Disorder & Normal Control & t-value \\
BSQ & $46.3(8.7)$ & $28.4(6.5)$ & $7.08^{\text {*** }}$ \\
BDI & $16.8(11.7)$ & $7.4(7.2)$ & $2.94^{\text {** }}$ \\
STAI-state & $50.3(12.5)$ & $34.3(8.6)$ & $4.52^{\text {a** }}$ \\
STAl-trait & $52.5(12.7)$ & $39.2(12.1)$ & $3.28^{* *}$ \\
\hline
\end{tabular}

$$
\begin{aligned}
{ }^{* *} \mathbb{P} & <0.001 \\
{ }^{* *} \mathbb{P} & =0.01
\end{aligned}
$$

\section{Respiratory measures}

In order to check if the breathing manipulation had the intended effects and if both groups were affected likewise, breathing pace and $\mathrm{pCO}_{2}$ were calculated for both groups under the various conditions. Breathing pace gives some indication of the effort subjects delivered. Breathing pace was determined by counting the number of breatlis per minute during the period that $\mathrm{pCO}_{2}$ was kept at a certain level. Data are shown in figure 2.2 , right panel. In a repeated measures $2 \times 2 \times 2$ ANOVA (group: panic disorder/normal control $x$ condition: hypocapnia/isocapnia $x$ level: hyperventilation to 3.3 Vol\% vs 2.9 Vol\% $\mathrm{pCO}_{2}$ ) on these data only a trend towards an effect of level was found, $F(1,35)=2,67, p$ 


\section{Study 2}

$=0.11$, indicating that the different levels of hypocapnia or isocapnia were associated with a different breathing pace. Crucial to the validity of the $\mathrm{pCO}_{2}$ manipulation, there was no condition-effect, $F(1,35)<1$, meaning that as far as breathing pace is considered, the isocapnic periods did not differ from the hypocapnic periods.

End-tidal $\mathrm{pCO}_{2}$ was measured to check if the intended degrees of hyperventilation (real and placebo) were reached. $\mathrm{CO}_{2}$ data are presented in figure 2.2 , left panel. For each period in which $\mathrm{pCO}_{2}$ was kept on a certain level the mean end-tidal $\mathrm{pCO}_{2}$ was computed. As can be seen baseline levels of end-tidal $\mathrm{pCO}_{2}$ were fairly equal. A t-test confirmed this: $t(35)=0.54$ NS. The experimental $\mathrm{pCO}_{2}$-data were subjected to a repeated measures $2 \times 2 \times 2$ ANOVA (group $x$ condition $x$ level). According to the ANOVA there was no effect of group, $F(1,35)<1$; a highly significant effect of condition, $F(1,35)=284.71$, $p<0.001$; and a significant effect of level, $F(1,35)=37.14, p<0.001$, which was qualified by a significant effect of condition $x$ level, $F(1,35)=10.92, p<0.01$. There was no effect of group $\mathrm{x}$ condition, $F(1,35)<1$; no effect of group $\mathrm{x}$ level, $F(1,35)<$ 1. ns; and no interaction effect, $F(1,35)<1$. Thus, the groups seemed to have been subjected to the same $\mathrm{CO}_{2}$-levels in all conditions and the induced falls of $\mathrm{pCO}_{2}$ and the isocapnic periods seem to have been quite distinguishable, as they should be.

Figure 2.2. Mean $\mathrm{pCO}_{y}$ and mean breathing pace during real and placebo hyperventilation
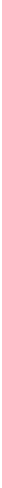

\section{Sensations}

To check whether sensations were experienced in the different experimental periods, sensation scores were computed by adding the (VAS) scores of the list of hyperventilation sensations. Means are depicted in figure 2.3. 
Study 2

Figure 2.3. Scores from visual analogue scales measuring sensations, subjective distraction and fear during different distracting conditions, inclading baseline (BL)
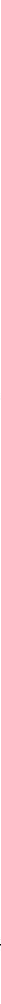

levet of pCO2 in real hyperventilation
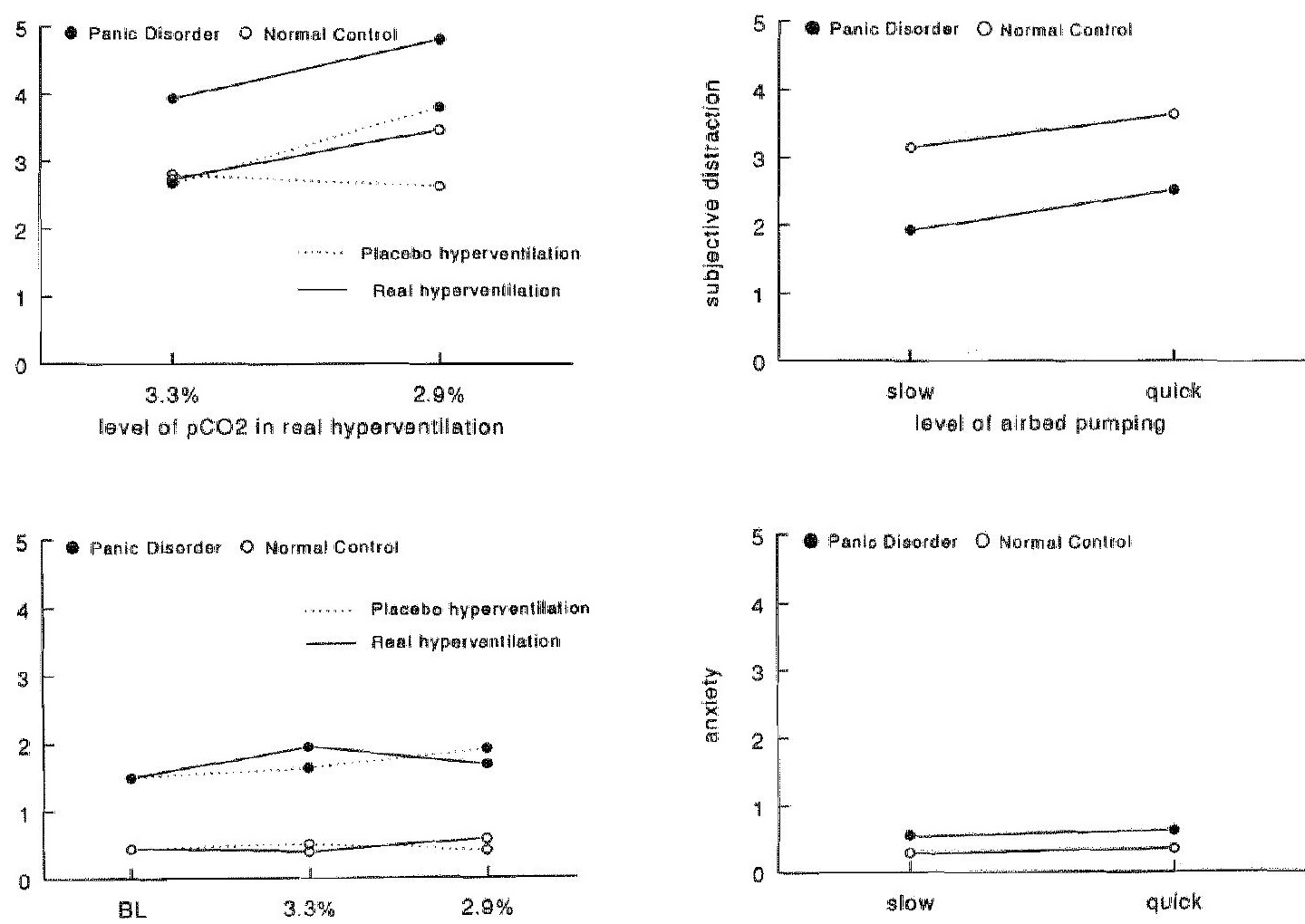

level of $0 \mathrm{CO} 2$ in real hyperwentilation

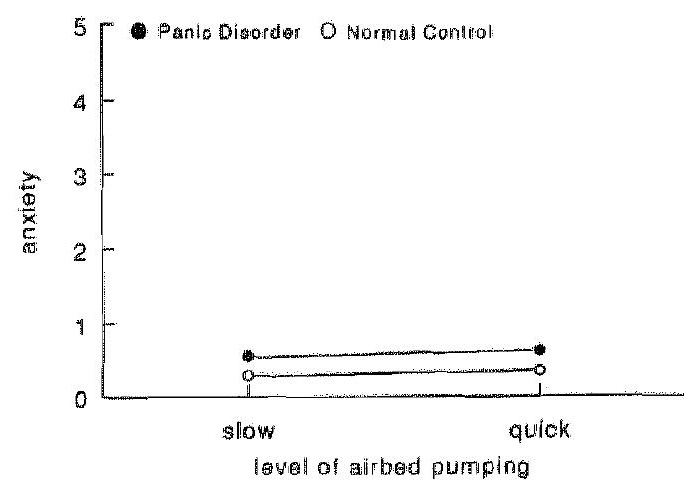




\section{Study 2}

To compare the report of sensations during the hyperventilation periods, a $2 \times 2 \times 2$ (group $x$ condition $x$ level) was executed on the sensation scores. The ANOVA revealed a main effect of group, $F(1,35)=5.35, p<0.05$; a main effect of condition, $F(1,35)=9.88$, $p<0.01$; an effect of level, $F(1,35)=3.97, p=0.05$; and a trend towards an interaction effect of condition by $\|$ level, $F(1,35)=2.84, p=0.1$. When the sensation score during the baseline task and the baselline sensations score during the baseline $\mathrm{CO}_{2}$ measurement were introduced as covariates into the analysis, the group-effect disappeared, $F(1,31)=1.12$, ns. Thus, the conditions were significantly different in the intensity of induced hyperventilation sensations. The panic patients reported more sensations overall, but this could be attributed to baseline differences.

Also a ANOVA was executed on the sensation scores during the airbed pumping conditions. The $2 \times 2$ (group: panic disorder/normal control $x$ level: quick/slow) ANOVA revealed no effect of group, $F(1,35)<1$; no effect of level, $F(1,35)<1$; and no interaction effect, $F(1,35)<1$. Thus, the groups did not differ in sensation reporting during the airbed pumping conditions, nor did quick pumping render more sensations than slow pumping. The manipulation also seemed to be successful in the sense that during real hyperventilation conditions, sensations increased whereas during airbed pumping conditions sensations did not.

\section{Exertion}

To check for subjective exertion during the hyperventilation conditions, VAS scores on this item were analysed with a $2 \times 2 \times 2$ (group $x$ condition $x$ lewel) ANOVA. This ANOVA showed no significant differences, only a trend towards an effect of level, $F(1,35)=$ $3.42, p=0.07$; indicating that subjects tended to feel they exerted themselves more in the heavier hyperventilation conditions than in the lighter. This applied both to the real and to the placebo hyperventilation conditions, since the interaction of condition $x$ level was not significant, $F(1,35)=1.06$, ns. When a $2 \times 2$ (group $\times$ level) ANOVA was done on the VAS scores asking for exertion during airbed pumping, no significant differences were found. The subjects seemed to have invested more exertion in the quicker pumping condition, but the results were not significant, $F(1,35)=2.13$, ns.

\section{Subjective distraction}

To investigate the subjective feeling of distraction during the hyperventilation conditions, a $2 \times 2 \times 2$ (group $\times$ condition $\times$ level) ANOVA was performed on the VAS scores for this item. Means are presented in figure 2.3. Significant effects were found of condition, $F(1,35)=9.55, p<0.01$; and of level, $F(1,35)=6.75, p<0.05$, indicating that both 
groups felt they were more distracted from the task by real hyperventilation than by placebo hyperventilation and also more by heavier breathing than by lighter breathing. Although the panic subjects seemed to think themselves to be more distracted from the task by real hyperventilation (see figure 2.3), the interaction of group $\mathrm{x}$ condition did not reach significance, $F(1,35)=2.38, p=0.13$; nor did the interaction of group $\mathrm{x}$ condition $x$ level, $F(1,35)=2.39, p=0.13$.

A $2 \times 2$ (group $\times$ level) ANOVA on the VAS scores regarding distraction during airbed pumping showed a trend towards an effect of group, $F(1,35)=3.01, p=0.09$ and a trend towards an effect of level, $F(1,35)=3.64, p=0.07$; but no significant interaction effect of group $x$ level, $F(1,35)<1$. Interestingly, in this condition panic patients seem to feel less distracted from the task than the control group, whereas the opposite was the case during real hyperventilation (see figure 2.3).

\section{Anxiety during the experiment}

To investigate whether the groups differed in anxiety during the periods of hypocapnia and isocapnia, the scores on the anxiety scales (VAS) were compared. Means are presented in figure 2.3. According to a repeated measures $2 \times 2 \times 2$ ANOVA there was a group-effect, $F(1,35)=6.57, p<0.05$, indicating that panic patients had been more anxious during all hyperventilation conditions than the control group. There was found to be no condition effect, $F(1,35)<1$; no effect of level, $F(1,35)<1$; no effect of group $x$ condition, $F(1,35)<1$; no effect of group $\mathrm{x}$ level, $F(1,35)<1$; no significant effect of condition $x$ level, $F(1,35)<1$; but a trend towards a significant interaction effect of group $\times$ condition $\times$ level, $F(1,35)=3.72, p=0.06$, suggesting that the groups reacted with different anxiety towards heavier and lighter (placebo-) hyperventilation. When baseline anxiety during the task and during baseline $\mathrm{pCO}_{2}$-measurement wits introduced as a covariate, the group effect was no longer significant, $F(1,31)=2.05, p=0.16$, showing that most of the anxiety during the hyperventilation conditions was due to baseline differences. A $2 \times 2$ ANOVA on the anxiety scores during airbed pumping showed no differences for group, $F(1,35)=1.03$; nor for level, $F(1,35)<1$; nor an interaction effect, $F(1,35)<1$.

\section{Performance on reaction time task}

Reaction times that were more than 3 standard deviations away from the individual mean of a subject were discarded. Means are presented in figure 2.4. From the means of the reaction times in the distraction conditions, baseline reaction times were subtracted to reveal the interference by the experimental conditions. On the interference scores of the 


\section{Study 2}

hyperventilation conditions a $2 \times 2 \times 2$ (group $x$ condition $x$ level) ANOVA was performed. The ANOVA revealed no effect of group, $F(1,35)<1$; no effect of condition, $F(1,35)$ $<1$, no interaction effect of group $x$ condition, $F(1,35)<1$, no effect of level, $F(1,35)$ $=1.53$, ns; no interaction of group $\mathrm{x}$ level, $F(\mathbb{1}, 35)<1$; no interaction of condition $\mathrm{x}$ level, $F(1,35)=1.6, \mathrm{~ns}$; and no interaction of group $\mathrm{x}$ condition $\mathrm{x}$ level, $F(1,35)<1$.

Figure 2.4. Mean reaction times in ms and mean number of errors on the tonetask during different distracting conditions, including baseline (BL)
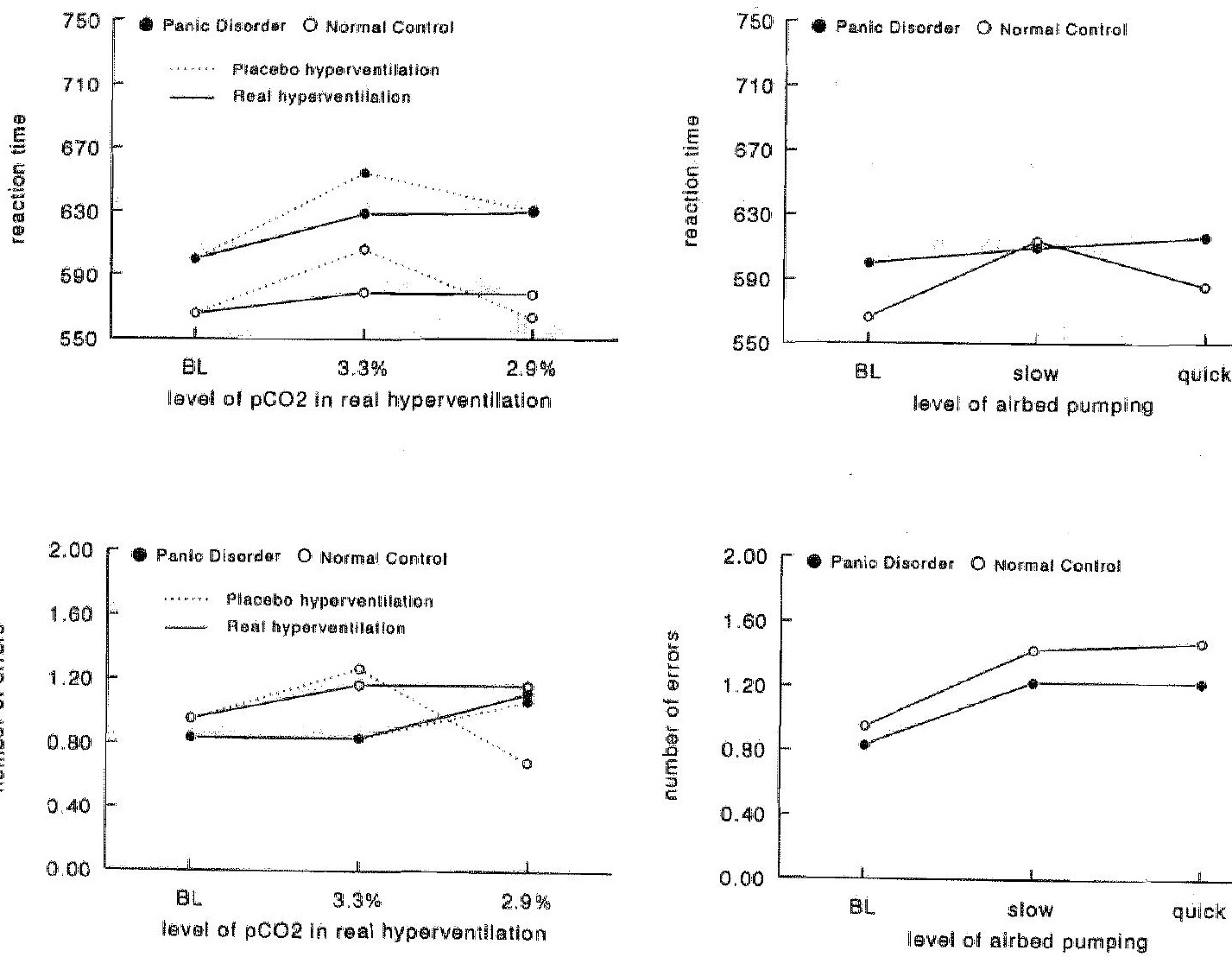
Thus, the groups did not show different responses to real or placebo hyperventilation, as was indicated by a similar interference in both groups in all thyperventilation conditions. When an $2 \times 2$ (group $x$ level) ANOVA was done on the interference scores in the airbed conditions no effect of group was found, $F(\mathbb{1}, 35)<1$, no effect of level, $F(1,35)<1$; and no interaction effect, $F(1,35)=1.64$. Thus, also airbed purnping had no different effect on the reaction times of the groups.

Apart from increased reaction times, distraction might cause more errors in differentiating the tones. Therefore a $2 \times 2 \times 2$ (group $x$ condition $x$ levell) ANOVA was executed on number of errors made during the different hyperventilation conditions, again corrected for baseline level. Uncorrected means are presented in figure 2.4. According to this ANOVA, there was no effect of group, $F(1,35)<1$; no effect of condition, $F(1,35)<$ 1; nor of group $x$ condition, $F(1,35)<1$; no effect of level, $F(1,35)<1$; a trend towards an effect of group $x$ level, $F(1,35)=3.11, p=0.09$; no effect of condition $x$ level, $F(1,35)=1.23$, ns; and no interaction of group $x$ condition $x$ level, $F(1,35)<1$. Thus, the only difference between the groups was that panic patients tended to make somewhat more errors when they had to breathe faster more deeply, regardless of whether this was real or placebo hyperventilation.

The $2 \times 2$ (group $x$ condition) ANOVA on number of mistakes during airbed pumping. corrected for baseline levell, did not reveal significant effects either. There was no effect of group, $F(1,35)<1$; nor an effect of level, $F(1,35)<1$; nor an interaction effect, $F(1,35)<1$.

So far, no selective attention in panic patients was found, It could, however, be possible that the lack of finding differences was due to using a somewhat different method than that used by Crombez et al. (1994) in their experiment about distraction by pain. Crombez et al. used only 2 noises (comparable to the tones in the present experiment) during a painful heat stimulus as target stimuli. Since it was conceivable that the lack of significant results was due to the repeated presentation of tones in the present experiment, the analysis on reaction latencies was repeated using only the reaction times on the first two tones of every condition. Means are presented in figure 2.5 .

The ANOVA on the interference scores in the hyperventilation conditions revealed a trend towards an effect of group, $F(1,35)=3.18, p=0.08$, indicating that the panic group had slower reaction times on the first two tones when having to breathe more quickly and more deeply. However, again no effect of condition was found, $F(1,35)=1.71$, ns, nor an effect of group $x$ condition, $F(1,35)<1$. Also the other interactions were far from significant. The ANOVA on the interference scores in the airbed pumping conditions revealed no effect of group, $F(1,35)<1$; no effect of level, $F(1,35)<1$; and no 


\section{Study 2}

interaction effect, $f(1,35)=1$, ns.

Figure 2.5. Reaction times in ms during different distracting conditions including baseline (BL), using only the first tones of the tonetask
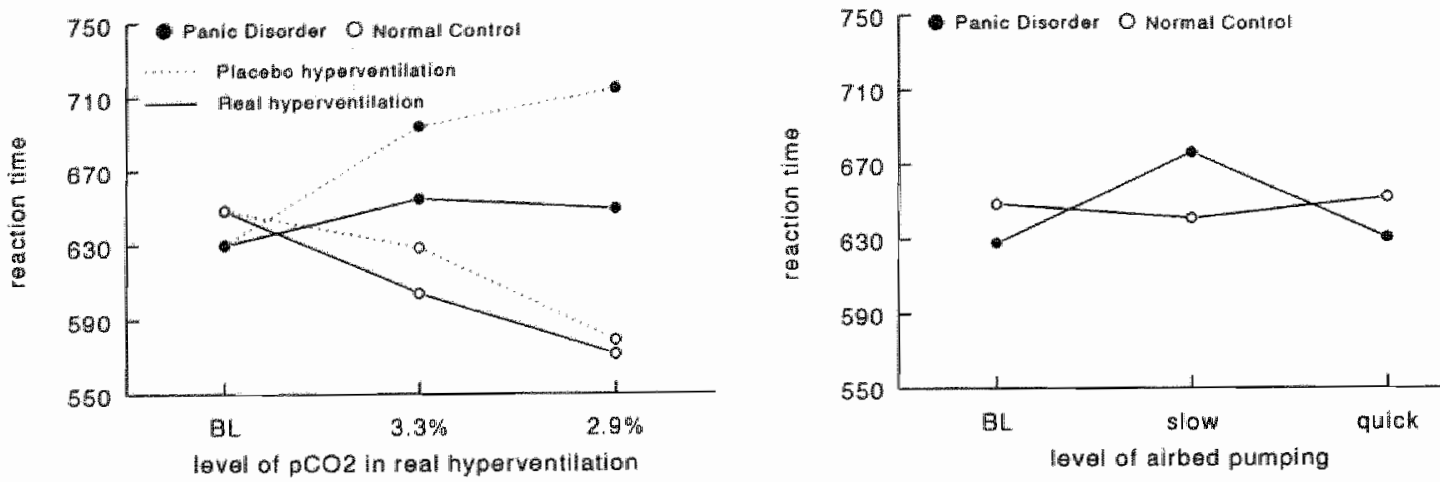

\section{Discussion}

The hypothesis that panic patients show selective attention for hyperventilatory sensations was not clearly confirmed. When mean reaction times on the tone task were compared, panic patients did not show more interference than normal controls under hyperventilation conditions. Also, panic patients were not more distracted by hyperventilation than by placebo hyperventilation. Only when the first two tones of each reaction time task were compared, did panic patients seem to show more interference than normal controls on both placebo and teal hyperventilation.

What might be the reason for not clearly finding panic patients displaying selective attention for the real sensations while they did so for words describing these sensations (McNally et al., 1994; McNally et al., 1990)? Furthermore, what might be the reason that the ratings of subjective distraction indicated that the panic patients thought themselves to be more distracted by real hyperventilation than by placebo hyperventilation while this was not confirmed by the objective data? One possibility is that the method to measure selective attention was not sensitive enough. An indication is that the mean reaction times during the distraction conditions were not significantly slower than the mean reaction times at baseline. Another indication is that when the reaction times on the 
first two tones of each tone task were included in the anallysis, a trend became visible showing panic patients to be more distracted in the hyperventilation conditions. Although using only the first two reaction times makes the measurement of course less reliable; it may be a more sensitive method. Also, this is more like the method used by Crombez et al. (1994), as was already pointed out in the results section. It may be that after having heard some tones shortly after another, it becomes easier to hear the relative length of the following tone. When the performance gets easier, perhaps subjects react to the tones more quickly and automatically. Reaction times later on in the task could then obscure differences between the groups. It may also be that sensations attract the attention of panic patients only in the begining. Also in this case, only the first tones are affected. In the same line, Crombez et al. (1994) found that reaction times were much more affected at the begiming of a noxious stimulus than 5 seconds later.

One may argue that a second possible reason for not finding clear selective attention may be that the manipulation was not strong enough to cause deterioration in the performance of the task. However, $\mathrm{pCO}_{2}$ was found to drop considerably during hyperventilation and sensations increased as a function of intensity of hyperventilation (see figure 2.3). It may be that stronger hyperventilation would be needed to find effects, but the question would arise if this has any ecological validity: in non-experimental situations $\mathrm{pCO}_{2}$ usually does not seem to drop so far. Suess, Alexander, Smith. Sweeney and Marion (1980) observed decreases in $\mathrm{pCO}_{2}$ of $0.1-0.4 \mathrm{kPa}$ during stress (i.e. the anticipation of electric shocks). Bass, Lelliot and Marks (1989) report a mean decrease in $\mathrm{pCO}_{2}$ of circa $0.7 \mathrm{mmHg}$ in agoraphobics who had vivid images during fear talk. After monitoring 22 panic-like attacks of 16 patients suspected of hyperventilation, Hornsveld et al. (1996) found only one attack that was attended by a decrease in $\mathrm{pCO}_{2}$ larger than $1.4 \mathrm{kPa}$. Thus, the drop in $\mathrm{pCO}_{2}$ in the lightest degree of hypocapria used in the present study (around $1.2 \mathrm{kPa}$ ) seems to be already on the heavy side.

It is also possible that differences in anxiety or arousal worked against the hypothesis. In line with this argument is the finding in some studies that anxiety actually speeded up reaction times in Stroop paradigms (Amir, McNally, Riemann, Burns, Lorenz \& Mullen, 1996; Riemann \& McNally, 1995). Since the patients indicated more anxiety during the hyperventilation periods in contrast to the controls, this anxiety might have speeded up instead of slowed down their reaction times. To control for this speeding, reaction times were reanalysed with increase of anxiety (VAS scores during distraction conditions minus baseline) as a covariate. The $(2 \times 2 \times 2)$ ANOVA on mean interference scores of the hyperventilation conditions again showed no significant results. When taking the first two tones of each reaction time task, the $(2 \times 2 \times 2)$ ANOVA revealed only the same trend of group, $F(1,34)=3.06, p=0.09$, indicating that regardless of reported anxiety, panic 


\section{Study 2}

patients showed more distraction during the first two tones, both during real hyperventilation and during placebo hyperwentilation.

Taken together, the results showed only marginal evidence for panic patients displaying selective attention towards bodily sensations. This selective attention, however, was not specific for hypocapnic sensations: a comparable interference was induced by an isocapnic breathing procedure. It could be argued that isocapnic overbreathing generated sensations in panic patients as well, making it logical that panic patients became distracted. Still, it is remarkable that there seems to be no relationship between intensity of reported sensations and interference. It might be that the method used was not sensitive enough for showing this connection but it might also be that scanning of the internal environment, assuming that this occasioned the interference in panic patients, did not increase any more as sensations increased.

A possible confounding variable in the present experiment was the fact that subjects were told that breathing as requested might induce sensations like dizziness. Panic patients are possibly more used to experience these sensations than normal controls and may also have expected more dramatic effects of the manipulation. This might have caused panic patients to be more alert during the breathing procedure, leading to interference. Therefore, the marginal interference that was found cannot be ascribed to panic patients being always alert to bodily sensations. To be able to conclude that bodily sensations attract the attention of panic patients in an automatic way, it may be desirable to induce sensations without panic patients expecting them. On the other hand, it may not be necessary to assume that panic patients are continuously monitoring sensations. Since most panic attacks appear to be triggered by environmental stimuli (Street, Craske \& Barlow, 1989), selective attention may be "cued" as well.

In the present study, breathing into the face-mask without breathing instructions generated an equal level of sensations in panic patients as isocapnic overbreathing did. The facemask might have served as a cue and might have caused considerable anxiety in itself. When relatively simple events like breathing in a face-mask are enough to induce sensations, it may not be necessary to suppose mechanisms like hyperventilation to be the origin of bodily sensations in panic disorder. 


\section{Study 3}

\section{Selective attention for cardiac information in panic patients}

\section{Summary}

With various reaction time paradigms, panic patients have been shown to have selective attention for threatening sensations. However, almost all of these paradigms use words describing sensations and not the threatening sensations themselves. To increase the ecological validicy, in the current study selective attention for heartbeat information was measured with a paradign derived from the dot probe detection task but using. "real" heartbeat information instead of words. The resulis undeed showed selective attention for ECG information in panic patients. However, an accelerated ECG did not attract the attention of panic patients mote than a slower ECG. Against expectation, both panic patients and normal controls shifted their attention away from an accelerated ECG. Possible explanations are explored.

\section{Introduction}

Several studies have investigated whether panic patients have selective attention for feared badily sensations. The phenomenon might be important because selective attention might cause greater interoceptive input, increasing the probability that feared somatic sensations are experienced (Ehlers \& Breuer, 1996). Preliminary support for the hypolhesis that panic patients are more interoceptively aware comes from studies using questionnaires, asking subjects how they think about their being bodily aware. For instance, in a study by Belfer and Glass (1992) subjects with panic disorder were found to score higher than controls and simple phobics on a questionnaire measuring body consciousness. Schmidt, Lerew and Trakowski (1997) found that panic patients scored higher on a scale developed to measure hypervigilance for bodily sensations. However, there might be discrepancies in what subjects report and what they really do. Panic patients may, for example, be aware of current psychological models of the disorder and reporting much bodily awareness may reflect a demand characteristic. It seems therefore important to measure 


\section{Study 3}

atterition in a way that circumvents subjects' beliefs or objectives.

Studies on selective attention less subject to these problems are for instance reaction-time tasks like the Stroop task (MacLeod, 1991), or the dot probe detection task (MacLeod, Mathews \& Tata, 1986). The Stroop task uses the rationale that it takes more time to name the colour of a word when its meaning attracts attention. In several studies with this task. panic patients has been shown to slow down at words that are related to their disorder, like catastrophe words (e.g., death, collapse), bodily sensation words (e.g. dizzy, heartbeat: McNally, Riemann \& Kim, 1990) or physical threat words (e.g. disease, mutilated: Mogg, Mathews \& Weinman, 1989; fatal, illness: Hope, Rapee, Heimberg \& Dombeck, 1990) or panic threat words (e.g. dizzy, fear: McNally, Amir, Louro, Lukach, Rieman \& Calamari, 1994). In the dot probe detection task subjects have to react to a dot that replaces one of two words that are simultaneously presented. If subjects are quicker to detect dots replacing threat words than dots replacing neutral words, this is interpreted as selective attention to threat-related information. In a study with this task, panic patients were shown to be quicker to detect dots that replaced physical threat words than dots that replaced neutral words (Asmundson, Sandler, Wilson \& Walker, 1992).

However, the question is what selective attention for words tells us about selective attention for bodily sensations. A word in itself is no sign of threat. And even if its content represents a feared bodily sensation or a feared event, this might only indicate that panic patients are concerned about these matters, making the cognitive representations more readily accessible (Klinger, 1975; Riemann \& McNally, 1995). Of course, concerns about bodily sensations, for instance, may be related to selective attention for the sensations. However, before it can be concluded that panic patients indeed scan their environment for signs of danger (Beck, Emery \& Greenberg, 1985), selective attention for the signs of danger themselves, rather than for their representations, should be demonstrated. The present study aimed to investigate whether panic patients show selective attention for cardiac events, using a paradigm that appears to be more ecologically valid than existing paradigms. The set-up is comparable to the dot probe detection task (MacLeod et al., 1986), but used more direct information of heartrate instead of words. Moreover, since it seems plausible that heartrate information is especially attention-attracting for panic patients when an acceleration can be perceived (a probable sign of danger), the second issue to be examined was whether a quicker pattern of heartrate attracts the attention of panickers more than of normals. 


\section{Method}

\section{Subjects}

Subjects were recruited via an advertisement in a local newspaper asking for persons having recurrent unexpected panic attacks. The persons who reacted were contacted by telephone and were diagnosed by a trained psychologist, using the Structured Clinical Interview for DSMIII-R (SCID, Spitzer \& Williams, 1986), as to their fulfiling the DSMIII-R criteria of panic disorder. Exclusion criteria were current major depression or hallucinations. In total, 44 persons were interwewed. Of these, 24 fulfilled the stated criteria and were asked to participate. Five of them cancelled participation; hence ultimately 19 subjects (10 women, 9 men) with panic disorder participated in the experiment. As a control group, 19 subjects (10 women, 9 men) matched on age, sex and education were recruited via an advertisement asking for healthy subjects. Mean age of the panic group was 43.8 years $(S D=11.95)$. Mean age of the control group was 44.6 years $(S D=13.32)$.

\section{Materials}

A character detection task was used to measure selective attention. The task was presented on a colour VGA monitor. At each trial of the task two moving pictures were presented simultaneously in two opposite corners of the screen. The pictures consisted of an ECG, taken from an already existing data file (not from the subjects themselves), and a moving line, created with the computer program "Lissajoux" in which sine functions can be combined in two dimensions. Each picture could be presented in two different speeds a slower and a quilcker one. Every combination of pictures was possible but when two ECGs or two lines were presented, they were equal in speed. At each trial two pictures were visible for 3 seconds and directly afterwards one of them was replaced by wither an E or an F. The task of the subject was to decide as quickly as possible which character he/she had seen and to indicate this by pressing one of two keys on the keyboard. It was presumed that detection of the character would be faster when attention had been directed at the signal that was presented just before at the same corner of the screen. To be sure that everything was presented equally trequently at all comers, the presentation of signals and characters was completely balanced, adding up to 96 signal-character presentations. This meant that every combination of pictures was presented 8 times.

To measure fear for bodily sensations, subjects completed the Bodily Sensations Question naire (BSQ, Chambless, Caputo, Bright \& Gallagher, 1984). Also administered were the State-Trait Anxiety Inventory (STAI, Spielberger, Gorsuch \& Lushene, 1970) to measure 


\section{Study 3}

antiety and the Beck Depression Inventory (BDI, Beck, Ward, Mendelson, Mock \& Erbaugh, 1961) to measure current depression.

To investigate whether the groups differed in various subjective aspects, visual analogue scales (VAS) were used. Subjects were asked to rate how much they had tried to control their heartbeats, the scale ranging from "not at all" to "totally". Anxiety during the experiment was measured by a VAS ranging from "not at all anxious" to "extremely anxious". Subjects indicated the feeling they had had that the ECG represented the beating of their heart on a scale from "not at all" to "tolally". Furthermore, they were asked to indicate how agreeable they found each presentation using scales ranging from "very disagreeable" to "very agreeable". Subjective attention was assessed by asking questions about how much they had looked at the ECG and the line, the scales running from "mot at all" to "totally".

\section{Procedure}

Subjects filled in the BSQ, the BDI and the STAI. Then they were told that their heartrate would be measured while they had to perform a reaction time task. They were told that their heartrate could be seen now and then on the PC screen. Then, three electrodes were attached to them, ostensibly to measure their heartrate. After this, subjects were shown the ECG and the moving line. It was explained how each peak in the ECG represented a beat of their hearts and also that the moving line was just a picture without meaning. Then, subjects practised the task for six trials: pressing as quickly as possible one of two keys of the keyboard, depending on the character they saw ( $E$ or $F$ ). After the practice, the experimenter left the room and the subject carried out the task. When the task was completed, the subject filled in the wisual analogue scales. Then the electrodes were removed and the subjects were asked whether they had discovered that the ECG shown was not their own. After this, they were debriefed.

\section{Results}

\section{Questionnaires}

Two subjects, one in the panic group and one in the control group said they did not believe that the ECG shown represented their heartrate. Therefore these subjects were not included in the rest of the analysis. Scores of the remaining subjects on the different questionnaires are presented in table 3.1. The groups differed significantly on the BSQ. $t(34)=7.16, \mathrm{P}<0.001 ;$ the $\mathrm{BDI}, \mathrm{t}(33)=3.03, \mathrm{P}<0.01$; the STAI state, $\mathrm{t}(34)=$ 
$4.48, \mathrm{P}<0.001$; and the STAI trait, $\mathrm{t}(34)=3.43, \mathrm{P}<0.01$.

Table 3.1. Descriptive characteristics of the panic disorder and normal control groups

\begin{tabular}{lcc}
\hline Questionnaires & Panic Disorder & Normal Control \\
BSQ & $47.3(9.2)$ & $28.2(6.6)$ \\
BDI & $16.5(11.3)$ & $6.9(7.0)$ \\
STAI state & $50.8(13.0)$ & $34.2(8.8)$ \\
STAI trait & $51.8(12.1)$ & $38.2(11.7)$ \\
\hline
\end{tabular}

Means from the VAS scores are presented in table 3.2. According to a t-test the groups did not differ in trying to control their heartbeats, $t(34)=0.41$, NS. Comparison of the anxiety indicated during the task revealed a trend towards panic subjects being more anxious during the task than controls, $t(34)=1.94, P=0.06$. Comparing the feeling indicated that the ECG represented the beating of the heart did not reveal a significant difference between the groups, $t(34)=1.62, P=0.11$.

To test whether the pictures were found equally agreeable, a $2 \times 2$ (group $\times$ picture) ANOVA was performed on the VAS scores on this question. The ANOVA revealed an effect of group, $F(1,34)=4.54, \mathrm{P}<0.05$; no effect of picure, $F(1,34)=1.36$, NS; and no interaction effect, $F(1,34)=0.00$, NS. It seems that the panic patients overall liked the presentations less than the control group.

Table 3.2. Mean scores of the panic disorder and control group on VASs

\begin{tabular}{|c|c|c|c|c|}
\hline & Panic Disorder & \multicolumn{2}{|c|}{ Normal Control } & \\
\hline Tried to control heart & $2.18(2.15)$ & \multicolumn{2}{|c|}{$2.60(3.52)$} & \\
\hline Anxiety during task & $2.20(2.67)$ & \multicolumn{2}{|c|}{$0.85(1.29)$} & \\
\hline \multirow[t]{3}{*}{ Feeling $\mathrm{ECG}=$ heart } & $5.45(3.74)$ & \multicolumn{2}{|c|}{$3.52(3.42)$} & \\
\hline & \multicolumn{2}{|c|}{$\mathrm{ECG}$} & \multicolumn{2}{|c|}{ moving line } \\
\hline & Panic Disorder & Normal Control & Panic Disorder & Normal Control \\
\hline Agreeablemess picture & $5.80(2.95)$ & $7.25(2.08)$ & $5.21(3.26)$ & $6.65(1.57)$ \\
\hline Looking at picture & $6.70(3.62)$ & $5.86(3.05)$ & $4.96(3.44)$ & $4.55(2.71)$ \\
\hline
\end{tabular}


Study 3

To examine whether the groups differed in their ratings of how much they had looked at the pictures, $2 \times 2$ (group $x$ picture) ANOVA was performed on the VAS scores on these questions. This ANOVA revealed no effect of group, $F(1,34)=0.43$, NS; but a significant effect of picture, $\mathrm{F}(1,34)=9.03, \mathrm{P}<0.01$, indicating that both groups reported they had been looking most at the ECG picture. No interaction effect was found, $\mathrm{F}(1,34)=0.18, \mathrm{NS}$.

\section{baseline response latencies}

Reaction times that were more than 3 standard deviations away from the individual mean of a subject were excluded from the analysis. Mean reaction times were computed for the different combinations of pictures. To investigate whether the pictures provoked equal response latencies and to investigate whether the growps had equal baseline response rates, mean latencies were compared on trials showing two equal pictures, rendering a $2 \times 2$ (group $x$ picture) ANOVA. The ANOVA showed no difference between groups, $\mathbb{F}(1,34)$ $=0.00$, NS; a trend towards an effect of picture $\mathrm{F}(1,34)=2.83, \mathrm{P}=0.1$; but no interaction effect, $\mathbb{F}(1,34)=0.15$, NS. After two ECGs subjects tended to have longer latencies $(M=692 \mathrm{~ms})$ than after two lines $(M=675 \mathrm{~ms})$.

\section{Selective attention}

To estimate whether selective attention had occurred, response latencies after characters replacing an ECG, when the opposing picture had been the moving line, were compared with response latencies after characters replacing the moving line, when the opposing picture had been an ECG. Means are presented in figure 3.1.

Figure 3.1. Mean reaction times in ms after ECGs and lines

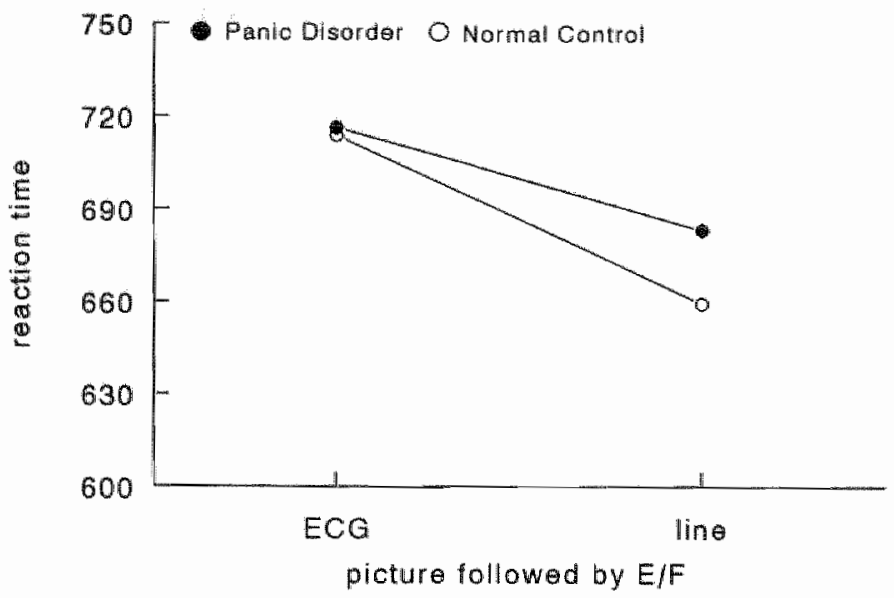


On these means a $2 \times 2$ (group $x$ picture) ANOVA was performed. The ANOVA revealed no effect of group, $F(1,34)=0.2, \mathrm{NS}$; an effect of picture, $F(1,34)=87.20, \mathrm{P}<$ 0.001 ; and a significant interaction effect, $F(1,34)=5.18, P<0.05$. Figure 3.1 shows that both groups were quicker to react when the character replaced the line picture than when the character replaced the ECG picture. However, as shown by the interaction effect, compared with the control group panic patients were relatively slow on the line pictures. This indicates that panic patients paid more attention to the ECG than the control group.

To investigate whether a quicker pattern of heartrate was more attention-attracting for panic patients than for controls, a $2 \times 2 \times 2$ (group $x$ picture $x$ speed) ANOVA was performed. Latencies of trials showing pictures of different speed, for instance a slow heartrate opposing a quick moving line, were not included in this analysis, nor" were latencies after two equal pictures. Means of the response latencies included in the analysis are presented in figure 3.2. According to the ANOVA the crucial interaction effect (group $x$ picture $x$ speed) was not significant, $F(1,34)=0.13, N S$; but the interaction of picture $x$ speed was, $F(1,34)=5.41, P<0.05$. As can be seen in figure 3.2 , this indicates that after having seen quick pictures, both groups reacted faster on characters replacing the line pictures and slower on characters replacing the ECG pictures. In terms of attention, this indicates that both groups paid more attention to the lines and less to the ECGs when the pictures were quick than when the pictures were slow.

Figure 3.2. Mean reaction times in ms after slow and quick moving ECGs and lines

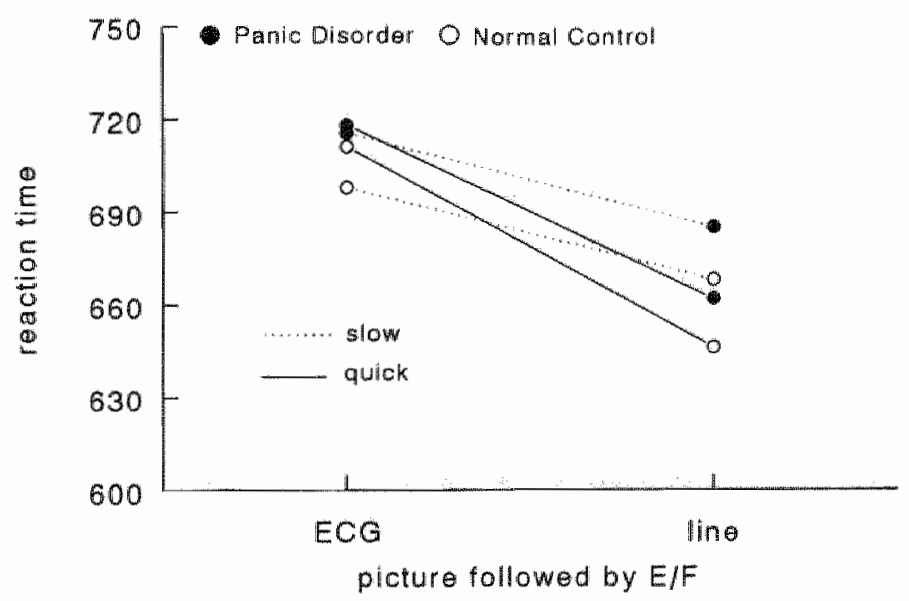


Study 3

\section{Discussion}

The data confirmed that relative to normal controls panic patients paid more attention to the ECG pictures than to the neutral stimuli. The groups did not differ in their attention for the quick moving pictures in comparison with the slow moving pictures: both groups shifted their attention away more from the quick heartrate picture than from the slow heartrate picture.

Normal controls tended to ignore the ECG picture while panic patients did so significantly less. This finding supports the hypothesis that panic patients, more than normal subjects, have the tendency to attend to cues related to bodily sensations. Results are in line with studies using the Stroop task (Hope et al., 1990; McNally et al, 1994; McNally et al., 1990; Mogg et al., 1989) or the dlot probe detection task (Asmundson et al., 1992). In addition, the current study shows that selective attention occurs for "direct bodily information" 100 . This is a more direct indication that panic patients selectively attend to interoceptive cues. A possible disadvantage of the current paradigm was that the paradigm required subjects to believe the ECG information was their own. When they were asked, only two people reported having noticed that this was not the case and most other persons were very amazed that in fact the ECG had not been their own. Therefore, it seems unlikely that subjects would have reacted differently if the feedback had been real. However, it seems to be possible that a person does believe that the picture shown had something to do with some bodily process but does not understand how to translate it to his or her own heartbeats. In this case it may not be appropriate to interpret paying attention to the ECG as a tendency to monitor heartrate. An indication of how much subjects perceived the abstract picture as their own heartbeats came from the VAS-score asking how much the subject had had the feeling that the figure they saw was the beating of the heart. These VAS scores were on average only moderately high (see table 3.2). To test whether this could have influenced the results, the present VAS score was taken as a covariate in an ANOVA on the interference scores of panic patients and normal controls. The results still revealed an effect of group, $F(1,32)=6.34, P=0.02$. Thus, although this does not rule out the possibility that some subjects only weakly related the ECG to their heartbeats, at least the between group difference could not be attributed to patient/control differences in ability to decipher the ECG picture.

It is remarkable that both panic patients and normal controls reported that they had looked more at the ECG than at the moving line while the contrary was apparent from their reaction times. It appears possible that they did look more at their ECG than at the linepicture but became absorbed in their ECG and for this reason were slower to react. 
However, even if they were absorbed, this would be as much the case when the character appeared at the opposite side of the screen, replacing the line picture. Since subjects in this case had to shift their gaze before they could detect the character, their reaction would also be slower when reacting to the mon-ECG one. Thus, the relative slowness after the ECG pictures cannot be explained by subjects looking more at these pictures. It seems therefore advisable not to rely simply on the judgement of subjects when the direction of attention is to be established. This also implies that outcomes of studies which rely solely on questionnaire data, like those of Belfer and Glass (1992) and Schmidt $e t$ al. (1997), may reflect differences in the answering characteristics of subjects rather than differences in selective attention.

It was expected that panic patients would shift their attention to the quick-moving ECG even more than to the slow-moving ECG. However, the opposite was the case. Like the control subjects, panic patients shifted their attention away from the ECG when a quicker heartrate was visible. Why should the panic patients, more than normals, have attended to the ECG in general but have failed to do so when the ECG showed an acceleration, which may be supposed to be fearful for them (see Ehlers, Margraf, Roth, Taylor \& Birbaumer, 1988) and consequently should attract attention in particular? It could be speculated that selective attention is a general mechanism that has the function to quickly notice the occurrence of danger. It may be that when danger has been remarked, it is no longer useful to attend to it. Instead, it may be more important to direct attention towards possibilities to avert the danger, like ways to escape or means to get help from. In line with this kind of reasoning is the finding that spider-anxious subjects, when simultaneously being presented slides of spiders and flowers, tended to focus the first $500 \mathrm{~ms}$ on the spider, but after that shifted their gaze to the flowers (Hermans \& Eelen, 1998). Thus, it might be that panic patients paid attention to the ECG as long as it was relatively slow but as soon as an acceleration was perceived, they shifted their attention away from the ECG. However, normals too tended to shift their attention away from the accelerated ECG, although for normals the ECG accelerations would not be perceived as dangerous. Why should they have shifted their attention away as well? It could be supposed that the perceived accelerations were perhaps not perceived as dangerous but still had some embarrassing properties. Then, the data suggest that panic patients as well as normals tend to ignore rather than focus on bodily information that is disturbing. This conclusion, however, would be at odds with the finding from Ehlers and Breuer (1995) that panic patients shifted their attention towards electric shocks applied to the ring fingers, whereas controls did not. It may be that the discrepancy in results is due to the duration of time that the threatening stimulus was presented. In Ehlers and Breuers' experiment this time was probably very short while in the present experiment the time the ECGs were shown 
Study 3

was 3 seconds. It may be that in the beginning of a presentation of a quick ECG, panic patients did attend to it but had shifted their attention away when attention was actually measured. Another reason for the difference in results might be that Ehlers and Breuer used electric shocks which do not give information about bodily: state, making this paradigm less suitable to models of panic disorder. On the other hand, electric shocks do elicit reall sensations, whereas the heartrate feedback in the present experiment of course did not. Moreover, an electric shock has harmful properties that an accelerated ECG, although perhaps representing some future danger, does not. In sum, it is not clear whether the fact that paric patients as well as controls shifted their attention away from the quick heartrate information was due to the time this information was presented, the nature of the information or that panic patients are in this aspect perhaps not different from controls.

Studies until now have concentrated on attention for symbolic representations of threat. Less research has been done into selective attention for real sensations or to investigate the ecological validity of paradigns like the modified Stroop task and the dot probe detection task. Especially in panic disorder, in which attention for sensations is ascribed such a central role, research should preferably focus not on attention to abstract representations of feared sensations but on attention for feared sensations itself. Until such research is carried out, it is unclear whether selective attention for words describing bodily sensations can be taken as evidence for selective attention for bodily sensations. 


\section{Study 4}

\section{Can selective attention for heartbeat information be induced by fear of heartbeat acceleration?}

\section{Summary}

Selective attention for bodily sensations is often found in patients with panic disorder. Whether this may be the result of fear was investigated in a group of nomal subjects. One group of subjects was made to fear an acceleration in their heartbeats or an increase in their muscle tension by threatening them with an electric shock should this occur. When subjects were under threat of these shocks, attention for ECG and EMG feedback was measured. Another group of subjects was told that an acceleration in one of two external signals (moving lines on a screen) predicted the occurrence of electric shocks. Contrary to the hypothesis that fear would induce selective attention for fear-relevant information, the subjects tended to shift their attention away from this information. The findings support the hypothesis that selective attention for threatening information is a vulnerability characteristic for developing an anxiety disorder rather than a result of fiear.

\section{Introduction}

Cognitive models of panic assume that selective attention for bodily sensations plays a role in the causation and maintenance of panic disorder. When relatively much attention is directed to bodily sensations, feared sensations may become more salient and more readily perceived, making them more liable to culminate into panic attacks (Logan $\&$ Goetsch, 1993; Williams, Mathews \& Macleod, 1996).

Several authors have investigated whether panic patients display selective attention for bodily sensations by using Stroop tasks (MacLeod, 1991). In such tasks panic patients are found to be especially slow to name the colour of words related to their disotder, like catastrophe words (e.g., death, collapse) and bodily sensation words (e.g. dizzy, heartbeat: McNally, Riemann \& Kim, 1990), physical threat words (e.g. fatal, illness: Hope, Rapee, Heimberg \& Dombeck, 1990) or panic threat words (c.g. dizzy, fear: 
McNally, Amir, Louro, Lukach \& Calamari, 1994). This is interpreted as panic patients paying selective attention for threat-related material. However, interference is not necessarily due to selective attention. For instance, induction of anxiety might interfere with colour-naming performance (Ehlers \& Breuer, 1995). Furthermore, the interference effect is not necessarily due to attention to the meaning of the words. It may also represent a delay in the production of the response (Asmundson, Sandler, Wilson \& Walker, 1992).

These problems are ruled out by the dot probe detection task (MacLeod, Mathews \& Tata, 1986), another task developed to measure selective attention. In this task subjects do not react to the words themselves but to a dot that follows one of two words presented on a PC screen. In this case subjects react more quickly to a dot when they attended to the word that was just before presented at the same place. Selective attention to threat will lead to quicker reaction times to dots that replace threat-related words. In a study with this task, panic patients were shown to be quicker to detect dots that replaced physical threat words than dots that replaced neutral words (Asmundson, Sandler, Wilson and Walker, 1992). Alternative explanations as applied to the interference in Stroop tasks are ruled out with the dot probe detection task, giving more support for the hypothesis that panic patients selectively attend to threat.

However, in the dot probe detection task too, the attention-attracting stimulus is a word, while in real life panic patients are assumed to fear sensations, not words. Interestingly, Ehlers \& Breuer (1995) found that, relative to controls, panic patients were quicker in detecting a target stimulus (vibration of one index finger) when an electric shock was applied just before to the same hand, than when the electric shock was given just before to the other hand. This indicates that selective attention is not restricted to verbal representations of sensations, but occurs also with the physical sensations themselves. Meanwhile assuming that electrical shock was as aversive and as frightening to panic disorder patients as to healthy controls, the fact that panic patients showed more selective attention in this test suggests that their selective attention extends beyond the realm of sensations that they typically fear, like dizziness, palpitations or breathlessness.

Thus, selective attention for physical threat in panic patients has repeatedly been found in studies with different paradigms. What is the causal status of this selective attention? on the one hand, selective attention to bodily sensations may be an individual characteristic that predisposes one to perceiving bodily sensations and may increase the risk of developing panic disorder. Alternatively, selective attention to frightening cues may be a consequence of fear. In line with this argument, it was repeatedly found that reduction of fear by cognitive behaviour therapy is attended by a reduction in selective attention for threat (Lavy \& Van den Hout, 1993; Watts, McKenna, Sharrock \& Trezise, 1986). 
Furthermore, Merckelbach. Van Hout, de Jong and Van den Hout (1990) demonstrated that an attentional bias could be induced by aversive classical conditioning, although the paradigm does not make clear if the bias arose from fear. However, Van den Hout, Armz, Janssen, de Jong and Pool (in press) failed to induce an attentional bias for parachute words in persons on the brink of jumping from an aeroplane with a parachute for the first time in their lives. If fear alone should be able to induce selective attention. one would expect an attentional bias in these persons for words related to jumping and falling. It is, however, possible that the participants in this experiment were a highly selective group because they liked to jump from aeroplanes. Also some of the words used (for instance "parachute") might be associated with safety rather than with fear. It is therefore not clear if an attentional bias might have been expected.

If selective attention for bodily sensations results from interoceptive fear or, more precisely, from the expectation that these sensations are predictive of threat (e.g. palpitations being predictive of a heart attack; see Clark, 1986), it follows that prowoking such expectation in healthy subjects would lead to selective attention for feared sensations. The current study investigates this hypothesis. Students were induced to fear either a heartbeat acceleration or an increase in muscle tension. This was achieved by threatening them that they would receive an electric shock should their heartbeat frequency accelerate or their muscle tension rise. Whille under this threat, their attention was measured for information about their heartbeat frequency and muscle tension. Visual attention was assessed by a character detection task, a paradigm comparable with the dot probe detection task (McLeod at al, 1986). In the present task two bodily signals (an ECG and an assumed EMG signal) were simultaneously presented on a PC screen, one of which was immediately followed by a character ( $E$ or F). Depending on the character presented, subjects had to press either the $E$ or the $F$ on the keyboard. Detection latency was recorded for each probe. The hypothesis was that when subjects believed that a heart-beat acceleration would be followed by an electric shock. an attentional bias would be induced for the ECG signal (especially when it showed an acceleration). When subjects believed that an increase in muscle tension would be followed by an electric shock, an attentional bias was hypothesised for the visual signal that represented their EMG. To investigate whether an attertional bias for bodily signals can be induced in the same way as an attentional bias for extemal signals, a control experiment was carried out in which the electric shock was predicted by the acceleration of a moving line that was in itself meaningless. 
Study 4

\section{Method}

\section{Subjects}

Subjects were 45 students from the University of Maastricht Data from 2 (male) students were not used because they ascertained that the ECG and EMG signals were not their own. Of the remaining subjects, 3 were male, 41 were female. Subjects were divided into 4 groups, 2 groups getting the character detection task with EMG and ECG signals and 2 groups getting the same task with moving lines.

\section{Materials}

To investigate if the groups were equally anxious and were equally anxious for bodily sensations, the State-Trait Anxiety Inventory (STAI, Spielberger, Gorsuch \& Lushene, 1970), and the Bodily Sensations Questionnaire (BSQ, Chambless, Caputo, Bright \& Gallagher, 1984) were administered.

A character detection task was used to measure visual attention. The task was presented on a colour VGA monitor. Of the task two variations existed: one that showed only ECG and EMG signals and a control task that presented only moving lines. Apart from the pictures presented, the tasks were identical. The ECG and EMG signals used were taken from already existing data files (not from the subjects themselves). Two variations of both signals existed: a slower one and a quicker one. The moving lines were created with the computer program "Lissajoux" in which sinus functions can be combined in two dimensions. With this program two types of undulating lines were created that could be easily distinguished. One of them resembled a rope that rolled upwards and downwards, hereafter called "rope"; the other one resembled an ingenious character $Z$ that was endlessly rewritten, hereafter called "crinkle". Of both a quicker and a slower variant was made, moving as quickly as to be comparable to the movement of the ECG and EMG signals in the parallel task.

At every trial of the reaction-time task two signals (or lines) were presented simultaneously in two opposite corners of the screen. When two ECGs or two EMGs were presented, they were equal (as was the case when two lines of the same type were presented). The moving signals were visible for 3 seconds and directly replaced by either an $E$ or an $F$. The task of the subject was to decide as quickly as possible which character he/she had seen and to indicate this by pressing one of two keys on the keyboard. To be sure that all signals were presented equally frequently at all corners, the presentation of signals and characters was completely balanced, adding up to 96 signal-character presentations. This meant that every combination of signals or lines was presented 8 
times. For instance, in the case of the bodily signals the possible combinations were: two ECGs (both slow or both quick), two EMGs (both slow or both quick), a quick ECG with a slow EMG, a slow ECG with a quick EMG, a quick ECG with a quick EMG and a slow ECG with a slow EMG.

To induce fearful expectation, an electric pain shock was used. It was produced by a shock generator and delivered through two electrodes attached to the left ankle. It had a rising time of $0.5 \mathrm{sec}$ to a preselected level, remained for $3 \mathrm{sec}$ and returned to zero during $0.5 \mathrm{sec}$.

Nine VAS (visual analogue scales) served as a manipulation check. Subjects were asked if they tried to control their heartbeats, if they tried to control their muscle tension, if they used the heartbeat information or the muscle tension information from the screen or information provided by the crinkle or the rope. These scales ran from "not at all" to "totally". Furthermore, it was asked how agreeable they found each presentation ranging from "inot at all agreeable" to "very agreeable" and how anxious they were for the shocks, just before starting the task and also during the first half and during the second half of the task. These scales ran from "not at all anxious" to "very anxious". Also, the ECG/EMG groups were asked to indicate on a VAS how much they had the feeling that the signals they had seen represented their own heartbeats and their muscle tension.

\section{Procedure}

All groups

First, subjects had their left ankle connected to the shock-generator. Subsequently they received a light electrical stimulus with its peak at $0.5 \mathrm{~mA}$. The stimulus was repeated, each time $0.3 \mathrm{~mA}$ stronger, till the subject indicated that the pain arising from the stimulus was 7 on a scale from 0 to 10 , with 0 meaning "no pain at all" to 10 "most terrible pain that can be imagined from this sort of stimulation". This stimulus was taken as individual set-point during the task. Subjects completed the STAI and the BSQ and then five electrodes were attached to them connected with a switch-board. They were told that the two electrodes on their chest and the one on the upper-back were used to measure their heartbeats and that the two on their lower back were used to measure their muscletension.

\section{Continuation for the groups receiving the detection task with bodily signals}

ECG and EMG were shown on the screen and subjects were explained how these signals were linked with their heartbeat frequency and muscle tension. After this the character detection task was explained and practised. Then subjects were told that one of the signals they saw, either the ECG or the EMG, would tell them something of when they would 


\section{Study 4}

receive a shock in the following task. They were told that a computer program would be started that reacted to heartbeat accelerations or increases in muscle tension. When an acceleration (increase) was detected by the program, a shock would be delivered to the subject. To illustrate this the experimenter switched something on in the apparatus-room and warned the subject that the program was started. In the condition where heartbeat predicted a shock, the subject was asked to rise a few times from the chair to produce a heartbeat acceleration. When the subject had moved up and down a few times the preselected shock was administered and the experimenter asked whether the subject had already felt something. In the condition where muscle tension predicted a shock, the subject was startled by a loud tone, ostensibly to produce an increase in muscle tension. Shortly after the startle the subject received the shock. Subjects were told that a number of these shocks were to be expected during the task "depending on whether heartbeat accelerations (increases in muscle tension) occurred and that these shocks would be variable in intensity, some being weaker than the previous shock, some being stronger.

\section{Continuation for the groups receiving the detection task with moving lines}

Both moving lines were shown on the screen. The lines were given a name and were shown until the subject could recognise them. Subsequently the character detection task was explained and practised. Subjects were then told that one of the lines they saw, either the "rope" or the "crinkle", would tell them something of when they would receive a shock in the following task. One group was told that an acceleration in the "rope" predicted the shock, the other group that the "crinkle" predicted the shock. To illustrate this the experimenter performed the same procedure as for the bodily signals (above). The subject saw the line that predicted the shock on the screen and saw it again when it accelerated, afterwards receiving a shock. Subjects were given the same information about the number and variability of the shocks as in the bodily signals conditions.

\section{Continuation for all groups}

Subjects had to indicate on a VAS how anxious they were about receiving shocks during the experiment. Then the light was dimmed; the experimenter warned the subject that the computer program that generated shocks would be switched on again and withdrew into the adjacent room (with a one-way screen). The subject was then asked through the intercom to start the task.

During the task the subject received 12 shocks, the intensity varying between the set-point plus $0.3 \mathrm{~mA}$ and the set-point minus $0.3 \mathrm{~mA}$. The shocks were always administered after the signals on the screen showed an acceleration in heartbeat frequency or an increase in muscle tension or an acceleration in the moving line they thought predicted the shock. 
Shocks were distributed so as to ensure that the shock was given once during every combination of presentations and to interfere in the least possible way with the pressing of the $\mathrm{E}$ or $\mathbb{F}$ key. After completing the task subjects filled in the VASs serving as a manipulation check.

\section{Results}

\section{Questionnaire data}

Scores of the subjects on the different questionnaires are presented in table 4.1. According to an ANOVA the groups did not significantly differ on the $B S Q, F(3,39)=1.28, P$ $>0.1$; the STAJ-trait, $\mathbb{F}(3.19)=0.45, \mathrm{P}>0.1$; or the STAI-state, F(3.39) $=0.08, \mathrm{P}$ $>0.1$.

Table 4.1. Descriptive characteristics of the groups

\begin{tabular}{ccccc} 
& \multicolumn{4}{c}{ shock predicted by } \\
Age & heart frequency & muscle tension & crinkle & rope \\
BSQ & $20.6(1.3)$ & $19.8(3.4)$ & $19.3(1.0)$ & $19.9(0.7)$ \\
STAI-state & $33.5(6.3)$ & $35.7(9.3)$ & $39.8(9.2)$ & $33.1(9.7)$ \\
STAI-trait & $40.4(7.1)$ & $36.5(8.6)$ & $36.2(7.0)$ & $35.0(8.7)$ \\
\hline
\end{tabular}

\section{Manipulation checks}

The VAS scores that served to check the manipulation are presented in tables 4.2 and 4.3. To check if the subjects were equally fearful of the shocks, ANOVAs were done to compare the different groups on the questions asking for fear of the shocks. The groups were found not to differ in fear for the shocks before making the task, $F(3,38)=1.61, P$ $>0.1$. However, there was a significant difference in fear for the shocks during the first half of the task, $F(3,39)=3.56, P<0.05$. Post-hoc t-tests revealed that the group that had the rope as the shock predictor reported significantly less fear than the ECG group $(t(19)=2.69, \mathrm{P}<0.05)$; the $\mathrm{EMG}$ group $(\mathrm{t}(20)=2.27, \mathrm{P}<0.05)$; and the crinkle group $(\mathrm{t}(18)=3.14, \mathrm{P}<0.01)$. During the second half of the task the groups were found to be equally feartul of the shocks, $\mathrm{F}(3,39)=1.84, \mathrm{P}>0.1$. It is of course not possible to conclude from this data whether the groups displayed enough fear for the shocks to induce biases. From the means it is clear that the fear during the second half of 


\section{Studly 4}

the task was already less than during the first half. However, since the mean score of fear is around 4 on a scale of 10 , we may assume that subjeets had on average considerable (but not extreme) fear for the shocks.

Table 4.2. Scores on visual analogue scales: fear for shock

shock predicted by

heart frequency muscle tension crinkle rope

Fear for shock:

\begin{tabular}{lllll} 
before & 5.48 & 5.38 & 4.02 & 4.06 \\
first half & 5.70 & 5.12 & 5.41 & 3.17 \\
second half & 2.34 & 4.11 & 2.58 & 2.28 \\
\hline
\end{tabular}

On the VAS scores on whether the subjects used the information from the pictures on the screen, $2 \times 2$ MANOVAs (group $x$ picture) were performed, comparing those groups that had seen the same pictures, either ECG/EMG or moving lines. It was expected that, if the subjects believed one of the pictures to be predictive of the shocks, this picture was most informative for the subject. Thus, if subjects indicated they had used more information from the picture coupled with the shock than from the other picture, i.e. when an interaction of group $x$ picture could be demonstrated, this would be indicative of a successful manipulation. The MANOVA with the groups seeing ECG/EMG revealed a significant interaction effect, $\mathrm{F}(1,21)=7.52, \mathrm{P}=0.01$. As can be seen in table 4.3 , this interaction, however, seemed mainly due to the tendency of the subjects that were made to fear heartbear accelerations to use more heartbeat information. The MANOVA with the groups seeing lines also revealed an interaction effect, $F(1,18)=4.97, P=0.04$; indicating that the groups indleed used mainly the information from the line that was most relevant for them (i.e. that predicted the shock).

To test whether the pictures were found equally agreeable, $2 \times 2$ (group $x$ picture) MANOVAs were performed on the VAS scores arising from this question. For the groups seeing ECG/EMG the interaction effect was not significant, $F(1,21)=1.44$, NS. It is noteworthy that there was an effect of picture, $F(1,21)=4.84, P<0.05$; meaning that both groups judged looking at ECG as more agreeable than looking at EMG. For the groups looking at the moving lines, the interaction effect was significant, $F(1,21)=11.57, P<$ 0.01 . Both groups rated the line that had nothing to do with the shock as the more agreeable one. The other main effects were not significant.

To check whether the ECG/EMG groups were different in trying to control their 
heartbeats and their muscle tension, a MANOVA was performed on the related VAS scores. The interaction effect was significant, $\mathbb{F}(1,21)=25.85, \mathbb{P}<0.001$; meaning that the groups were different in this respect. Subjects that were threatened by a shock when having a heartbeat acceleration reported that they had indeed tried to control their heartbeats, whereas subjects that were threatened by a shock following a muscle tension increase reported that they had chiefly tried to control their muscle ternsion.

Table 4.3 Scores on visual analogue scales: use, agreeableness, control

shock predicted by heartbeat frequency

muscle tension

\begin{tabular}{|c|c|c|c|c|}
\hline picture & $\mathrm{ECG}$ & $\mathrm{EMG}$ & $\mathrm{ECO}$ & EMG \\
\hline Use information & 5.54 & 2.74 & 2.68 & 2.68 \\
\hline Agreeable & 7.36 & 6.76 & 5.70 & 4.28 \\
\hline Tried control & 6.65 & 2.03 & 5.51 & 7.50 \\
\hline \multicolumn{5}{|c|}{ shock predicted by } \\
\hline & \multicolumn{2}{|c|}{ crinkle } & \multicolumn{2}{|c|}{ rope } \\
\hline picture & crinkle & rope & crinkle & rope \\
\hline Use information & 4.38 & 3.73 & 2.71 & 4.15 \\
\hline Agreeable & 4.56 & 6.90 & 5.77 & 4.44 \\
\hline
\end{tabular}

\section{Selective Attention}

For each subject mean reaction times were calculated. Reaction times that were 2 standard deviations away from the individual mean of a subject were excluded from the analysis. Mean reaction times after different combinations of pictures are presented in figure 4.1. The simplest test to see if selective attention for threatening pictures was induced was to examine whether subjects were quicker at detecting the $E / F$ after pictures representing threat (when the opposite picture was non-threatening) than at detecting the $\mathrm{E} / \mathrm{F}$ after pictures representing non-threat (the opposite picture being threatening). Therefore 2×2 MANOVAs (group: shock predicted by ECG vs EMG or shock predicted by crinkle ws rope $x$ picture followed by E/F : ECG vs EMG or crinkle vs rope) were performed. The MANOVA comparing the ECG/EMG groups revealed no effect of group, $F(1,21)=0.67$, NS; but a significant effect of picture, $F(1,21)=4.93, P=0.04$, indicating that when E/F followed EMG, subjects had quicker reaction times. The crucial 


\section{Study 4}

interaction effect was not significant, $F(1,21)=0.35, \mathrm{NS}$, indicating no selective attention for the threatening pictures. The MANOVA comparing the crinkle/rope groups revealed no effect of group, $F(1,18)=0.08$; $N$; an effect of picture, $F(1,18)=5.62, \mathrm{P}$ $=0.03$, indicating that when $\mathrm{E} / \mathrm{F}$ followed the rope, subjects had quicker reaction times; and a tendency towards an interaction effect, $\mathbb{F}(1,18)=2.99, P=0.10$, which seemed, however to indicate selective attention for the non-threatening pictures. Thus, no selective attention seemed to have been induced for the threatening pictures.

Figure 4.1. Mean reaction times in ms. The left panel shows the groups seeing ECG/EMG;

The right panel shows the groups seeing crinkle/rope
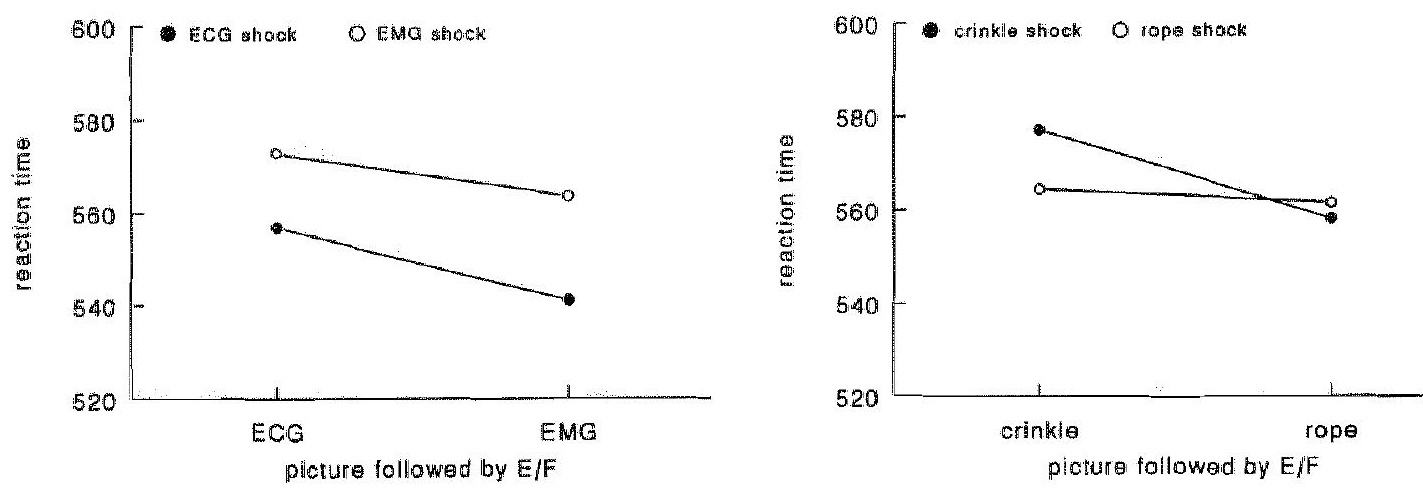

To investigate whether the pictures that showed an acceleration or increase had an added effect in attracting the attention of the groups that were made to fear this acceleration, a $2 \times 2 \times 2$ (group $x$ picture followed by $\mathrm{E} / \mathrm{F} \times$ kind (i.e. quick/slow)) MANOVA was performed. Latencies of trials showing pictures of different kinds, for instance a slow heartrate opposing a picture slowing low muscle tension, were not included in this analysis. Means of the response latencies included in the analysis are presented in figure 4.2. According to the MANOVA on ECG/EMG groups there was no effect of group, $F(1,21)=0.12$, NS; no effect of picture, $F(1,21)=2.66, P=0.12$; no effect of group $x$ picture, $F(1,21)=0.02$, NS, no effect of kind, $F(1,21)=2.45, P=0.13$; no effect of group $x$ kind $F(1,21)=1.61$, NS; no effect of picture $x$ kind, $F(1,21)=0.01$, NS; but a significant interaction effect of group $x$ picture $x$ kind, $F(1,21)=5.44, P<0.05$. As can be seen in figure 4.2 , the quick moving threatening pictures had longer latencies as compared to the quick moving non-threatening pictures, while the reaction times to the 
slow moving pictures showed the reverse direction. The interaction indicates that when the picture predicting threat was present, attention shifted towards the non-threatening picture, pleading against the hypothesis.

The MANOVA on the crinkle/rope groups showed no affect of group, $F(1,21)=0.03$, NS; an effect of picture, $F(1,21)=16.5, \mathrm{P}=0.001$; no effect of group $\mathrm{x}$ picture, $F(1,21)=1.02, \mathrm{NS}$; no effect of kind, $F(1,21)=0.13, \mathrm{NS}$; no effect of picture $x$ kind, $F(1,21)=0.21, \mathrm{NS}$; and no interaction of group $x$ picture $x$ kind, $f(1,21)=1.57$, NS. Thus, for the line groups, quick moving pictures did not seem to attract either mole or less attention than slow moving pictures.

Figure 4.2. Mean reaction times in ms after slow and quick moving pictures. The left panel shows the groups seeing ECG/EMG; The right panel shows the groups seeing crinkle/rope
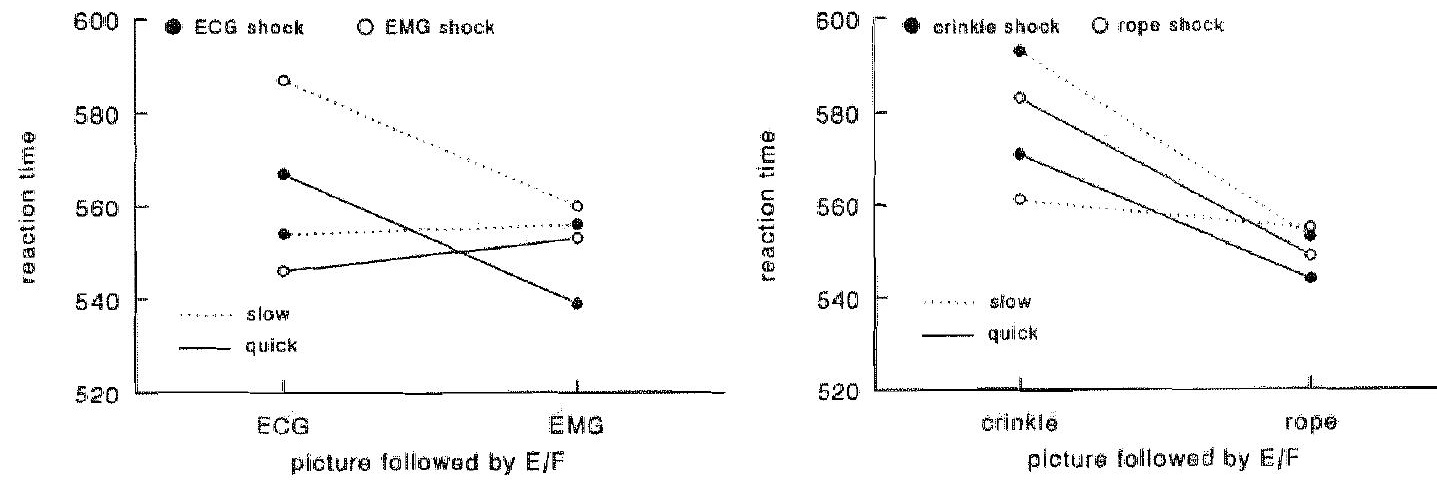

\section{Discussion}

We did not find that fearful expectation induced selective attention for the stimulus that predicted a threatening event. On the contrary, as evident from the fact that quicker reaction times were found on characters that replaced pictures not associated with the shocks, subjects seemed to selectively shift attention away from the threatening stimulus and to attend to the neutral stimulus. This seems to indicate that selective attention for physical threat does not result straightforwandly from fear for or the expectation of a 


\section{Study 4}

harmful event, a finding which is in line with the hypothesis that selective attention might be a vulnerability characteristic rather than a result of fear.

Of course, in the present experiment it must be borne in mind that a lot of differences exist between the situation of our subjects with the situation of panic disorder patients. Much too depends on the success of the manipulation. Although the questions that served as a manipulation check showed that subjects indeed were fearful of the shocks, tried to control the part of the body that was related to the shocks and did like the pictures less that were predictive of the shocks, we cannot be certain that the shocks induced enough fear or that the pictures presented were thought by the students to be really related to the shocks. Moreover, the results of the present study are not completely consistent. Selective attention for neutral information was found only for the quick pictures in the groups seeing ECG/EMG and only for all pictures together in the groups seeing the lines. It is not clear if these differences were due to the nature of the pictures, i.e. representing internal events (ECG/EMG) or external events (crinkle/line), or that for instance the massive effect of picture in the last MANOVA of the line groups overshadowed a possible interaction effect of group $x$ picture $x$ kind. Furthermore, the small number of subjects might be the cause that interactions failed to become significant.

The finding that fear does not induce selective attention in normals is in line with the study of Van den Hout et al. (in press), in which novice parachuters, in spite of heightened state anxiety, did not show Stroop interference for words related to parachuting. Moreover, the finding that normal subjects display selective attention for neutral instead of threatening stimuli is not an isolated finding. For instance, MacLeod et al. (1986) found that normal control subjects shifted their attention away from emotionally threatening words, whereas anxious patients shifted their attention towards the threat term. MacLeod and Mathews (1988) found that shortly before an examination, high trait anxious subjects showed selective attention for relevant threat words whereas low trait anxious subjects tended to avoid these words. McNally (1995) speculated that perhaps normal subjects have cognitive biases to protect them against the development of anxiety disorders. However, not all studies support this hypothesis. Using a similar dot probe detection task as that used by Macleod and Mathews (1988), Mogg, Mathews, Bird and Macgregor-Morris (1990) found that both high and low trait anxious subjects under acute stress shifted their attention towards threat-related words. However, the kind of stress used in this study (false feedback of failure or success) might have induced a lot of other emotions and cognitions besides fear.

The present paradigm is in an important respect different from paradigms using words describing threat. Threatening words do not consistently predict threat nor are they dangerous in themselves. It is therefore uncertain whether words have the same attention 
attracting properties as real sources of danger or cues predictive of danger. In the present paradigm, subjects were told that the pictures presented were directly predictive of a threatening event (an electric shock). Although it is uncertain that all subjects were completely persuaded about this, at least their reaction times were influenced by the information given. This supports the assumption that selective attention is not restricted to verbal representations but can occur also for acute threatening information.

Apart from the possibility that shifting attention away from a threat-predicting stimulus is a protective reaction, it might be that subjects avoided looking too much at this stimulus since it was not important enough and distracted them from their task: detecting characters as quickly as possible. If the stimuli would had been more threatening, they might not have been so easily ignored. In fact, there are indications that threatening stimuli are focussed on by subjects (Loftus, 1987).

Using a comparable task, Kroeze and Van den Hout (submitted) found differences in selective attention between panic patients and normal controls. However, even panic patients seemed to have a tendency to shift attention away from the ECG pictures, although they succeeded less well than normals. It might be that panic patients also try to avoid danger cues but succeed less well when the cues are appraised as more threatening. This would suggest a curvilinear relationship between threat and attention: little appraisal of threat would result in ignoring the danger cues, but when the threat increases the attention paid to the danger is increased.

In sum, fear of bodily change did not induce selective attention for information of this change, nor did fear of a change in an external stimulus induce selective attention for this stimulus. On the contrary, subjects tended to shift their attention away from the threatening information. This finding seems to support the hypothesis that selective attention for threat may be a vulnerability characteristic for developing or maintaining an anxiety disorder. However, it is also possible that attention has a curvilinear relationship with the appraisal of threat. What constitutes a minor threat for normals may be a major threat for anxiety patients. This difference in appraisal might explain why normal subjects shift their attention away from a danger stimulus, whereas panic patients show selective attention for the same stimulus. Selective attention for threat might then still be a result of having panic disorder. 



\section{Study 5}

\section{No superior perception of hyperventilatory sensations in panic disorder}

\section{Summary}

It has been argued that panic disorder patients may be more skilled at detecting changes in actual physiology than others. The present study investigated if panic patients are better than controls in perceiving sensations produced by light hyperventilation. Twelve panic patients and 28 control subjects underwent a procedure in which they were exposed twelve times to one minute of light hyperventilation or one minute of "placebo" hyperventilation (isocapnia). Differences in sensations. reported during real hyperventilation were compared to sensations reported during "placebo" hyperventilation. Results demonstrated an absence of superior perception of hyperwentilatory sensations in paric patients.

\section{Introduction}

For some time hyperventilation has been thought to be a main generator of bodily sensations reported by panic patients, both during and between attacks (Rapee, 1987). More recently a number of researchers have questioned the validity of the theory and have concluded that, although hyperventilation might in some cases give rise to symptoms, which in turn might lead to a panic attack, it seems unlikely that hyperventilation is a main cause of panic attacks (Hornsveld, 1996; Margraf, 1993). As a consequence, focus has shifted to other mechanisms which can account for the sensations reported by panic patients. One of them is the possibility that these patients may be more skilled at detecting actual changes in physiology than others. The hypothesis is interesting because it might explain why panic patients experience sensations in the first place and also it can resolve the more general finding that panic patients are apt to report many sensations (Barsky. 1992b). Furthermore, superior perception is by some researchers thought to be an important maintaining factor in the disorder (Rapee, 1994). The reasoning is that panic

Kroeze, S. \& van den Hout, M.A. (1998). No superiot perception of hyperventilatory sensations in panic patients. Behaviour Research and Therapy, 36, 285-295. 


\section{Study 5}

patients are afraid of bodily sensations and that superior perception renders even minor physiological changes a source of fright.

Support for more accuracy in the perception of heartbeat sensations by panic patients has repeatedly been found by Ehlers (Ehlers \& Breuer, 1992; Ehlers \& Breuer, 1996; Ehlers, Breuer, Dohn \& Fiegenbaum, 1995). In addition, she found that superior heartbeat perception was predictive of relapse of the disorder after therapy (Ehlers, 1995). This latter finding supports the idea that superior perception might be a maintaining factor. Unfortunately, not all studies investigating superior perception of heartbeats in panic patients had similar results, many studies finding no differences between panic patients and controls (Antony, Brown, Craske \& Barlow, 1995; Antony, Meadows, Brown \& Barlow, 1994; Asmundson, Sandler, Wilson \& Norton, 1993; Barsky, Cleary, Sarnie \& Ruskin, 1994) and one study finding indication that improved perception was inversely related to scores on the Anxiety Sensitivity Index (Butler \& Rapee, 1991). Ehlers points out how methodologies used in some studies might account for different findings. Nevertheless, untill the results are replicated the issue does not seem to be completely resolved.

All these studies concern the perception of heartbeat sensations. However, by concentrating only on cardiac sensations a lot of other sensations which are experienced as frightening by panic patients are left out. It may be that some patients are better in perceiving heartbeat sensations because these sensations are relatively important for them. Others may be more impressed by other sensations. Rapee (1994) tried to circumvent this problem by inducing a wider range of sensations. He let subjects inhale different concentrations of $\mathrm{CO}_{2}$ or room air. Panic disorder subjects were not better in distinguishing inhalations with increased $\mathrm{CO}_{2}$ from inhalations with room air than non-anxious control subjects. Thus, this study was not supportive of the hypothesis that panic patients are superior perceivers of changes in physiology. However, although sensations induced by $\mathrm{CO}_{2}$-inhalations may be similar to sensations experienced by panic patients, stress and anxiety are not accompagnied by hypercapnia, but by slight increases in ventilation and thus, in slight hypocapnia (Van den Hout et al, 1992). It seems highly unlikely that vigorous hyperventilation as is often exercised in the lab, is common (Hornsveld, 1996). But when panic patients are indeed superior perceivers, they do not need strong sensations to be able to observe and subsequently to misinterpret them. Thus, instead of assuming that panic patients panic because of a special tendency to hyperventilate, it is here supposed that their panic attacks might be stimulated or maintained by their ability to detect small drops in $\mathrm{CO}_{2}$. Support for this hypothesis might be gathered from the fact that Sanderson, McCauley and Di Nardo (1992) found that unexpected panic attacks as compared to situationally cued panic attacks tended to be associated with a specific set of 
symptoms, including paresthesias; dizziness, unreality and dyspnea. It might not be accidental that these symptoms are produced specifically by hyperventilation (Hornsveld, Garssen, Fiedeldij Dop \& Van Spiegel, 1990).

The present study was undertaken to test if, relative to healthy controls, panic patients are better in perceiving sensations that are produced by various degrees of hyperventilation. To control for non-specific effects of hyperwentilation, both groups were subjected to "placebo-hyperventilation" conditions in which breathing movement was identical to the hyperventilation conditions but where $\mathrm{CO}_{2}$ was kept at baseline level by adding $\mathrm{CO}_{2}$ to the inspired air.

\section{Method}

\section{Subjects}

Twelve subjects with panic disorder and 28 healthy subjects paticipated in the study. Clinical subjects were recruited from an ambulant hospital for mental health and diagnosed by a trained psychologist. These subjects were asked to participate directly after their admission to the hospital and after being diagnosed. Of these subjects 5 were male, 7 were female. Mean age was 36.1 years $(S D=6.5$ ). Eight other potential candidates refused participation for various reasons, one of them being fear for the procedure. For differences between the group of refusers and the group of participants see the results section. The healthy subjects were recruited by means of an advertisement in a local newspaper and were admitted to the experiment after being screened for current and past psychiatric history. Exclusion criteria were having or having had (uncued) panic attacks and having any current psychiatric illness. Also subjects with known asthma or heart problems were excluded. Nine control subjects were male, 19 were female and the mean age was 38.3 years $(\mathrm{SD}=10.7)$.

\section{Apparatus}

To be able to manipulate $\mathrm{pCO}_{2}$ a construction for this purpose was copied from Hornsveld (1996). Subjects breathed in a face mask with two separate airways, one for the inhaled air and one for the exhaled air. From the exhaled air $\mathrm{pCO}_{2}$ was assessed by means of a capnograph (DATEX, multicap CNO-103). On the inspiratory airway a plastic tube (20 $\mathrm{cm}$ long and $8 \mathrm{~cm}$ ID) was attached. Normally, room air was breathed through this tube, but since the tube was halfway connected to a $100 \% \mathrm{CO}_{2}$ cylinder, $\mathrm{CO}_{2}$ could be added to the inhaled air, the concentration of which could be manually varied. The purpose of 


\section{Study 5}

adding $\mathrm{CO}_{2}$ to the inhaled air was to be able to let people breath as though they were hyperventilating while in fact their $\mathrm{pCO}_{2}$ stayed at baseline. Subjects sat with their back to the gas cylinder so that they could not see if $\mathrm{CO}_{2}$ was added or not.

\section{Measures}

At the beginning of the experiment subjects completed the Anxiety Sensitivity Index (ASI) (Reiss, Peterson, Gursky \& McNally, 1986), the Beck Depression Inventory (BDD (Beck, Ward, Mendelson, Mock \& Erbaugh, 1961) and the State Trait Anxiety Inventory (STAI) (Spielberger, Gorsuch \& Lushene, 1983). To measure hyperventilation sensations, at different times 5 sensations were rated by the subject on a visual analogue scale assessing how strong each sensation was experienced for the last 10 seconds, the scale running from having experienced the sensation "not at all" to having experienced the sensation "extremely". At the same times anxiety was rated on a similar visual analogue scale. Hyperventilation sensations were chosen on basis of a pilot experiment in which a period of real hyperventilation was compared to a period of "placebo" hyperventilation, "placebo" hyperventillation meaning that the subjects breathed as quick and as deep as in the real hyperventilation condition but that the drop in $\mathrm{pCO}_{2}$ was prevented by adding $\mathrm{CO}_{2}$ to the inspired air. The sensations that differentiated best between these conditions were considered to most specific for hyperventilation and were therefore used in the present experiment. These sensations were dizziness, trembling, paresthesias, a feeling of unreality and palpitations.

\section{Procedure}

After the subjects had filled in the questionnaires, it was explained that the study was about the relationship between breathing and sensations. They were told that they would be asked to breathe quicker and deeper for twelve short periods. After each period they would have to fill in on a checklist what they felt during the interval indicated by the experimenter. It was said that it would be normal, though not necessary, to experience sensations because a drop in blood $\mathrm{CO}_{2}$ would occur. They were also told that at several instances during the breathing periods they would receive some $\mathrm{CO}_{2}$ through the mouthpiece. It was explained that the amount of $\mathrm{CO}_{2}$ they would receive would not exceed their normal range because it was only to compensate for the drop of $\mathrm{CO}_{2}$ that normally followed when breathing too quickly.

After the explanation, the subjects were asked to breathe normally into the face mask, and then asked to wait for some minutes. During the next 2 minutes their baseline $\mathrm{CO}_{2}$ was obtained. Following this the subjects filled in the checklist with the five hyperventilation sensations and the anxiety scale, and it was explained that the intensity of the same 
sensations would be asked about during subsequent tests. The subjects then had one practice session in which they were asked to breathe quicker and deeper according to the instructions of the experimenter. The instructions were such as to establish for one minute a level of 3.2 vol. $\% \mathrm{CO}_{2}$ as constant as possible. Ten seconds before the end of the period the experimenter asked the subject to pay close attention to what hefshe felt. At the end of the period subjects could remowe the mask and fill in the checklist of sensations. They had a pause of two minutes to restore themselves, during which they could read some periodicals if they wished to.

The same course of events as in the practice session was now repeated 12 times, with 6 real hyperventilation periods and 6 "placebo" hyperventilation periods, during which $\mathrm{CO}_{2}$ was kept at baseline ("isocapnia"). The real hyperventilation periods consisted of three different levels, each of which was induced twice by giving the subjects instructions so that the level was maintained for 1 minute. The levels were 3.6 vol. $\% \mathrm{CO}_{2}, 3.2$ vol. $\%$ $\mathrm{CO}_{2}$ and 2.8 vol. \% $\mathrm{CO}_{2}$. In the placebo conditions subjects got the same instructions as in the experimental conditions. The experimenter looked at the pace of breathing to decide if the same pace was reached as in the experimental conditions and stimulated the subject to reach each time the same depth of breath. All breathing periods were followed by filling in the checklist, and between each period subjects always had a pause of 2 minutes.

\section{Results}

\section{Refusers}

The refusal group and the participating group of panickers could be compared on 2 questionnaires that are standardly completed by all clients of the mental health institute: the FQ (fear questionnaire) (Marks \& Mathews, 1979) and the SCL-90 (somatic complaint \ist) (Arrindel \& Ettema, 1986). The refusing panickers semed to avoid agoraphobic situations significantly more than the participating panickers, $t(18)=2.27, P$ $<0.05$, but their anxiety for these situations was not significantly different, $1(18)=$ 1.79, $\mathrm{P}=0.09$. On a measure of anxiety on which they had to score their anxiety of the least days on a 5 -point Likert scale the groups did not differ, $t(18)=0.37, P=0.72$. The SCL-90 showed no differences on agoraphobic complaints, $1(17)=1.39, \mathrm{P}=0.18$; and an insignificant difference in total complaints, $1(17)=1.78, \mathrm{P}=0.09$. Thus, because of the high refusal rate the panic group might have turned out somewhat less agoraphobic, though not especilally less anxious. 


\section{Study 5}

\section{Questionnaires}

Scores on the different questionnaires are presented in Table 5.1. The groups differed significantly on the ASI, $t(36)=5.82, \mathrm{P}<0.001$; the $\mathrm{BDI}, \mathrm{t}(37)=4.22, \mathrm{P}=0.001$; the STAl-state, $\mathrm{t}(38)=4.37, \mathrm{P}=0.001$; and the STAI-trait, $\mathrm{t}(38)=4.06, \mathrm{P}<0.001$. On the baseline measure of hyperventilation sensations, when all 5 sensations were added, the groups did not differ significantly, $t(38)=1.08$, NS. The difference in baseline anxiety, as measured by the visual analogue scale, was almost significant, $t(38)=2.03$, $\mathbb{P}=0.06$.

Table 5.1. Descriptive characteristics of the panic disorder and normal control groups

\begin{tabular}{lrcc}
\hline Questionnaires & Panic Disorder & Normal Control & t-value \\
ASI & $27.6(11.9)$ & $6.8(5.1)$ & $5.82^{\cdots *}$ \\
BDI & $13.2(7.8)$ & $3.3(3.1)$ & $4.22^{* *}$ \\
STAI-state & $46.1(13.3)$ & $28.3(7.0)$ & $4.37^{*}$ \\
STAl-trait & $52.3(10.5)$ & $32.4(15.6)$ & $4.066^{* *}$ \\
baseline HV-symptoms (VAS) & $1.74(2.23)$ & $1.06(1.62)$ & 1.08 \\
baseline Anxiety (VAS) & $0.83(0.97)$ & $0.22(0.53)$ & $2.03^{*}$ \\
\hline "tw $\mathrm{P}<0.001$ & & & \\
$-\mathrm{P}=0.001$ & & & \\
${ }^{*} \mathrm{P}<0.1$ & & &
\end{tabular}

\section{Respiratory measures}

In order to check if the manipulation had the intended effects and if both groups were affected likewise, breathing pace and $\mathrm{pCO}_{2}$ were calculated for both groups under the various conditions. Breathing pace gives an indication of the effort subjects delivered. Breathing pace was determined by counting the number of breaths in the minute that $\mathrm{pCO}_{2}$ was kept at a certain level. Since every level was induced two times the mean of 2 equal periods was taken as mean breathing pace for that level. Data are shown in figure 5.1 , left panel. In a repeated measures $2 \times 2 \times 3$-MANOVA (group $x$ condition $x$ level) on these data only an effect of level was found, $F(2,74)=107.79, P<0.001$, indicating that the different levels of hypocapnia or isocapnia were associated with a different breathing pace. Importantly, there was no condition-effect, $F(1,37)=1.29$, NS, meaning that as far as breathing pace is considered, the isocapnic periods did not differ from the hypocapnic periods.

End-tidal $\mathrm{pCO}_{2}$ was measured to check if the intended degrees of hyperventilation (real 
and placebo) were reached. $\mathrm{CO}_{2}$-data are presented in figure 5.1 , right panel. of every period the mean end-tidal $\mathrm{CO}_{2}$ was computed during the minute in which $\mathrm{pCO}_{2}$ was kept on the aimed level. Since every level was induced two times the mean of 2 equal periods was taken as mean $\mathrm{pCO}_{2}$ for that level.

Figure 5.1. Mean breathing pace and mean $\mathrm{pCO}_{2}$ during real and placebo hyperventilation periods
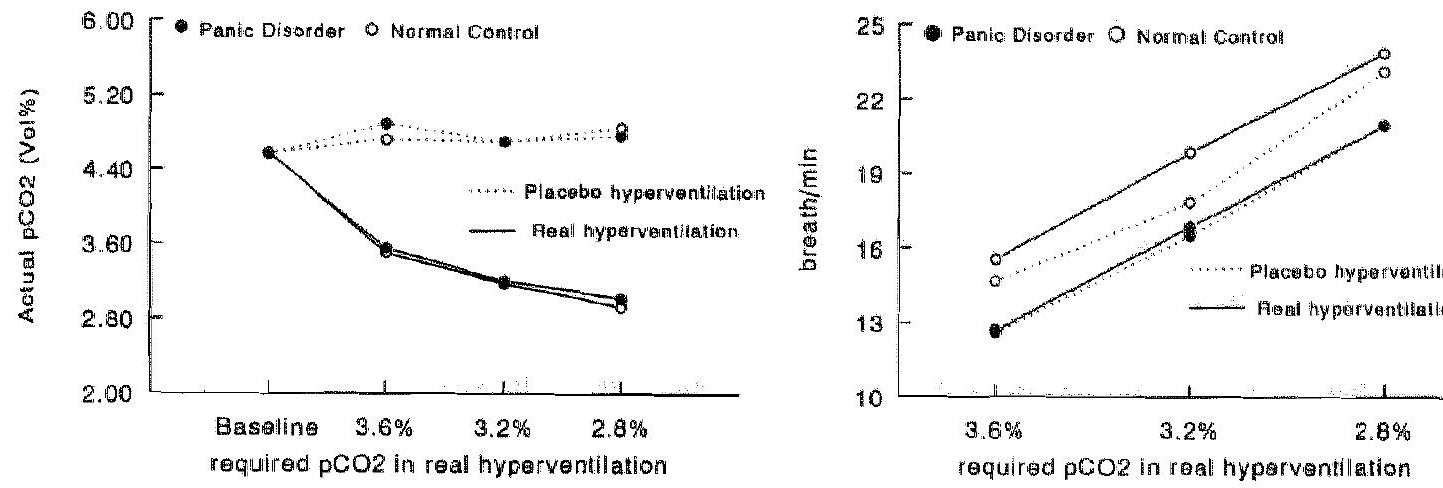

As can be seen baseline levels of end-tidal $\mathrm{pCO}_{2}$ are fairly equal. A t-test was done to confirm this: $t(37)=0.03$, NS. The experimental $\mathrm{CO}_{2}$-data were subjected to a repeated measures $2 \times 2 \times 3$ MANOVA (group $x$ condition: hypocapnia/isocapnia $x$ level of hypocapnia). According to the MANOVA there was no effect of group, $F(1,37)=0.05$, NS; a significant effect of condition, $F(1,37)=661.83, P<0.001$; a significant effect of level, $F(2,74)=11.17, \mathrm{P}<0.001$, which was qualified by a significant effect of condition $x$ level, $\mathrm{F}(2,74)=9.62, \mathrm{P}<0.001$. There was no effect of group $x$ condition, $F(1,37)=0.51$, NS; no effect of group $x$ level, $F(2,74)=1.11$, NS; and no interaction effect, $F(2,74)=0.91$, NS. Thus, the groups seemed to have been subjected to the same $\mathrm{CO}_{2}$-levels in all conditions and the induced drops of $\mathrm{pCO}_{2}$ and the isocapnic periods seem to be quite distinguishable, as they should be.

\section{Perception of hyperventilatory sensations}

To examine if subjects detected the periods of real hyperventilation (hypocapnia) we compared their scores on the sensation checklists of these periods with the periods of "placebo" hyperventilation (isocapnia). The reasoning was that when in a period of hyperventilation more hyperventilation sensations were reported than in the corresponding 


\section{Study 5}

placebo hyperventilation period the drop of $\mathrm{pCO}_{2}$ was perceived. The intensity of sensations during each period was assessed by adding the (VAS) scores of the sensations of the checklist. Since every level of hypocapnia was induced 2 times the mean of two checklists was taken as the sensation score for that $\mathrm{CO}_{2}$-level. Mean symptom scores for each level of hyperventilation and the corresponding control period are depicted in figure 5.2 , left panel.

To investigate if any difference existed between the groups in the detection of the hyperventilation periods, difference scores were computed by subtracting each isocapnia sensation score from each corresponding hypocapnia sensation score. On these difference scores a $2 \times 3$-MANOVA (group $x$ level of hypocapnia) was performed. According to this MANOVA, no effect was found of group, $F(1,38)=0.1, P=0.76$; there was an effect of level, $\mathrm{F}(2,76)=9.78, \mathrm{P}<0.001$; and no interaction effect, $\mathrm{F}(2,76)=0.43, \mathrm{P}=$ 0.65. Apparently, the larger the hypocapnia the more sensations are reported. However, the groups seemed to be equally good at perceiving the periods of hyperventilation, at least the difference in sensations they reported between the hypocapnic episodes and the isocapnic episodes was the same, regardless of the level of hypocapnia.

Wigure 5.2. Mean intensity of hyperventilatory sensations and anxiety during real and placebo hyperventilation periods
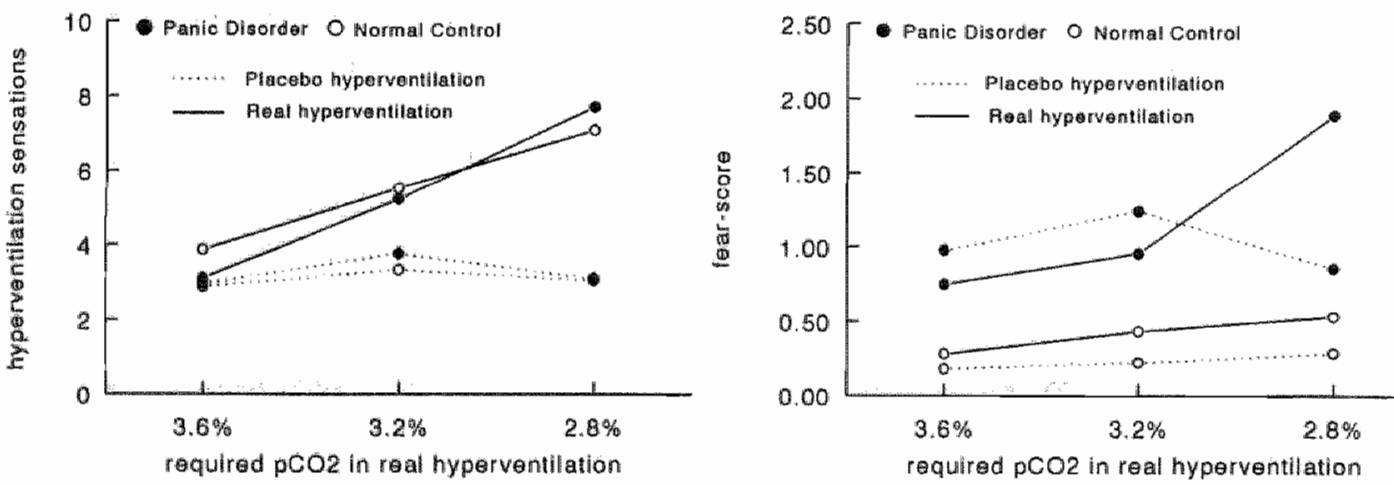

\section{Anxiety during hyperventilation}

To investigate if the groups differed in anxiety during the periods of hypocapnia and isocapnia, the scores on the anxiety scales were compared. For every level of hypocapnia and every isocapnic period the mean of two equal periods was computed. Data are 
presented in figure 5.2 , right panel According to a repeated measures $2 \times 2 \times 3$-MANOVA (group $\mathrm{x}$ condition: hypocapnia/isocapnia $\mathrm{x}$ level) there was a trend towards a groupeffect, $F(1,38)=3.62, P=0.07 ;$ a trend towards an effect of condition, $F(1,38)=$ $2.89, \mathrm{P}=0.1$; a significant effect of level of hypocapnia, $\mathrm{F}(2,76)=6.80, \mathrm{P}<0.005$; no effect of group $x$ condition, $F(1,38)=0.00, N S ;$ no effect of group $x$ level, $\mathbb{F}(2,76)$ $=1.62$, NS; a significant effect of condition $x$ level, $F(2,76)=9.49, \mathrm{P}<0.001$; and a significant interaction effect of group $x$ condition $x$ level, $F(2,76)=7.34, P=0.001$. Thus, hypocapnia seemed to be generally more anxiety provoking than isocapnia but the groups differed in this respect depending on the level of hypocapnia. Panic patients reported finding especially the greatest level of hypocapnia anxiety provoking whereas in the two smallest levels of hypocapnia they found isocapnia even more frightening than hypocapnia. This might be due to their feeling no difference between the two conditions or perhaps their noticing the addition of $\mathrm{CO}_{2}$ in the isocapnic conditions, which they found to be frightening.

\section{Discussion}

Contrary to the hypothesis that panic patients might be better than controls in perceiving sensations produced by light hyperventilation, no superior perception was found. The question arises whether panic patients indeed are no better perceivers than normals or whether the methodology used could be responsible for this finding. The manipulation succeeded very well. The different periods of hyperventilation were well discernible from the placebo hyperventilation periods as was shown by the $\mathrm{CO}_{2}$-manipulation check. Also, the groups did not differ in level of $\mathrm{pCO}_{2}$ or in their breathing pace in any of the conditions. Moreover, in both groups there was a clear dose-response relationship: the lower the $\mathrm{pCO}_{2}$, the more symptoms were reported. Thus, the lack of finding superior perception in the panic group does not seem to be attributable to the manipulation. However, some potential limitations of the study should be mentioned.

Firstly, the sample of panic patients was small. From the data it seems rather unlikely that this could have affected the results. Figure 5.2 shows that on the two lightest levels of hyperventilation, controls performed even better than panic patients. Still, lines cross with panic patients reporting more sensations at the highest level. Could it be then that if the sample of panic patients had been greater, the interaction could have become significant, meaning that the panic patients were more sensitive to this higher level of hyperventilation? This seems highly unlikely. The interaction is far from significant and 


\section{Study 5}

given the observed mean and standard deviation one would need 348 subjects per group to get a power of $80 \%$, at a significance level of $5 \%$.

Secondly, the results might be affected by the under-representation of patients with severe agoraphobia. Ehlers, in one study, reports that patients with agoraphobia showed better heartbeat perception than did patients without agoraphobic avoidance (Ehlers \& Breuer, 1992). Still, it is unlikely that under-representation of agoraphobics was responsible for the absence of between-control differences in perception. Firstly, six of the panic subjects in the present experiment were agoraphobic and secondly, these subjects tended to be non-significantly worse in detecting the hyperventilation periods than their nonagotaphobic fellow patients.

A third point that deserves comment is the method of measuring perception used in this study. The commonly recommended way of measuring perception is signal detection, while in this study differences in intensity of sensations were examined. Though both can be regarded as measures of perceived stimulus saliency, the differences are clear. The reason we opted for intensity of sensations instead of the possibly more sensitive signal detection was practical. Signal detection analysis is based on the presupposition of a signal and a non-signal. However, the method of inducing "placebo-hyperventilation" could hardly be called a non-signal event. Since in this condition much the same sensations are reported as in real hyperventilation (see also Hornsveld, 1996), the choice for the subject to decide if this condition was real hyperventilation or not inevitably became a choice of sensation-intensity itself. Furthermore, if report of sensations had been influenced by any factors present in one or both of the groups, this influence was considered to be ruled out by using the sensations reported in the placebo hyperventilation periods as comparison. It was therefore decided to take the difference in sensation report as the dependent variable. As it turned out, sensations reported in the placebo hyperventilation periods were very similar in both groups and also seemed to be nearly equal at the different levels of placebo hyperventilation. Therefore there were also no problems with ceiling effects.

A point that can be made is the fact that the addition of $\mathrm{CO}_{2}$ could have been noticed by some subjects. Unfortunately, we have no data about the number of subjects in both groups that did smell the $\mathrm{CO}_{2}$. The question therefore remains whether smelling the $\mathrm{CO}_{2}$ could have influenced the results. Smelling $\mathrm{CO}_{2}$ could have affected the reporting of hyperventilation symptoms in two ways. One of the possibilities is that smelling $\mathrm{CO}_{2}$ is aversive or anxiety provoking to a subject. In this case, sensation intensity in the placebo hyperventilation conditions could have turned out too high. From the data, it seems, however, not very likely that this influenced the results. No dose-response relationship is present for quantity of inhaled $\mathrm{CO}_{2}$ and reported sensations, nor for quantity of inhaled 
$\mathrm{CO}_{2}$ and reported anxiety. However, the very smelling the $\mathrm{CO}_{2}$ could have raised the reported hyperventilation sensations. This cannot be completely excluded, but taking the baseline level of hyperventilation sensations into account it seems that the control group has an even greater increase in these sensations in the placebo hyperventilation conditions than the panic disorder group. If smelling the $\mathrm{CO}_{2}$ has occasioned more reporting of sensations in the placebo conditions, this seems to have been the case in the control group as well. Another consequence of smelling the $\mathrm{CO}_{2}$ could be that it warned the subject that the period was a placebo period and that thus no sensations were to be expected. In this case sensation reporting in the placebo hyperventilation condition would have turned out too low. However, this does not seem to have been the case. At the lightest level of hyperventilation, none of the groups showed differences in sensation reporting between placebo hyperventilation and real hyperventilation. If smelling the $\mathrm{CO}_{2}$ had lowered sensation reporting, at this level too the hyperventilation periods should have been discernible by sensation report.

Thus, even considering the above-mentioned concerns, the study clearly demonstrates an absence of superior perception of hyperventilatory sensations in panic patients. A reason for not finding superior perception in this study, while it is found in heartbeat-studies (Ehlers \& Breuer, 1992; Ehlers \& Breuer, 1996; Ehlers et al., 1995), could be the kind of sensations that are under examination here: Maybe a sensation needs to be especially feared by a patient to make him or her more sensitive to the sensation. This, however, would imply that the panic subjects in the present sample did not fear the monitored sensations or that panic patients in general fear sensations produced by hyperventilation less than they fear heartbeat sensations. We have no direct data to investigate this, but there is indirect evidence indicating that panic patients in general and also the panic subjects in this sample fear hyperventilatory sensations. Van den Hout, Van der Molen, Griez and Lousberg (1987) report that panic patients fear dizziness, the most prominent hyperventilatory sensation, even more (though not significantly more) than palpitations. In our sample, scores on the ASI-questions asking about fear of dizziness and trembling were as high as scores on the question asking about fear of palpitations. Also, all these scores were significantly higher in the panic group than they were in the control group. It is, however, still possible that the patients that refused participation were especially fearful of wearing a mask or of sensations of shortness of breath and that these are just the persons who may be the better detectors of hyperventilatory sensations. To investigate this further we compared the scores of the refusers and the non-refusers on the SCL-90 questions about complaints of dizziness and complaints of difficulties with breathing. On the question how much they were troubled by dizziness, the groups did not differ. However, on the question how much they were troubled with difficulties of breathing, the 


\section{Study 5}

groups differed significantly $(\mathrm{p}<0.05)$, the refusal group reporting being more troubled by this complaint. To explore whether this could have compromised the results, the Pearson correlation was computed between the SCL-score of the participating panic subjects on this question and their difference-score between real and placebo hyperventillation (indicating how well hyperventilation was perceived). The correlations between breathing complaints and difference score relating to the two heaviest levels of hyperventilation were close to zero, but the correlation with the difference scores relating to the lightest levell of hyperventilation was 0.49 . This correlation was not significant but might suggest that breathing problems in panic disorder patients are related to a better perception of hyperventilation. However, the low number of subjects and the fact that this correlation is based on one question makes it impossible to draw more from it than a suggestion.

One might wonder why Rapee (1992) found that paresthesias in particular, a symptom so exclusively bound to hyperventilation (Hornsveld et al., 1990), was the very symptom that distinguished uncued from cued panic attacks. If superior detection of hyperventilation had been demonstrated, there would have been extensive room for speculation and theorising. Given the recent evidence that the so-called "hyperventilation attacks" are actually not attended by hyperventilation, (i.e. no drops in $\mathrm{pCO}_{2}$. Hornsveld, 1996), it may be wise to postpone speculation and test whether Rapee's findings can be replicated and; if so, whether paresthesias during. uncued panic are indeed due to hyperventilation.

There is evidence (Ehlers, Margraf, Davies \& Roth, 1988; McNally, Riemann \& Kim, 1990; McNally, 1992) that panic patients tend to selectively attend to bodily sensations. In real life, this selective attention may increase the saliency of bodily cues, resulting in more interoceptive input. In the present study, all subjects were urged to focus all their attention to bodily sensations provoked by hyperventilation. Thus, attention-induced "somatic amplification" (Barsky, 1992a) may have been maximised in both groups alike, overshadowing between-group differences in symptoms due to spontaneous allocation of attention to internal cues. Thus, there remains the distinct possibility that, in real life, panic patients perceive more sensations as a result of relatively much attention being deployed at sensations produced by, for instance, mild hyperventilation. This, however, would not be a matter of superior perception as such but rather an effect of selective attention to internal cues. 


\section{Study 6}

\section{No superior perception of respiratory resistance in panic disorder}

\section{Summary}

It has been suggested that panic patients may be superior perceivers of physical changes in their bodies. This might be important because panic attacks are typically triggered by bodily sensations and an increased experience of minor sensations might increase the chance of having a panic attack. In the present study panic patients and normal controls were compared in their ability to perceive small resistances in the inspiratory alrway. A threshold resistance task comparable to that used by Harver, Katkin and Bloch (1993) was used for this purpose. To control for differences in response bias the task included trials in which no resistance was present. No support was found for the hypothesis that panic patients are superior in the perception of alirway resistances in comparison with normal controls. The lack of finding differences in perception was not due to differences in the number of false alarms or missing answers.

\section{Introduction}

In the literature concerning the cognitive theory of panic disorder it is suggested that panic patients are relatively good in detecting changes in physiology (Ehlers, 1993). This ability to perceive little changes might be important because panic attacks are typically triggered by bodily sensations and an increased experience of minor sensations might increase the chance of having a panic attack.

Sensations most prominently feared by panic patients are those that are present during panic attacks. It is therefore not surprising that several studies have tested whether panic patients are superior in the perception of especially these sensations. The results of the studies, however, do not unanimously favour the hypothesis of superior interoception. For instance, studies concentrating on the perception of heartbeat sensations, have yielded controversial outcomes. Some studies did find superior perception of heartbeats in panic patients (Ehlers \& Breuer, 1992; Ehlers \& Brewer, 1996; Ehlers, Brewer, Dohn \& 


\section{Study 6}

Fiegenbaum, 1995), others did not (Antony, Brown, Craske, Barlow \& et, 1995; Antony, Meadows, Brown \& Barlow, 1994; Asmundson, Sandler, Wilson \& Norton, 1993; Barsky, Cleary, Sarnie \& Ruskin, 1994). The different results are thought to be due to differences in the methodology used (Ehlers et al., 1995). However, also studies investigating superior perception of other sensations, using methods for which this critique does not apply, had negative results. Rapee (1994) investigated whether panic patients were better in detecting low concentrations of $\mathrm{CO}_{2}$ in air. When this gas-mixture is inhaled, it induces sensations similar to those reported and feared by panic patients. Patients were not found to be better than normals in detecting the inhalations with $\mathrm{CO}_{2}$. A study by Kroeze and Van den Hout (1998) investigated whether panic patients were better than normals in perceiving periods of light to moderate hyperventilation, which produces sensations comparable to those feared by panic patients. Again, there was no evidence that panic patients are superior perceivers of bodily changes.

Thus, the only studies that yielded some evidence for superior perception in panic patients are about heartbeat perception. Yet, many more sensations are feared by panic patients than palpitations. Regardless of whether superior perception is a cause or a consequence of experiencing panic attacks, there is no obvious reason why it should not be observable for other feared sensations too. Van den Hout, Van der Molen, Griez and Lousberg (1987) found that gasping for air was reported by panic patients to be as fearsome as palpitations. It seems therefore quite imaginable that panic patients are very sensitive to resistances in the airway. One study that addresses the issue of superior perception of respiratory resistance has been reported by Tiller, Pain and Biddle (1987). In this study panic patients seemed to perform worse at perceiving the magnitude of loads added to the inspiration than normals. However, since patients with panic disorder and patients with other anxiety disorders were lumped together, it is impossible to draw strong conclusions. In the present study a further attempt was made to investigate the perception of respiratory resistance in panic patients. A threshold resistance task comparable to those used by Harver, Katkin and Bloch (1993) was used to compare the perceptual performance of panic disorder patients with control subjects. To control for differences in response bias the task included trials in which no resistance was present.

\section{Method}

\section{Subjects}

Subjects were recruited via an advertisement in a local newspaper asking for persons 
having recurrent unexpected panic attacks. The persons who reacted were contacted by telephone and were diagnosed by a trained psychologist, using the Structured Chinical Interview for DSMII-R (SCID. Spitzer \& Williams, 1986), as to their fulfilling the DSMIII-R criteria of panic disorder. Exclusion criteria were current major depression or hallucinations. In total, 44 persons were interviewed. Of these, 24 fulfilled the stated criteria and were asked to participate. Five of them cancelled participation; hence ultimately 19 subjects (10 women, 9 men) with panic disorder participated in the experiment. Of the participating patients, 14 met the DSMIII-R criteria for agoraphobia, 5 did not. As a control group, 19 subjects (10 women, 9 men) matched on age, sex and education were obtained via an advertisement asking for healthy subjects. Mean age of the panic group was 43.8 years $(S D=11.95)$. Mean age of the control group was 44.6 years $(\mathrm{SD}=13,32)$.

\section{Questionnaires}

To measure fear for bodily sensations, subjects completed the Bodily Sensations Questionmaire (BSQ: Chambless, Caputo, Bright \& Gallagher, 1984). Also admininistered were the State-Trait Anxiety Inventory (STAI: Spielberger, Gorsuch \& Lushene, 1970) to measure anxiety and the Beck Depression Inventory (BDI: Beck, Ward, Mendelson, Mock \& Erbaugh, 1961) to measure current depression. Anxiety during the experiment was measured by a visual analogue scale (VAS) with the question how anxious they had been during the experiment from "not at all" to "extremely".

\section{Apparatus}

Subjects, seated facing a computer screen, breathed into a face mask with two separate airways. On the inspiratory airway a plastic ube was connected $(180 \mathrm{~cm}$ long and $3.2 \mathrm{~cm}$ diameter). The end of this tube was attached to a valve that could natrow the tube by turning into different positions. The valve was manipulated by an electronic device. In the experiment 8 positions of the valve were used: the position that left the tube completely open and 7 positions that made equal steps between $96 \%$ and $84 \%$ closure of the tube. The narrowing of the tube always coincided with the appearance of the Dutch word for "next" on the PC screen. This was done to inform the subject that the next inhalation he/she should try to feel whether breathing in was more difficult and to answer by pressing one of two buttons. Also, "next:" appeared a number of times when the tube was not narrowed. This was done to control for false positives. Respiration was monitored by a capnograph (DATEX, Multicap, CNO-103).

During the experiment the experimenter followed the $\mathrm{pCO}_{2}$ of the subject on the monitor of the capnograph and pressed a button at the beginning of each exhalation of the subject. 


\section{Study 6}

Each time the button was pressed, the valve moved to the position chosen by the computer program. Normally, this was the most open position, but every 2-3 breaths the valve turned to one of the target positions (i.e. when the word "next" appeared on the PC screen) and remained in this position till the next exhalation. The target positions of the valve (including open) were chosen randomly with the restriction that each narrowing position was presented once and the open position twice in each of ten 9-position sequences.

\section{Procedure}

Subjects were informed that the experiment was about the perception of little changes during inhalation. Subjects were told the procedure and signed an informed consent in which they agreed to participate. Subjects filled in the BSQ, the BDI and the STAI. Then they were asked to breathe into the face-mask and to watch the PC screen for when the Dutch word for "next" appeared. Subjects were told that this word informed them that the next inhalation could be more difficult. After the inhalation following the word "next" the subject had to press one of two buttons to indicate whether or not it had been more difficult to breathe in. The subjects practised this task until they indicated they had twice perceived a clear narrowing of the tube. To make this feeling clear to subjects, during the practice period two positions of the valve were used that were easy to discriminate, one where the tube was $97,5 \%$ closed, the other $96 \%$ closed.

After practising, the subject performed the entire task, containing in total 90 targeted inhalations: every narrowing position $(96 \%, 94 \%, 92 \%, 90 \%, 88 \%, 86 \%$ and $84 \%)$ was presented 10 times and the open position 20 times. After the task, the subject scored on a VAS how anxious he/she had been during the task.

\section{Results}

\section{Questionnairres}

Mean scores of the groups on the different questionnaires are presented in table 6.1. The growps differed significantly on the BSQ, the BDI, the STAI state, and the STAI trait. The anxiety during the task as measured by a VAS was not significantly different, $t(36)$ $=1.51, p=0.14$. 
Table 6.1. Descriptive characteristics of the panic disorder and normal control groups

\begin{tabular}{lcc}
\hline Questionnaires & Panic Disorder & Normal Control \\
BSQ & $47.3(9.2)$ & $28.2(6.6)$ \\
BDI & $16.5(11.3)$ & $6.9(7.0)$ \\
STAI state & $50.8(13.0)$ & $34.2(8.8)$ \\
STAI trait & $51.8(12.1)$ & $38.2(11.7)$ \\
Anxiety during task (VAS) & $2.4(3.2)$ & $1.2(1.6)$ \\
\hline
\end{tabular}

standard deviations in parentheses

\section{Perception of airway resistance}

The number of correctly perceived narrowings (hits) of the tube in each group are presented in figure 6.1. To compute whether the groups differed in their ability to perceive the trials in which the tube was narrowed a $2 \times 7$ (group $\times$ percentage of closure) was performed on the number of hits. This MANOVA revealed no effect of group, $F(1,36)=0.74$, NS and no effect of group x percentage of closing, $F(6,216)=0.9$, NS, indicating that the groups did not differ in their overall number of hits, nor did they react differently to the various degrees of closure. The effect of percentage of closure was significant, $F(6,216)=9.38, p<0.001$, indicating that both groups had higher hit-rates when the percentage of closure was higher (see tigure 6.1).

Figure 6.1. Mean number of hits for each closure of the tube

$$
\text { - Panile Disorder - - No-. Normal Coniral }
$$

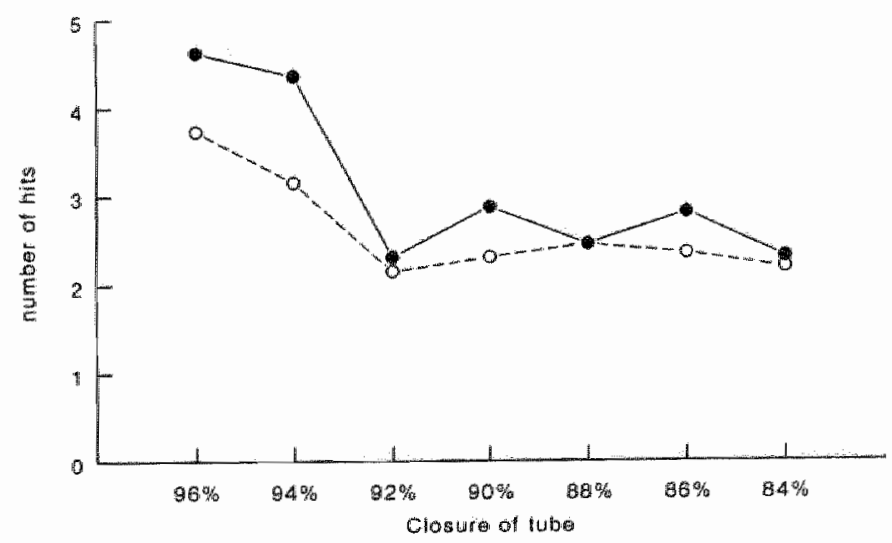




\section{Study 6}

To investigate whether the groups differed in number of false alarms (i.e. when a resistance was reported while the tube was completely open), these rates (see table 2) were compared in a t-test. The t-test revealed no differences between the groups, $\mathrm{t}(36)=$ 0.69 . NS. To investigate whether the groups differed in the number of trials on which they failed to give an answer, these rates too (see table 6.2) were compared with a t-test. The th-test revealed a trend towards panic patients having more missing answers, $t(36)=$ $1.86, p=0.08$ (2-tailed).

Since it was possible that the results were influenced by differences in numbers of false alarms and missing anwers, the MANOVA on the number of hits was repeated with these rates as covariate. This (2x7) MANOVA again revealed no effect of group, $F(1,34)=$ 0.67 , NS, indicating that the lack of finding differences in perception was not due to differences in the number of false alarms or missing answers.

Table 6.2. Mean percentage of false alarms and missing answers

\begin{tabular}{lcc}
\hline & Panic Disorder & Normal Controls \\
False alams & $27.5 \%(20.5)$ & $22.5 \%(22)$ \\
Missing answers & $10 \%(21)$ & $1 \% \quad(3.5)$ \\
\hline
\end{tabular}

standard deviations in parentheses

\section{Discussion}

No support was found for the hypothesis that panic patients are superior in the perception of airway resistances in comparison with normal controls. This finding is consistent with studies that failed to find differences between panic patients and normals in the perception of heartrate (Antony et al., 1995; Antony et al. „1994; Asmundson et al., 1993; Barsky et al. 1994), the perception of $\mathrm{CO}_{2}$ in air (Rapee, 1994) and the perception of hyperventilation (Kroeze \& Van den Hout, 1998). The results are at odds with the study by Tiller et al. (1987) on airway resistance since in that study panic patients were even worse than normals in feeling differences in resistance loads. However, Tiller et al. 's subjects had to indicate the (relative) size of the load, which is a different task than just indicating whether an obstruction is present or not. Findings by Holzl, Erasmus and Moltner (1996) on gastro-intestinal perception indicates that the detection threshold may be very distinct from the threshold at which a discrimination of different intensities becomes possible. Thus, it may be that panic patients are bad at discriminating intensities 
whille they still have a normal threshold of when they begin to perceive anything.

The results should be considered with care. Most of the subjects were strikingly bad in perceiving the resistances. As can be seen from figure 6.1 , only the bit-rate on the two heaviest resistances were substantially higher than the hit rate on the zero resistance. Also a number of subjects did not show an increase in hit rate when heavier loads were applied. Perhaps the range of resistances chosen was too much on the difficult side, giving subjects too little space to differ. However, if panic patients are much betrer in detecting resistances, they would rather need loads that are more difficult to detect than loads that are easier. It might be, however, that because the threshold of too many subjects was above the range applied, in fact there are data missing, which could have made a difference. Also, some subjects somewhere in the experiment may have given up believing that they would feel anything and could have started guessing or attending to the wrong cues. For instance, one subject said afterwards that he had attended to when his nose was itching since he thought that this was caused by the resistances. In this case it might be that more valid indications of obstruction that were in themselves observable for the subject were not attended to and consequently not perceived.

Another reason why the present study may have failed to find differences between the groups could be that the induced sensations were different from those present in daily life. Although the feeling of an interoceptive resistance is often compared to the feeling of bronchoconstriction, which does occur in daily life, it has been suggested that there are differences as well (Dahme, Richter \& Mass, 1996). Also, if subjects breathe through a tube, they perceive their bronchoconstriction together with the resistance of the tube. Thus, it seems possible that differences in inner airway impedance could have affected the results. However, although possible, it does not seem likely that these differences would be the cause of the failure of finding superior perceptual ability in panic patients. Carr, Lehrer, Jackson and Hochtron (1996) report that panic disorder patients have reduced bronchoconstriction, especially when under stress. Less inner airway resistance would, however, result in the external resistances being relatively large, resulting in the external resistances becoming easier to detect. Nevertheless, panic patients were not found to be better detectors. Thus, it seems unlikely that the lack of finding differences between patients and normals was due to differences in bronchoconstriction.

The present experiment is part of a larger series of studies finding no evidence that panic patients are interoceptive experts. The search for finding superior perception in panic patients seems not very fruitful. It may be, however, that subgroups of panic disorder patients are sensitive for some special sensation but not for sensations in general. Similarly, Pennebaker argues that accuracy should not be regarded as a unitary construct. That is, a person who is accurate in one bodily system may not be accurate in another 
system. In line with this, Harver et al. (1993) found no correlation between perceptual sensitivity on a heartbeat task and a resistive load discrimination task. If there are subgroups of panic patients with different sensibilities very large groups would be necessary to find differences between patients and normals in the ability to perceive a single sensation. It may then be more useful to make an index of reported sensations for each person and investigate the relationships with individual perceptual strengths. However, this line of research seems not very promising in the light of so many studies failing to show any differences between patients and normals. Moreover, it is not possible, for all sensations, to measure the intensity of the physiological foundation of sensations or manipulate the occurrence of sensations. For instance, what should be measured or manipulated in the case of nausea? Furthermore, the relationship between bodily changes and sensations seems quite inconsistent. For instance, Myrtek et al. (1995) carried out an experiment in which patients with cardiac neurosis had a number of ECG parameters monitored in an ambulatory setting. Neither heartpain nor excitement was correlated to any of the ECG parameters. Their conclusion is that the expression of excitement or pain is not due to physiological reasons but is a psychological phenomenon in these patients. Similarly, the bodily sensations panic patients report may be unrelated to physical changes. Pennebaker (1982) reports that even normal subjects assessed their heartrate more on basis of environmental cues than on actual heartrate.

Apparently there are more influences that may lead to sensations than accurate perceptions of physical changes. A low detection threshold may be but one of many factors that determine the degree in which sensations are perceived. Panic patients may have normal detection thresholds but still perceive more sensations given the same physical events. Another possibility is that increased reporting reflects preoccupation with sensations that are equally sallient to controls. Meanwhile, it seems more important to investigate in general which factors influence the perception and report of sensations than to focus on differences in detection thresholds. 


\section{Conclusions and General Discussion}

In the introduction top-down processes were introduced to explain why panic patients may have an increased experience of bodily sensations. It was stated that this dissertation would try to clarify some issues relating to these top-down processes. Six experimental studies have been described. The results of the experimental studies will now be summarized and then discussed.

\section{Results of experimental studies}

The first study explored whether selective attention may increase the saliency of bodily sensations and whether this could be the reason that the report of bodily sensations in panic patients is increased. "This was done by measuring sensation report after directing the attention of both panic patients and normals towards or away from sensations. Shifting attention proved indeed to influence the report of sensations, thereby supporting the hypothesis that selective attention might play a role in the generation of sensations in panic patients. However, against the hypothesis that a ceiling effect would occur in the panic group, both panic patients and controls reported more sensations after instructions to attend to them.

In the second study selective attention for hyperventilatory sensations was tested in panic patients and in normal controls. The results of the study were mixed. Hyperventilatory sensations as such did not attract the attention of panic patients more than that of normals. However, there was a tendency for panic patients to be more distracted by both real and placebo hyperventilation. Since also placebo hyperventilation induced sensations in panic patients, although not as much as real hyperventilation, this distraction could be seen as giving some support for the hypothesis that panic patients selectively attend to bodily sensations.

In study 3 it was demonstrated that panic patients relative to controls paid more attention to heartbeat information. Although attending to heartrate feedback is not the same as attending to real sensations, this study gives more direct support for the selective attention hypothesis than studies done so far, measuring attention for verbal descriptions of cues related to bodily sensations.

The issue of whether selective attention is a cause or a consequence of fear was investigated in study 4 . It was found that fear for heartrate changes did not induce selective attention for heartrate information nor did fear for muscle tension changes induce selective attention for information about these changes. On the contrary, subjects seemed 


\section{Conclusions \& Discussion}

to selectively shift their attention away from the threatening stimulus. This seems to indicate that selective attention is not just a result of fear. However, it may be that the subjects did not fear the stimuli enough to result in selective attention. If so, then selective attention may only arise in cases of extreme fear.

Study 5 examined whether panic patients were superior in detecting periods of mild hyperventilation. Panic patients were not found to be better able to distinguish between real hyperventilation and placebo hyperventilation. Thus, this study did not support the hypothesis that panic patients are interoceptive experts. Also in study 6 , panic patients were not found to be better perceivers of bodily changes. They did not perceive respiratory resistances better than normal controls.

\section{Discussion}

Overall the data supported the hypothesis that panic patients selectively attend to bodily sensations and did not support the hypothesis that panic patients were superior perceivers of bodily changes. Yet, not in all studies was the effect of selective attention equally persuasive. In study 1 panic patients seemed as inclined as normal controls to report an increase in sensations when they were asked to attend to them. This was against the hypothesis since it was assumed that for panic patients a ceiling effect would occur because attending to sensations was their normal state. It raises the question whether the sensations reported initially (before the subjects had been asked to attend to sensations) were indeed due to excessive attentional resources directed to the body. On the other hand, distraction caused sensation intensity to decrease, indicating that attention is able to influence the experience of sensations. Also in study 2 distraction influenced sensation report dramatically: during the reaction time task the report of sensations of panic patients dropped to the level of controls. However "only marginal evidence for selective attention for hyperventilatory sensations was found in panic patients. Also, the degree of attention for sensations was not found to be related to the degree of sensations reported: real hyperventilation did not distract panic subjects more from their task than placebo hyperventilation did although it induced significantly more sensations. Since attention paid to sensations will capture processing resources, it is curious that the degree of sensations was not related to deterioration in task performance. It seems possible that the situation or the expectation that the situation would induce sensations might have captured the attention rather than the sensations did. In other words, it might have been the "thoughts" about possible danger that caused the distraction. Since this interpretation of the data 
cannot be ruled out, it remains unclear whether or not the observed effects were really due to selective attention. Study 3 was not subject to these problems and seems to be a sounder demonstration of selective attention for bodily sensations in panic patients. Howewer, in this experiment attention for visual heartrate feedback was measured and not to heartrate itself. Although the data are highly suggestive, heartrate feedback is not the same as heartbeat sensations. It is for instance much easier to attend to heartrate feedback than to heartrate sensations. People are generally found to be quite bad at feeling their heartbeats (Hartl \& Strian, 1995) and it has not been sufficiently demonstrated that panic patients are much better at it (see the introduction). Could it be possible that people attend to sensations that cannot even be felt? It might be that ambiguous sensations in the region of the heart are noticed and interpreted as heartbeats or palpitations. In this case, accurate interoceptive ability is not needed to be able to attend to these sensations. The selective attention found may be due to this preoccupation with sensations attributed to the heart.

Although indications were found that panic patients do selectively attend to bodily sensations, selective attention for real sensations has still not been satisfactorily demonstrated. As may be clear from this dissertation, designing a crucial test for this is a complex undertaking. The attention of subjects has to be measured while sensations are induced (or its physical correlates measured). However, ideally subjects should not know that sensations are to be expected since this may influence the results. Furthermore, the attentional measurement should preferably bypass conscious thought since many attentional processes may not be accessible to consciousness. The experiment that meets these requirements is still far from thought out.

On the other hand, selective attention for cues rellated to sensations seems a rather well. established phenomenon (Asmundson et al., 1992; Ehlers \& Breuer, 1995; Hope et al., 1990; McNally et al. 1994; McNally et al., 1990; Mogg et al., 1989) and both studies 2 and 3 provide evidence for this. It might be considered whether perhaps this phenomenon in itself might be able to give panic patients a heightened experience of sensations. Because of sellective attention to cues related to sensations, such as cues related to catastrophes and illnesses, these cues will be quickly noticed. According to Pennebaker (1995), in daily life situational cues and commonly held bellefs might be as important for gathering information about bodily state as internal cues. This implies that when noticing threatening cues panic patients might infer from the danger communicated by these cues that bodily sensations are experienced. Thus, the belief that being in a crowd causes palpitations may be enough to cause the subjective experience of palpitations when in a crowd. This may seem odd, but Pennebaker argues that in the real world situational cues provide usefull assistance in our determining whether or not we are hungry, tired, sick or emotional. Since the ability of people to perceive bodily changes is rather tenuous, using 


\section{Conclusions \& Discussion}

these cues may normally be quite adaptive. On the other hand, it may be not be adaptive to notice all kinds of bodily changes. As long as this ability does not contribute to escaping from dangerous circumstances, it might only distract us from more important issues. Thus, taking a Pennebakerian view it seems possible that selective attention for cues believed to represent danger might increase the degree of threat perceived in the environment and therefore increase the number of sensations experienced.

However, the causal status of selective attention is still a matter of debate. Selective attention may cause fear by enabling cues of danger to be noticed quickly. In this case it may be a maintaining factor in panic disorder by leading to increased fear and/or the perception of sensations. On the other hand, selective attention may be secondary to the disorder, for instance arising as a consequence of the activation of cognitive structures relating personal concerns. In this case, selective attention might not necessarily play a maintaining role. Study 4 tried to shed light on this issue. It showed that inducing beliefs that increases in heartrate lead to shocks did not lead to selective attention for heartrate feedback. On the contrary, heartrate feedback seemed to be ignored after this manipulation. This supports the idea that selective attention is a relatively enduring characteristic, not simply to be induced by the belief that some stimulus predicts danger. If this is true, it indicates that selective attention may be present before the disorder started and hence may have contributed to the development of the disorder. However, it may be that selective attention only arises to stimuli that are appraised as extremely threatening and that this was not the case in study 4. A similar proposition is advanced in a recent review on selective attention by Mogg and Bradley (1998). They propose that attentional bias may have a curvilinear relationship with the subjective threat value of the stimulus: Mild evaluation of threat will lead to initial avoidance of the threat, whereas high evaluation of threat will lead to attentional vigilance. The attentional avoidance for the picture predicting (mild) threat in study 4 supports this hypothesis. This interpretation, however, implies that selective attention is a result of fear. The possibility remains that selective attention reciprocally occasions fear and therefore still has a role to play in the maintenance of the disorder. However, this possibility of reciprocity has yet to be tested.

It was not found that panic patients were superior perceivers of bodily changes. This may not be curious. As mentioned above, adequate perception of bodily changes may not even play an important role in generating (normal) sensations. Support for this is aiso the finding that self-report and physiological measures of bodily processes like skin conductance, heart rate and breathing rate are correlated but low (around +0.30: Pennebaker, 1982). However, interoception should not be dismissed too soon as an important generator of sensations in panic disorder. Even if panic patients are inadequate at identifying which of the sensations they feel can, for instance, be ascribed to the beating of their 
hearts, their heart still beats and consequently may occasion sensations. Furthermore, interoception need not occur always on a conscious level. Recently, a body of research has been brought forward on implicit perception, showing instances in which subjects were shown to be influenced by events not consciously perceived (Bornstein, 1992). As early as 1963 , Hefferline and Perrera showed that subjects could be trained to react to thumb twitches while they were not aware of these twitches. This opens the probability that panic patients perceive a lot more than they can tell. Furthermore, they may be guided by perceptions they are not aware of. Thus, it may be that panic patients are better able to perceive bodily changes on a level not touched by the present experiments. Aiternatively, they may not be better perceivers but their (subconscious) perceptions may be processed in a way that brings about anxiety.

It is important to mention that cognitive theories of panic do not necessarilly imply that panic patients have a heightened experience of bodily sensations. The fact that panic patients report more sensations may also be due to answering characteristics or to psychological characteristics like neuroticism, negative affectivity or anxiety (Watson \& Pennebaker, 1989). Still, the report of bodily sensations is a central feature of panic disorder and understanding the origin of these sensations is therefore an important issue. It is clear that the relationship between bodily changes and bodily sensations may be a complicated one. Selective attention for bodily sensations seems one of the possible mediating factors since it may influence what sensations are perceived and how strongly. However, other factors may be important too. Maybe stable personality features as mentioned above do not only influence the report of sensations, but also the way in which sensations are experienced.

Furthermore, the possibility remains that bottom-up processes increase the somato-sensory input in panic patients. It is very likely that there are many instances in which panic patients experienced sensations because of bottom-up processes and panicked because of these sensations. It seems less likely that a single process like hyperventilation may account for all panic sensations in all panic patients. As was shown by the challenge studies in the introductions, many processes give rise to panic like sensations. Besides, whether sensations are perceived and how they are experienced may still depend on topdown processes. Probably, not all interoceptive information transforms into what we call "sensations". There may exist some evaluation system that decides if the incoming somato-sensory input is important enough to get priority over other kinds of input (see also Mogg \& Bradley, 1998). Such a system might also influence how a sensation is experienced by giving it a certain meaning. For instance, a person breathing into a mouthpiece might feel short of breath, not because he is getting not enough air but because the mouthpiece causes the breathing to be slightly more difficult, which is 


\section{Conclusions \& Discussion}

interpreted as getting too little air. The sensation might furthermore be influenced by the importance that is attached to getting enough air and the importance that is atcached to competing incoming information. Such an evaluation system would not be specific for panic disorder patients. Everybody seems to need a system to be able to give priority to certain information and not to other information and to evaluate whether it is necessary to give an alarming message in the form of a sensation.

Adequate perception may not be as important in the generation of sensations as is generally believed. Possibly, cues other than internal ones may give rise to sensations, such as certain beliefs or expectancies. Meanwhile, the perception of bodily changes may occur on levels not accessible to awareness. This means that people may be aware of only part of what is perceived or what can be perceived when attended to. This also means that bodily changes may have influences we are not aware of. It will demand special research with new experimental tools to find out these influences. A conditioning paradigm such as Hefferline and Perrera used might be adapted to investigate whether subjects couid learn to react to (weak) bodily changes. They conditioned subjects to press a key when a thumb twitch occurred. Instead, subjects might be conditioned to react to bodily changes more relevant to panic disorder, for instance changes in heartrate. Alternatively, bodily changes might be induced, for instance by adding resistances to inhalation (see study 6) and subjects might be conditioned to these changes. Furthermore, it might be explored whether a conditioned stimulus is able to evoke a reaction previously evoked by an unconditioned stimulus. For instance, if in panic patients an increase in heartrate evokes anxiety, a light/tone, etc., having been paired with increases in heartrate should be able to evoke anxiety itself. Apart from conditioning paradigms, attempts could be made to adapt some of the methods to reveal unconscious processes as summed up by Jacoby, Toth, Lindsay and Debner (1992), for instance, by making use of the fact that people react faster to cues they had previously seen.

In all, some support was found for the hypothesis that panic patients selectively attend to bodily sensations. However, the study that demonstrated selective attention most clearly measured selective attention for visual heartrate feedback, which can only be regarded as an indirect measure of selective attention for bodily sensations. It was not found that selective attention was a result of fear. This indicates that selective attention is not simply a result of fear and is in line with the view that selective attention may have a causal or at least a maintaining role to play in anxiety disorders. The hypothesis that panic patients are superior perceivers of bodily changes was not supported. Panic patients were not better in detecting periods of hyperventillation nor in detecting resistances in the airway.

Future research should find out whether panic patients also selectively attend to real 
Canchusions \& Discussion

bodily sensations and whether selective attention indeed plays a role in the development of fear. Furthermore, it would be worthwhile to know in general more about the mechanisms that influence the experience and eventually the report of bodily sensations. Selective attention might play a mediating role by giwing priority to the processing of certain bodily events. However, also other psychological characteristics like neuroticism should be considered. Other fruitful lines of research might be the investigation of the (subconscious) perception of bodily changes and the effects the perception of these changes might have on a person. 



\section{References}

Amir, N., McNally, R. J., Riemann, B. C., Burns, J. Lorenz, M. \& Mullen, J. T. (1996) Suppression of the emotional Stroop effect by increased anxiety in patients with social phobia. Eehaviour Research and Therapy. 34, 945-948:

Antony, M. M., Brown, T. A., Craske, M. G., Barlow, D. H. Mitchell, W. B. \& Meadows, E A. (1995). Accuracy of heartbeat perception in panic disorder. social phobia, and nonanxious subjects. Jonrnal of Anxiery Disorders, 9, 355-371.

Antony, M. M. Meadows, E. A., Brown, T. A., \& Barlow, D. H. (1994) Cardiac awareness before and after cognitive-behavioral treatment for panic disorder. Journal of Amiety Disorders, $8,341-350$.

Arrindel, W. A., Ettema, H. (1986). Dimensionele structuur, betrouwbaarheid en valliditeit van de Nederlandse bewerking van de Symptom Checklist (SCL-909), gegevens gebaseerd op een fobische en een "normale" populatie. Nederlands Tijdschrift voor de psychologie, 36, 77-108.

Asmundson, G. J., Sandler, L. S., Wilson, K. G., \& Norton, G. R. (1993). Panic attacks and interoceptive acuity for cardiac sensations. Behaviour Research and Therapy. 31, 193-197.

Asmundson, J. G., Sandler, L. S., Wilson, K. G., \& Walker, J. R. (1992). Selective attention toward physical threat in patients with panic disorder. Joumal of Anxiety Disorders, 6, 295-303.

Anterican Psychiatric Association, A. P. (1987). Diagnostic and statistical mawnal of mental disorders (DSMLI-R). Washington, DC: American Psychiatric Association.

Baker, R. (1989). Introduction: where does 'Paric disorder' come from. In R. Baker (Eds.), Panic disorder: theory, research and therapy (pp. 1-15). New York: John Wiley and sons.

Barlow, D. H. (1988). Anxiety and its disorders. New York: "The Guilford Press.

Barsky, A. J. (1992a). Amplification, somatization, and the somatoform disorders. Psychosonatics, $33,28-34$.

Barsky, A. J. (1992b). Palpitations, cardiac awareness, and panic disorder. The American Journal of Medicine, 92.

Barsky, A. I., Cleary, P. D. Sarnie, M. K. \& Ruskin, J. N. (1994). Panic disorder, palpitations, and the awareness of cardiac activity. Jownal of Nerwows and Menal Disease, 182, 63-71.

Bass, C.. \& Gardner, W. N. (1985). Respiratory and psychiatric abnormallies in patients whth chronic symptomatic hyperventilation. British Medical Journal, 290, 1387-1390.

Bass, C. Lelliot, P., \& Marks, I. (1989). Fear talk versus voluntary hyperwentilation in agoraphobics and normals: a controlled study. Psychological Medicine, 19, 669-676.

Beck, A. T., Emery, G., Greenberg, R. L. (1985). Anxiety disorders and phobias: a cognitive perspective. New York: Basic Books.

Beck, A. T. Ward, C. H., Mendelson, M., Mock, J., \& Erbaugh, J. (1961). An inventory for measuring depression. Apchives of General Psychiatry, 41.561-571.

Belfer, P. L., \& Glass, C. R. (1992). Agoraphobic anxiety and fear of fear: Test of a cognitive-attentional model. Journat of Anxiety Disorders, 6, 133-146.

Bornstein, R. F. (1992). Perception whthout awareness: retrospect and prospect, In R. F. Bornstein \& T. S. Pittman (Eds.). Perception withont awareness. Cognitive, clinical and social perspec- 


\section{References}

Hives. New York: The Guilford Press

Buller, K. S., Rapee, R. M. (1991). The influence of anxiety on accuracy of heart rate estimations. Speciall 1sue: Research in anxiety and fear. Behoviour Change, 8, 117-123.

Carr, R. E., Lehrer, P. M. Jackson, A. \& Hochtron, S. M. (1996). Effect of psychological stress on. airway impedance in individuals with asthma and panic disonder. Joumal of Abnomal Psychology, 105, 137-141.

Chambless, D. L., Caputo, G. C., Bright, P., Gallagher, R. (1984). Arsessment of fear of fear in agoraphobics: The Body Sensations Questionnaire and the Agoraphobic Cognitions Questionmaire. Journat of Consulting and Clinical Psychology, 52, 1090-1097.

Charney, D. S., Woods, S. W. Price, L. H., Goodman, W. K., Glazer, W. M., \& Heninger, G. R. (1990). Noradrenergic dysregulation in panic disorder. In J. C. Ballenger (Eds.). Neurobiology of panic disorder. New York: Wiley-Liss.

Clark, D. M. (1986). A cognitive approach to panic. Behaviour Research and Therapy. 24, $461-470$

Clark, D. M. (1988). A cognitive model of panic attacks. In S. Rachman \& J. D. Maser (Eds.), Panic, psychological perspectives (pp. 71 -91). Hillsdale, N.J.: Lawrence Erlbaum Associates.

Clark, D. M. (1989). Anxiety states, panic and generalized anxiety (pp 52-97). In K. Hawton, P. M. Salkovskis, J. Kirk, \& D. M. Clark (Eds.). Oxford, UK: Oxford University Press.

Clark, D. M. (1992). Cognitive mediation of lactate induced panic. Paper presented at the 24th annual AABT convention, San Francisco.

Clark, D. M. (1993). Cognitive mediation of panic attacks induced by biological challenge tests. Advances in Behaviour Research and Therapy, 15, 75 84.

Coplan, J. D., Papp, L. A., King, D. L., \& Gorman, J. M. (1992). Amelioration of mitral valve prolapse after treatment of panic disorder. American Joumal of Psychiary, $149,1587-1588$.

Cowley, D. S., \& Roy-Byrne, P. P. (1987). Hyperventilation and panic disorder. The anterican fournal of wedicine, 53, 929-937.

Crombez, G. Baeyens, F., \& Eelen, P. (1994). Sensory and temporal information about impending pain: The influence of predictability on pain. Behoviour Research and Therapy, 32, 611-622.

Dahme, B., Richter, R. \& Mass, R. (1995). Interoception of respiratory resistance in asthmatic patients. Biological Psychology, 42, 215-229.

Davey, G. C. L. (1989), UCS revaluation and conditioning models of acquired fears. Behavior Research and Therapy, 27, 521-528.

de Ruiter, C. Garssen, B., Rijkers, H. \& Kraaimaat, $\mathbb{F}$. (1989). The hyperventilation syndrome in panic disorder, agoraphobia and generalised anxiety disorder. Behavour Research and Therapy, $27.647-655$.

Devereux, R. B., Perlof, J, K., Reichek, N., \& Jlosephon, M. E. (1976). Mitrall valve prolapse. Circulation, $54,3414$.

Eaton, W. W. Dryman, A., \& Weissman, M. M. (1991). Panic and phobia. In L. N. Robins \& D. A. Regier (Eds.), Psychiatric disorders in America (pp. 155-179). New York: Free Press.

Ehlers, A. (1993). Interoception and panic disorder. Special Issue: Panic, cognitions and sensations. 
Adwances in Behaviour Research and Therapy, 15, 3-21.

Ehlers, A. (1995). A 1-year prospectiwe study of panic attacks: Clinical course and factors associated with maintenance. Jownal of Abnormal Psychology, 104, 164-172.

Ehlers, A., \& Brever, P. (1992). Increased cardiac awareness in panic disorder. Joumal of Abnormal Psychology, 101, $371-382$.

Ehlers, A., Breuer, P. (1995). Seltective attention to physical threat in subjects with panic artacks and specific phobias. Joumal of Anxiety Disorders, 9, 11-31.

Ehters, A., B Breuer, P. (1996). How good are patients with panic disorder at perceiving their heartbeats? Biological Psychology, 42, 165-182.

Ehlers, A., Brewer, P., Dolm, D., \& Fiegenbaum, W. (1995). Heartbeat perception and panic disorder: Possible explanations for discrepant findings. Behawour Research and Therapy, 33, $69-76$.

Ehlers, A., Margraf, J., Davies, S., \& Roth, W. T. (1988). Selective processing of threat cues in subjects with panic attacks. Special Issue: Information processing and the emotional disorders. Cognition and Emotion, 2, 2011-219.

Ehlers, A., Margraf, J., Roth, W. T., Taylor, B., \& Birbaumer, N. (1988). Anxiety induced by false heartrate feedback in patients with panic disorder. Behaviour Research and Therapy, 26 , $1-11$.

Frijda, N. H. (1986). The emotions. Cambridge: Cambridge University Press.

Garssen, B. (1980). Role of stress in the development of the hyperventiltation syndrome. Psychotherapy and Psychosomatics, 33, 214-225.

Garssen, B. (1986). Psychofysiologie wan de ademhaling en het hypervertilatie syndroom, doctoral dissertation. Delft: Eburon.

Garssen, B., Buikhuisen, M., \& van Dyck, R. (1996). Hyperventilation and panic attacks. American Journal of Psychiatry, 153, 513-518.

Garssen, B., wan Veenendaal, W., \& Bloemink, R. (1983). Agoraphobia and the hyperventilation syndrome. Behaviour Research and Therapy, 2I, 643-649.

Gelder, M. G. (1986). Panic attacks; New approaches to an old problem. British Jownat of Psychiatry, $149,346-352$.

Goldstein, A. J., \& Chambless, D. L. (1978). A reanalysis of agoraphobia. Behavior Therapy, 9 , $47-59$

Gorman, J. M. (1986). Panic disorder: Focus on cardiovascular status. Paper presented at the Paper presented at the $13 \mathrm{th}$ Annual Meeting of the American Psychiatric Associaltion, Washington, DC.

Gorman, J. M., Liebowitz, M. R., Fyer, A. J., Fyer, M. R. \& Klein, D. F. (1986). Possible respiratory abnormalities in panic disorder. Psychopharnacology Bulletin, 22, 797-801.

Gorman, J. M., \& Papp. L. A. (1990). Respiratory physiology of panic In J. C. Ballenger (Eds.), Neurobiology of panic disorder. New York: Wiley-Liss.

Griez, E., \& Van den Howt, M. A. (1984). Carbon dioxide and anxiety: an experimental approach to a clinical claim. Maastricht: Rijksuniversiteit Limburg. 


\section{References}

Grossman, P. (1983). Respiration, stress and cardiovascular function. Joumal of Psychosomatic Research, $28,97-104$.

Haenen, M. A. Schmidt, A. J. M., Kroeze, S., \& van den Hout, M. A. (1996). Hypochondriasis and symptom reporting - the effect of attention versus distraction. Psychotherapy awd Psychosomatics, $65,43-48$.

Hart, L. (1992). Die Panikstörung. Eine untersuchung zur Rolle der Wahrnehmumg von Körperprozessen. Frankfurt: Peter Lang.

Hart, I., \& Strian, F. (1995). A clinical approach to cardiac perception. In D. Vaitl \& $\mathbb{R}$. Schandry (Eds.). From the heart to the brain. The psychophysiology of circulation-brain interaction. Frankfurt/Main: Peter Lang-Verlag.

Harver, A., Katkin, E. S. \& Bloch, E. (1993). Signal-detection outcomes on heartbeat and respiratory resistance detection tasks in male and female subjects. Psychophysiology, 30 , 223-230.

Hefferline, R. F, \& Perrera, T. B. (1963). Proprioceptive discrimination of a covert operant without its observation by the subject. Science, $139,834-835$.

Hermans, D., \& Eelen, P. (1998). Eye movement registration as a continuous measure of attention deployment: data from a group of spider anxious students. Paper presented the meeting of the FWO Research Community on the acquisition, representation and activation of affect, Leuven, Belgium.

Hibbert, G., \& Pilsbury, D. (1988). Hyperventilation in panic attacks: Ambulant monitoring of transcutaneous carbon dioxide. British Journal of Psychiatry, 0192.

Hibbert, G., \& Pilsbury, D. (1989). Hyperventilation: Is it a cause of panic attacks? British Joumal of Psychiatry.0192.

Holt, P. E., \& Andrews, G. (1989). Provocation of panic: three elements of the panic reaction in four anxiety disorders. Behaviour Research and Therapy, 27, 253-261.

Holzl, R., Erasmus, L.-P., \& Moltner, A. (1996). Detection, discrimination and sensation of visceral stimuli. Biological Psychology, 42, 199-214.

Hope, D. A., Rapee, R. M., Heimberg, R. G., \& Dombeck. M. J. (1990). Representations of the self in social phobia: Vulnerability to social threat. Special Issue: Selfhood processes and enotional disorders. Cognitive Therapy and Research, 14, 177-189.

Hornsweld, H. (1996). Farewell to the hyperventilation syndrome. Doctoral dissertation. University of Amsterdam.

Hornsveld, H., Garssen, B., Fiedeldij Dop, M., \& Van Spiegel, P. (1990). Symptom reporting during hyperventilation and mental load compared: implications for diagnosing hyperventilation syndrome. Jowrial of Psychosomatic Research, 34, 687-697.

Hornsveld, H., Garssen, B., \& van Spiegel, P. (1995). Voluntary hyperventilation: the influence of duration and depth on the development of symptoms. Biol Psychol, 40, 299-312.

Hornsveld, H. K., Garssen, B., Fiedeldij Dop, M. J. C., van Spiegel, P. I., \& de Haes, J. C. J. M. (1996). Double-blind placebo-controlled study of the hyperventillation provocation test and the validity of the Lyperventilation syndrome. The Lancet, 348, 154-158. 
Jacoby, L. J., Toth, I. P., Lindsay, D. S., \& Debner, J. A. (1992). Lectures for a layperson: Methods for revealing unconscious processes. In R. F. Bornstein \& T, S. Pitman (Bds.), Perception without awareness. Cognime, clinical and social perspectives ( $\mathrm{pp}$. 81-120). New York: The Guilford Press.

James, W. (1890). The principles of psychology. New York: Holt, Rineltart and Winston.

Katerndahl, D. A., \& Realini, J. P. (1993). Lifetime prevalence of panic states. American Journal of Psychiatry, 150, 246-249.

Klinger, E. (1975). Consequences of commitment to and disengagement from incentives. Psychological Review, 82, 1-25.

Kroeze, S.. \& Van den Hout, M. A. (submitted). Selective attention for cardiac information in panic patients.

Kroeze, S., \& Van den Hout, M. A. (1998). No superior perception of hyperventilatory sensations in panic disorder. Behaviour Research and Therapy.

Lavy, E. H. (1993). Attentional bias and anxiety: conceptual issues and empirical data. Doctoral dissertation. Rijksuniversiteit Limburg.

Lavy, E. H., Hout, M. v. d. (1993). attentional bias and spider phobia: Conceptual and clinical issues. Behaviour Research and Therapy, 31, 297-310.

Ley, R. (1985). Blood, breath and fears:" A hyperventilation theory of panic attacks. Chical Psychology Review, 5, 271-285.

Liebowitz, M. R., Gorman, J., Fyer, M., Pitton, D., Levy, S., Appleby, I., Anderson, S., Paly, M., Davies, S., \& Klein, D. F. (1985), Lactate provocation of panic attacks:

Biochemical and physiological findings. Archives of General Psychiatry, 42, 709-719.

Loftus, E. F., Lofus, G. R. \& Messo, J. (1987). Some facts about "weapon focus". Law and Human Behaviour, 11, 55-62.

Logan, A. C., \& Goetsch, V. L. (1993). Attention to external threat cues in anxiety states. Clinical Psychology Review, 13, 541-559.

Lum, L. C. (1981). Hyperventilation and anxiety state. Hournal of the Royal Society of Medicine, 14.4 .

Macleod, C. (1998). Selective attention in "anxiety"; causal relations. Paper presented at the World Congress of cognitive and behavioral therapies, Acapulco, Mexico.

Maclead, C., Mathews, A. (1988). Anxiety and the allocation of attention to threat. The Quarterly Journal of Experimental Psychology, 40A, 653-670.

MacLeod, C., Mathews, A., \& Taia, P. (1986). Attentional bias in emotional disorders. Journal of Abnormal Psychology, 95, 15-20.

Macleod, C. M. (1991). Half a century of research on the Stroop effect: An integrative review. Psychological Bulletin, 109, 163-203.

Margraf, J. (1993). Hyperventilation and panic disorder: A psychophysiological connection. Special Issue: Panic, cognitions and sensations. Advances in Behaviour Research and Therapy, 15. 49-74,

Margraf, J., \& Elhlers, A. (1988). Etiological models of panic-medical and biological aspects. In $\mathbb{R}$. 


\section{References}

Baker (Eds.), Panic disorder: theory, research and therapy. New York: John Wiley and Sons.

Margraf, J., Ehlers, A., \& Roth, R. T. (1992). Expectancy effects in experimental panic induction: a psychophysiological interaction.

Margraf, J., Ehlers, A., \& Roth, W. T. (1986). Sodium lactate infusions and panic attacks; A review and critique. PSychosomatic Medicine, 48, 23-51.

Margraf, J., Ehlers, A., \&oth, W. T. (1988). Mitral valve prolapse and panic disorder: A review relationship. Psychosomatic Medicine, 50, 93-113.

Marks, I. M. \& Mathews, A. M. (1979). Brief standard self-rating for phobic patients. Behaviour Research and Therapy, 17, 263-267.

Maser, J. D., \& Woods, S. W. (1990). The biological basis of panic. Psychiatric Medicine, 8, $121-147$

McLeod, D. R., Hoehn-Saric, R., \& Stefan, R. L. (1986). Somatic symptoms of anxiety: Comparison of self-report and physiological measures. Biological Psychiatry, 21, 301-310.

McNally, R. J. (1990). Psychological approaches to panic disorder: a review. Psychological Bulletin, 108, 403419 .

MoNally, R. J. (1994). Panic disorder, a critical analysis. New York: The Guilford Press.

McNally, R. J. (1995). Automaticity and the anxiety disorders. Behaviour Research and Therapy, $33,747-754$.

McNally, R. I., Amir, N., Louro, C. E., Lukach, B. M. Rieman, B. C. \& Calamari, J. E. (1994). Cognitive processing of idiographic emotional information in panic disorder. Behaviour Research and Therapy, 32, 119-122.

McNally, R. J., Riemann, B. C., \& Kim, E. (1990). Selective processing of threat cues in panic disorder. Behaviour Research and Therapy, 28, 407-412.

McNally, R. J., Riemann, B. C., Louro, C. E., Lukach, B. M. \& Kim, E. (1992). Cognitive processing of emotional information in panic disorder. Behaviour Research and Therapy, 30 , 143-149.

Merckelbach, H., van Hout, W., de Jong, P., \& van den Hout, M. A. (1990). Classical conditioning and attentional bias. Behaviour Research and Therapy, 21, 185-191.

Mogg, K., \& Bradley, B. P. (1998). A cognitive-motivational analysis of anxiety. Behaviour Research and Therapy, 36, 809-848.

Mogg, K., Mathews, A., Bird, C., \& Macgregor-Morris, R. (1990). Effects of stress and anxiety on the processing of threat stimuli. Joumal of Personality and Social Psychology, 59, 1230-1237.

Mogg, K. Mathews, A. \& Weinman, J. (1989). Selective processing of threat cues in anxiety states: A replication. Behoviour Research and Therapy, 27, 317-323.

Myrtek, M. . Stiehls, W., Hermann, J. M., Brugner, G., Muller, W., Hoppner, V., \& Fichtler, A. (195). Emotional arousal, pain, and ECG changes during ambullatory monitoring in patients with cardiac neurosis and controls: Methodological considerations and first results. In D. Vaitl \& $\mathrm{R}$. Schandry (Eds.). From the heart to the brain (pp. 319-335). Frankfurt am Main: Peter Lang.

Nutt, D., \& Lawson, C. (1992). Panic attacks, a neurochemical overview of models and mechanisms. British Journal of Psychiarry, $160,165-178$. 
Papp, L. A., Klein, D. F., \& Gorman, J. M. (1993). Carbon dioxide hypersensitiwity, hyperventilation, and panic disorder. American Jowrnal of Psychiatry, 150, 1149-1157.

Pennebaker, J. M. (1995). Beyond laboratory-based cardiac perception: ecological interoception. In D. Vaitl \& R. Schandry (Eds.). From the heart to the brain. The psychophysiology of circulationbrain interaction. Frankfurt/Main: Peter Lang-Verhag.

Pennebaker, J. W. (1982). The psychology of physical symproms. New York: Springer-Verlag.

Plutchik, R. (1994). The psychology and biology of emotion. New York: Harper Collins College Publishers.

Rapee, R. (1987). The psychological treatment of panic attacks: Theoretical conceptualization and review of evidence. Clinical Psychology Review, 7, 427-438.

Rapee, R., Mattick, R., \& Murrell, E. (1986). Cognitive mediation in the affective component of spontaneous panic attacks. Joumal of Behavior Therapy and Experimenal Psychiatry, 17 , 245-253.

Rapee, R. M. (1994). Detection of somatic sensations in panic disorder. Behaviour Research and Therapy, 32, 825-831.

Rapee, R. M. (1995). Psychological factors influencing the affective response to biological challenge procedures in panic disorder. Journal of Anxiety Disorders, 9, 59-74.

Rapee, R. M., Ancis, J. R., Barlow, D. H. (1988). Emotional reactions to physiological sensations: Panic disorder patients and non-clinical Subjects. Behaviour Research and Therapy. $26,265-269$

Rapee, R. M. Sanderson, W. C., McCauley, P. M., \& Di Nardo, P. A. (1992). Differences in reported symptom profile between panic disorder and other DSM-III-R anxiety disorders. Behaviour Research and Therapy; 30, 45-52.

Reiss, S., Peterson, R. A., Gursky, D. M. \& McNally, R. J. (1986). Anxiety sensitivity "anxiety frequency and the predictions of fearfulness. Behawiour Research and Therapy, $24,1-8$.

Riemann, B. C., \& McNally, R. J. (1995). Cognitive pracessing of personally relevant information. Cognition and Emotion, 9, 325-340.

Sanderson, W. C., Rapee, R. M., \& Barlow, D. H. (1989). The influence of an illusion of control on panic attacks induced via inhalation of $5.5 \%$ carbon dioxide-enriched air. Archives of General Psychioutry, 46, 157-162.

Sawage, D. S., Devereux, R. B., Garrison, R. B., Castell, W. P., Anderson, S. J." Levy, D., Thomas, H. E. Kannel, W. B., \& Feinleib. M. (1983). Mitral valve prolapse in the general population, 2. Clinical features: The Framingham study. American Heart Jowrhal, 106, 577-581.

Schmidi, A. J. M. Wolfs-Takens, D. I., Oosterlaan, J., \& van den 14out, M. A. (1994). Psychological mechanisms in hypochondriasis: Attention-induced physical symptoms without sensory stimulation. Psychotherapy and Pychosomatics, 61, 117-120.

Schmidt, N. B., Lerew, D. R., \& Trakowski, J. H. (1997). Bodly vigilance in panic disorder: Evaluating attention to bodily perturbations. Journal of Consulting and Clinical Psychotogy, 65. 214-220.

Spielberger, C. D., Gorsuch, R. L., \& Lushene, R. E. (1970). STAI manual for the State-Trail 


\section{Refierences}

Anxiery Inwentory. Palo Alto, CA: Consulting Psychologists Press.

Spitzer, R. L., \& Williams, J. B. W. (1986). Structured Clnical Interniew for DSM-IIL-R (SCDO)

New York: New York State Psychiatric Institute, Biometrics Research.

Street, L. L., Craske, M. G., Barlow, D. H. (1989). Sensation, cognitions and the perception of cues associated with expected and unexpected panic attacks. Behoviour Research and Therapy, 27. $189-198$

Suess; W. S.. Alexander, B., Smith, D. D., Sweeney, H. W. \& Marion, R. J. (1980). The effects of psychological stress on respiration: a preliminary study of anxiety and hyperventilation. Psychophysiology, 17, 535-540.

Tilier, I. Pain, M., \& Biddle, N. (1987). Anxiety disorder and perception of inspiratory resistive loads. Chest, 91, 547-551.

Tyrer, P., Lee, I, \& Alexander, J. (1980). Awareness of cardiac function in anxious, phobic and hypochodriacal patients. Psychological Medicine, 10,171-174

Van den Hout, M. A., Arntz, A., Janssen, S., De Jong, P. \& Pool, K. (1998). No threat related processing bias in low trait-anxious/ high state-anxious novice parachuters. Cognitive Therapy and Research, 22, 125-135.

Van den Hout, M. A., Hoekstra, R., Arnt, A., Christiaanse, M, Randschaert, W., \& Schouten, E. (1992). Hyperventilation is not diagnostically specific to panic patients. Psychosomatic Medicine, $54,182-191$.

Van den Hout, M. A., Van der Molen, G. M., Griez, E. J., \& Lousberg, H. (1987). Specificity of interoceptive fear to panic disorders. Journal of Psychopathology and Behavioral Assessment, 9 , 99.106.

Van Zijderveld, G. A. (1995). The role of adrenaline in anxiety and anxiety disorders, a psychophysiological study. Doctoral dissertation. Vrije Universiteit van Amsterdam.

Watson, D. \& Pennebaker, J. W. (1989). Health complaints, stress, and distress: Exploring the central role of negative affectivity. Psychological Review, 96, 234-254.

Watts, F. N., McKenna, F. P.. Sharrock, R., \& Trezise, L. (1986). Colour naming of phobia-related words. British Journal of Psychology, 77, 97*108.

Weissman, N. J., Shear, M. K.. Kramer-Fox, R., Devereux, R. B. (1987). Contrasting patterns of autonomic dysfunction in patients with mitra! valve prolapse and panic attacks. American Jounal of Medicine, 82, 880-888.

Willians, J. M. G., Mathews, A. \& MacLeod, C. (1996). The emotional Stroop task and psychopathology: Psychological Bulletin, 120,3-24.

Williams, K. M. G., Watts, F. N., MacLeod, C., \& Mathews, A. (1988). Cognitive Psychology and Emotional Disorders. New York: Wiley. 


\section{Summary}

A panic attack is an episode of suddenly increasing anciety accompanied by sensations such as dizziness, trembling, palpitations, sweating and fear of dying or going crazy (APA, 1994). Those diagnosed with panic disorder will regularly experience panic attacks, the cause of which remains unclear. An influential scientific explanation of panic attacks is offered by the cognitive theory, described by Clark (1986). According to this theory, panic attacks occur because feared bodily sensations are misinterpreted as a sign of impending catastrophe such as, for example, a heart attack. The resulting fear is assumed to intensify the bodily sensations, thus exacerbating the fear. This vicious circle would evennally lead to a fully fledged panic attack.

Different hypotheses have been put forward concerning the origin of the bodily sensations that may give rise to catastrophic interpretations. In the introduction to this thesis a number of hypotheses are discussed. Some, like the hyperventilation and mitral valve prolaps hypotheses, propose that the bodily sensations originate from some physical abberration. Others assume that certain ways of processing of bodily signals will increase the frequency and salience of these signals. Two of these hypotheses, i.e, the selective attention and superior perception hypotheses, are central to the discussion and experimen tal work in this thesis.

According to the selective attention thypothesis, panic disorder patients selectively attend to bodily sensations. As a result, they are thought to perceive an increased number of sensations more intensely. Studies 1,2 and 3 in this thesis tested whether panic patients do in fact show selective attention to bodily sensations and whether this leads them to report more symptoms.

The first study investigated whether selective attention leads panic patients to perceive a larger number of bodily sensations than that perceived by normal control subjects. Panic patients and controls were asked to report bodily sensations during three conditions. In the first condition, subjects were asked to direct their attention towards their bodilly sensations. In the second, neutral condition, no attention instruction was given to the subjects. Finally, in the third condition, subjects" attention was distracted by giving them a simple task to perform. It was expected that control subjects would report more bodily sensations in the first than in the second condition. Panic patients, however, were not expected to increase the number of reported sensations, because of their increased baseline reports in the neutral conditions (a so-called ceiling effect). Panic patients were also expected to decrease their number of reported sensations to a larger extent than the normal controls when attention was directed away from the sensations. The results confirmed the latter expectation. However, in the first condition, panic patients and 


\section{Summary}

controls showed comparable increases in the number of sensations reported. Thus, data from this study only parly supported the selective attention hypothesis.

In the second study, selective attention for hyperventilation sensations was measured in panic patients and normal controls. These particular sensations were chosen because of their resemblance to the symptoms during panic attacks. Moreover, it has been demonstrated previously that many people will (slightly) hyperventilate in fear-provoking situations. It is therefore conceivable that panic patients will behave similarly and, due to their selective attention, will be aware of bodily sensations that remain undetected by normal controls. The level of attention for hyperventilation symptoms was assessed by the decrease in performance on a reaction task during deep and rapid breathing (instructed byperventilation). The reaction task involved the quick discrimination of tones of either 100 or 200 msec duration. There were two conditions: real and placebo hyperventilation. During placebo hyperventilation, subjects received the same breathing instruction as in the real hyperventilation condition, but in this case $\mathrm{CO}_{2}$ was added to the inhalation air in order to prevent a fall in blood $\mathrm{CO}_{3}$ lewels. Contrary to expectation, the results failed to show larger distraction in panic patients than in nomal controls. Nevertheless, a slight indication was found that panic patients were distracted more by real than by placebo hyperventilation.

The third study investigated whether panic patients selectively attend to information related to body functioning. As palpitations are known to be one of the main sensations feared by panic patients, this study involved measurements of attention for information related to heartbeats in panic patients and normal controls. An ECG signal and another moving figure were presented on a computer screen simultaneously. Direction of attention was measured by the level of performance on a reaction task. The results indeed showed that panic patients did direct their attention to the ECG signal more than control subjects did. This was confirmative of the hypothesis that panic patients allocate more attention to body-related information.

The demonstration of selective attention in panic patients does not necessarily imply that attention plays a key role in the development and maintenance of panic disorder. This is because selective attention may be either cause or consequence of the fear of bodily sensations. To clarify this issue, study 4 was conducted. Students were made to fear either a heartrate acceleration or increased muscle tension. Following that, assessments were made as to whether these specific fears produced increased attention for ECG and EMG signals, allegedly reflecting subjects' ongoing heart beats and muscle tension. Contrary to expectation, this specific attention effect was not found. Rather, it was found that the students directed their attention towards the non-threatening information. Therefore, it was concluded that fear does not necessarily cause sellective attention although, 
admittedly, this might not hold for extreme fear.

Studies 5 and 6 investigated whether panic patients are superior perceivers of bodily sensations. If this were the case, modest bodily changes might lead to relatively strong sensations in panic patients. Study 5 addressed the perception of hyperventilation symptoms, whereas study 6 focussed at the perception of respiratory resistance. Neither study showed a difference between panic patients and control subjects in ability to detect lowered blood $\mathrm{CO}_{2}$ or narrowing of a respiration tube. Consequently, the hypothesis that panic patients have a superior perception of bodily changes was rejected.

All in all, it was concluded that although some data exist indicating that panic patients have selective attention for bodily sensations, the evidence is inconclusive. Furthermore, the ability of panic patients to detect small bodily changes was concluded to be no better than normal subjects. Moreover, fear of specific bodily changes dows not appear to evoke selective attention. This is in line with the hypothesis that selective attention for bodily sensations is a relatively stable characteristic that might contribute to the dewelopment and maintenance of panic disorder. 



\section{Samenvatting}

Een paniekaanval is een periode van plotseling opkomende intense angst waarbij sensaties optreden als duizeligheid, trillen, hartkloppingen, zweten, angst om dood te gaan, en angst om gek te worden (APA, 1994). Wie een paniekstoornis heeft, heeft regelmatig van deze aanvallen, zonder dat hiervoor een duidelijke oorzaak aanwezig lijkt te zijn. Een invloedrijke wetenschappelijke verklaring voor het ontstaan van de aanvallen wordt geboden door de cognitieve theorie van paniek, zoals beschreven door Clark (1986). Volgens deze opvatting ontstaat een paniekaarval doordat lichamelijke sensaties, zoals hartkloppingen, geïnterpreteerd worden als voorbode van een op handen zijnde catastrofe, zoals een hartaanval. De angst die hierdoor wordt opgeroepen zou de lichamelijke sensaties versterken, wat vervolgens weer angst oproept. De vicieuze cirkel die zo ontstaat zou uiteindelijk uitmonden in een paniekaanval.

Over de oorsprong van lichamelijke sensaties die aanleiding geven tot catastrofale interpretaties bestaan uiteenlopende hypothesen. In de inleiding van dit proefschrift wordt een aantal wan deze hypothesen besproken. Sommige, zoals de Iryperventilatie-hypothese en de valva mitralis prolaps-hypothese, veronderstellen dat de lichamelijke sensaties door een fysieke aberratie worden veroorzakkt. Andere veronderstellen dat een bijzondere verwerking van op zich normale lichamelijke signalen de frequentie en saillantie van deze signalen verhoogt. Het zijn deze hypothesen, met name de selectieve aandachts-hypothese en de superieure perceptie-hypothese, die in dit proefschrift onder de loep werden genomen en experimenteel werden getoetst.

Volgens de selectieve aandachts-hypothese hebben paniekpatiënten de neiging on selectief hun aandacht te richten op lichamelijke sensaties. Hierdoor merken zij vaker sensaties op en worden deze ook sterker ervaren. In studie 1,2 en 3 van dit proefschrift werd onderzocht of paniekpatiënten inderdaad selectief hun aandacht richten op lichamelijke sensaties en of dit tot een bovenmatige symptoom-rapportage leidt.

In de eerste studie werd onderzocht of selectieve aandacht ertoe leidt dat paniekpatienten meer lichamelijke sensaties waarnemen. Dit werd gedaan door bij paniekpatiénten en controle proefpersonen de waargenomen symptomen na te vragen in een drietal aandachtscondities: een conditie waarbij de opdracht werd gegeven de aandacht te richten op sensaties in het lichaam, een neutrale conditie waarbij geen opdracht werd gegewen en een conditie warin de aandacht werd afgeleid door middel van een eenvoudige taak. Verwacht werd dat controle proefpersonen bij het richten van de aandacht op lichamelijke sensaties meer symptomen zouden rapporteren dan in de neutrale aandachtsconditie maar dat paniekpatiënten dit verschil niet zouden laten zien. Immers, paniekpatiẻnten zouden ook tijdens de neutrale aandachtsconditie hun aandacht op sensaties gericht houden. Daarentegen zou de rapportage van sensaties tijdens afleiding bij paniekpatiënten meer 


\section{Samenwating}

omlang moeten gaan dan bij de controle proefpersonen. Overeenkomstig de verwachting daalde de tijdens de afleidingsconditie de symptoomrapportage van de panjekpatiënten significant meer dan bij de controle proefpersonen. De paniekpatiënten bleken echter net als de controlegroep meer sensaties te rapporteren als gevraagd werd de aandacht op lichamelijke sensaties te richten. In dit experiment werd dus maar ten dele steun gevonden voor de selectieve aandachts-hypothese.

In de tweede studie werd selectiewe aandacht voor een specifiek soort sensaties, namelijk hyperventilatie sensaties, gemeten bij panickpatienten en controle personen. De keus viel op hyperventilatie sensaties omdat sensaties die optreden bij hyperventilatie een grote gelijkenis vertonen met de symptomen van een paniekaanval. Bovendien is aangetoond dat veel mensen (in lichte mate) hyperventileren in angstige situaties. Het is denkbaar dat paniekpatiënten dit ook doen en vervolgens door selectieve aandacht sensaties waarnemen waar anderen aan voorbil zouden gaan. In de studie werd aandacht voor hyperventilatie sensaties gemeten door te bepalen in hoeverre proefpersonen werden afgeleid van een primaire taak wanneer ze tegelijkertijd de instructie kregen om diep en snel te ademen (te hyperventileren). De taak bestond uit het zo snel mogelijk onderscheiden van lange (200 ms) en korte (100 ms) tonen. De snelheid waarmee de taak werd gedaan werd bepaald tijdens echte hyperventilatie en tijdens placebo hyperventilatie. Tijdens placebo hypervenlillatie kregen de proefpersonen dezelfde ademinstructie als tijdens echte hyperventilatie maar door toevoeging van $\mathrm{CO}_{2}$ aan de inademingslucht werd voorkomen dat het $\mathrm{CO}_{2}$ gehalte in het bloed daalde. In tegenstelling tot de verwachting bleek uit de resultaten niet dat paniekpatiënten meer werden afgeleid door het hyperventileren dan de controlegroep. Wel was er een lichte indicatie dat paniekpatiënten meer werden afgeleid door zowel echte als placebo-hyperventilatie.

In de derde studie werd gekeken of paniekpatiënten selectief aandacht besteden aan lichamelijke informatie. Omdat hartkloppingen éen van de gevreesde sensaties van paniekpatienten is werd erwoor gekozen selectieve aandacht voor hartslag-informatie te meten bij zowel deze groep als een groep nomalen. Hiertoe werd een ECG tezamen met een ander bewegend figuur op een computerscherm aangeboden. Door middel van een reactietijd-taak werd bepaald waar de aandacht van de proefpersonen naartoe ging. Inderdaad werd gevonden dat paniekpatiënten meer dan dan de normalen de neiging hadden hun aandacht te richten op het ECG. Dit bevestigde de hypothese dat paniekpatiënten selectief" aandacht besteden aan lichamelijke sensaties.

Het feit dat selectieve alandacht bij paniekpatienten gevonden wordt wil nog niet zeggen dat deze aandacht een tol speelt bij het ontstaan of het in stand houden wan de paniekstoornis. Selectieve aandacht kan immers niet alleen de oorzaak maar ook het gevolg zijn van de angst voor lichamelijke sensaties. Om hier meer duidelijkheid over te verkrijgen 
werd studie 4 uitgevoerd. Studenten werden bang gemaakt voor een versnelling in hun hartslag respectievelijk een toename in spierspanning. Verwolgens werd bepaald of dezc angst leidde tot een verhoogde aandacht woor een van henzelf geacht ECG respectievelijk EMG. Dit bleek niet het geval te zijn. Eerder waren er aanwijzingen voor dar studenten hun aandacht richtten op de niet-bedreigende informatie. Er werd daarom geconcludeerd. dat selectieve aandacht niet slechts optreedt als gevolg van angst, alhoewel op basis van dit experiment geen uitspraken konden worden gedaan over de gevolgen van extreme angst.

In studie 5 en 6 werd onderzocht of paniekpatiënten superieur zijn in het waarnemen van lichamelijke sensaties. Als dit zo is zouden kleme lichamelijke veranderingen tot relatief sterke sensaties kunnen leiden. Studie 5 onderzocht de waarneming van hyperventilatic sensaties en studie 6 de waarneming van respiratoire weerstand. In geen van beide studies werd een verschil gevonden tussen paniekpatiënten en controle proefpersonen wat betreft hun vermogen om een verlaagd $\mathrm{CO}_{2}$ in het bloed respectievelijk de vernauwing van een buis war te nemen. De hypothese dat paniekpatiènten superieure waarnemers van lichamelijke veranderingen zijn werd derhalve verworpen.

Al met al werd geconcludeerd dat, hoewel er enige aanwijzingen waren voor selectieve aandacht bij paniekpatiënten voor lichamelijke sensaties, de resultaten wat dit betreft niet geheel overtuigend waren. Voor wat betreft het vermogen van paniekpatiënten on kleine lichamelijke veranderingen waar te nemen werd geconcludeerd dat zij hier niet beter in zijn dan controle proefpersonen. Het bleek verder dat angst voor lichamelijke veranderingen bij normalen niet tot selectieve aandacht voor deze veranderingen leidde. Dit is in overeenstemming met de hypothese dat selectieve aandacht voor lichamelijke sensaties een relatief stabiel kenmerk is dat zow kunnen bijdragen aan het ontstaan en het in stand houden van een paniekstoornis. 



\section{Dankwoord}

Veel mensen hebben meer of minder direct bijgedragen aan de totstandkoming van dit proefschrift. Ik wil met name de volgende mensen bedanken.

Mijn promotor Marcel van den Hout: altijd stond jij open voor nieuwe ideeên en je enthousiasme was aanstekelijk. Ondanks jouw drukke managers-taken vergat je toch nooit dat onderzoek doen eigenlijk belangrijker is. Mijn waardering hiervoor.

Tijdens de eerste jaren in Maastricht had ik veel steun aan mijn kamergenoot Joost Overduin. Ik heb veel van jou geleerd, van elastiekjes schieten tot onderzoeks-relevante zaken. Aan gezelligheid ontbrak het niet op onze kamer.

Ook was ik blij met lot- en naamgenote Sabine Janssen. Ik had altijd het gevoel dat ik op jou kon terugvallen als de zaken niet goed zouden gaan. Bedankt voor je steun en wriendschap. Birgit Mayer, mijn andere paranimf, wil ik graag bedanken voor alle thee en andere goede zorgen. Ook Sandra Mulkens wil ik bedanken: je was een fijne collega. Samen met Marie-Anne Haenen voerde ik mijn eerste experiment uit: Bedankt voor de goede samenwerking.

Bert Hoekzema, jij hebt me gered toen ik medio 1997 nog drie experimenten wou uitvoeren en dit qua apparatuur eerst onmogelijk leek. Verder bedankt voor de gezellige fietstochten die wij ondernomen tezamen met enkele reeds genoemden en Anja wan den Hout. Theo van Aerts, bedankt voor je technische ondersteuning in het lab en de mooie analyse-programma's. Peter de Jong was onmisbaar als er (snel) zaken opgelost moesten worden.

Op de RIAGG heb ik veel hulp gehad van het team dat de patiënten woor mijn onderzoek regelde. Met name Judith Semeijn en Hanny Keijsers werden nooit moe om mij te bellen of te helpen met praktische zaken om het onderzoek goed te laten verlopen.

Bij het diagnostiseren van de mensen die belden op de kranten-advertenties is veel werk verricht door Madelon Sijsenaar, Iris Nelissen en Carolien Appels. Jullie hebben vaak lang aan de telefoon moeten hangen, waarvoor mijn dank.

Verder wil ik alle collega's van de vakgroep DEP(t) en de onderzoeksschool EPP bedanken voor alle belangstelling en leerzame bijeenkomsten. Hellen Hornsweld en ook de overige leden van de werkgroep "Respiratoire Psychofysiologie" wil ik bedanken voor de hulp en goede raad bij het opzetten wan mijn eerste hyperventilatie-experiment.

Het OIO-bestaan zou een eenzijdig bestaan zijn geweest zonder de intensieve muziekbeoefening die ik ernaast deed. Evenmin als onderzoek doe je muziek maken en muziek leren maken alleen. Bedankt iedereen die met mij heeft samengespeeld en/of mij beter hobo heeft leren spelen.

Tenslotte Einar Krais, vrienden en familie: Ik ben blij dat jullie bestaan. 


\section{Curriculum Vitae}

Sabine Kroeze werd geboren op 29 juni 1968 te Leerdam. In 1987 behaalde zij haar gymnasium diploma aan het Gymnasium Haganum in Den Haag. Daarna ging zij psychologie studeren in Leiden en hobo aan het conservatorium in Den Haag. In 1993 studeerde $z$ ij af in de persoonlijkheidspsychologie en begin 1994 werd zij aangesteld als onderzoeker in opleiding aan de vakgroep Differentiële en Experimentele Psychologie aan de Rijksuniversiteit Limburg. In 1998 behaalde zij haar diploma als uirvoerend nusicus aan het Conservatorium in Maastricht. Dit proefschrift is het resultaat van lhaar werk aan de Maastrichtse Universiteit. 